\title{
El Precerámico medio de Huarmey: historia de un sitio (pv35-106)
}

Le Précéramique moyen de Huarmey : histoire d'un site (PV 35-106)

The Middle Preceramic of Huarmey: history of a site (PV 35-106)

Duccio Bonavia, Laura W. Johnson-Kelly, Elizabeth J. Reitz y Elizabeth S. Wing

\section{OpenEdition}

Journals

Edición electrónica

URL: http://journals.openedition.org/bifea/7096

DOI: $10.4000 /$ bifea.7096

ISSN: 2076-5827

Editor

Institut Français d'Études Andines

Edición impresa

Fecha de publicación: 1 agosto 2001

Paginación: 265-333

ISSN: 0303-7495

\section{Referencia electrónica}

Duccio Bonavia, Laura W. Johnson-Kelly, Elizabeth J. Reitz y Elizabeth S. Wing, « El Precerámico medio de Huarmey: historia de un sitio (pv35-106) », Bulletin de l'Institut français d'études andines [En línea], 30 (2) | 2001, Publicado el 08 agosto 2001, consultado el 07 diciembre 2020. URL : http:// journals.openedition.org/bifea/7096; DOI : https://doi.org/10.4000/bifea.7096

\section{(c) $(1)$}

Les contenus du Bulletin de l'Institut français d'études andines sont mis à disposition selon les termes de la licence Creative Commons Attribution - Pas d'Utilisation Commerciale - Pas de Modification 4.0 International. 


\title{
EL PRECERÁMICO MEDIO DE HUARMEY: HISTORIA DE UN SITIO (PV35-106) *
}

\author{
Duccio BONAVIA **, Laura W. JOHNSON-KELLY $Y^{* * *}$, \\ Elizabeth J. REITZ ${ }^{* * * *}$, Elizabeth S. WING ${ }^{* * * * *}$
}

\section{Resumen}

PV35-106 es el único sitio correspondiente al Precerámico medio que se ha podido ubicar en el área de Huarmey. Presenta la característica de tener una industria lítica muy particular, compuesta fundamentalmente por piezas astilladas y guijarros con golpe bipolar. El fechado radiocarbónico calibrado nos da para este yacimiento un lapso de tiempo que oscila entre cal. 5750 y cal. 4950 años a.C. A juzgar por los restos recuperados en las excavaciones, se trata de un grupo humano sedentario cuya economía básica fueron los recursos marinos. Pero hay indicios que ya se estaba iniciando un proceso hortícola. Las características culturales del sitio tienen parecido con las de la cultura Mongoncillo del vecino valle de Casma. Por todas las evidencias, parece que PV35-106 representa la transición entre la cultura Paijanense (Complejo Chivateros) y el Precerámico final.

Palabras claves: Arqueología peruana, tipología, Precerámico medio, etnobotánica, etnozoología.

\section{LE PRÉCÉRAMIQUE MOYEN DE HUARMEY : HISTOIRE D'UN SITE (PV 35-106) Résumé}

PV35-106 est le seul site correspondant au Précéramique moyen qui a pu être localisé dans la région de Huarmey. Le site se caractérise pour avoir une industrie lithique très particulière, composée fondamentalement par des pièces esquillées et des galets avec taille bipolaire. La

* La primera versión de este trabajo se escribió en 1989 y fue entregada para su publicación en Nawpa Pacha. Es por eso que en tres ocasiones ha sido citada. Concretamente en Bonavia et al. (1993) [“Bonavia et al., ms., 1989"], en Bonavia et al. (1996) ["Bonavia et al. (en prensa)"] y en Chauchat \& Bonavia (1998) ["Bonavia et al., sous presse"]. Dado que nunca fue publicado, hemos decidido hacerlo ahora. El texto ha sido revisado y puesto al día.

${ }^{* *}$ Laboratorio de Prehistoria, Departamento de Biología, Universidad Peruana Cayetano Heredia. Apartado 4314. Lima 100. Realizó el trabajo de campo y el estudio de los restos culturales. Es además autor de la discusión. E-mail: dbonavia@upch.edu.pe

**** Department of Anthropology, Cornell University, Ithaca. Se encargó del estudio de los restos botánicos. E-mail: 1wj1@ cornell.edu

**** Department of Anthropology \& Linguistics, The University of Georgia,Athens. Conjuntamente con Wing efectuó el estudio de los restos zoológicos.E-mail: ereitz@arches.uga.edu

***** The Florida Museum of Natural History, University of Florida, Gainesville.Conjuntamente con Reitz hizo los análisis de los restos animales. E-mail: eswing @ ufl.edu 
datation radiocarbone date le site entre environ cal. 5750 et cal. 4950 av. J.C. D'après les restes récupérés dans les fouilles, il s'agirait d'un groupe humain sédentaire ayant une économie basée sur les ressources marines. Mais il y a aussi des indices qui montrent qu'un processus d'horticulture était en train de se développer. Les caractéristiques culturelles du site ressemblent à celle de la culture Mongoncillo de la vallée voisine de Casma. En accord avec les évidences, on peut conclure que le site PV35-106 représente la transition entre la culture Paijanienne (Complexe Chivateros) et le Précéramique final.

Mots clés : Archéologie péruvienne, typologie, Précéramique moyen, ethnobotanique, ethnozoologie.

\section{THE MIDDLE PRECERAMIC OF HUARMEY: HISTORY OF A SITE (PV 35-106)}

\section{Abstract}

PV35-106 is the only site found in the area of Huarmey that belongs to the Middle Preceramic. The principal characteristic of this site is that it displays a very particular lithic industry, which consists mainly of splintered pieces of stone and pebbles with bipolar percussion. The radiocarbon date situates the site between cal. 5750 and cal. $4950 \mathrm{BC}$. According to the remains found in the excavations, the site would have been inhabited by a sedentary human group with a marine-based economy. But there are also indications that a horticultural process was developing. The cultural characteristics of the site are similar to the Mongoncillo culture of the neighbouring valley of Casma. All the evidence leads us to conclude that PV35-106 represents the transition between the Paijanense Culture (Chivateros Complex) and that of the Late Preceramic.

Key words: Peruvian Archaeology, Typology, Middle Preceramic, Ethnobotany, Ethnozoology.

\section{INTRODUCCIÓN}

Durante las exploraciones que efectuamos en el área de Huarmey (provincia homónima del departamento de Ancash) en la década de los años 70, en varias oportunidades visitamos este yacimiento, que nos llamó la atención por la gran cantidad de artefactos líticos que había en la superficie y por su factura particular. No se hizo ninguna recolección, con miras a no alterar la evidencia y conservarla intacta para el momento en que se pudiera efectuar trabajos sistemáticos.

Si bien la zona es conocida por los lugareños con el nombre de La Laguna, dado que otros sitios arqueológicos cercanos son denominados así, para evitar errores preferimos utilizar la sigla PV35-106.

En el mes de febrero de 1977, durante la ejecución del Proyecto Arqueológico Huarmey, observamos que el Pueblo Joven La Victoria se había extendido prácticamente hasta el límite noreste del yacimiento y era inminente el peligro que por lo menos parte de éste fuera destruido. Por eso decidimos llevar a cabo una investigación, a pesar que ella no estuvo en el programa de nuestro Proyecto; razón por la que no pudo ser de la envergadura que el sitio se merece. 


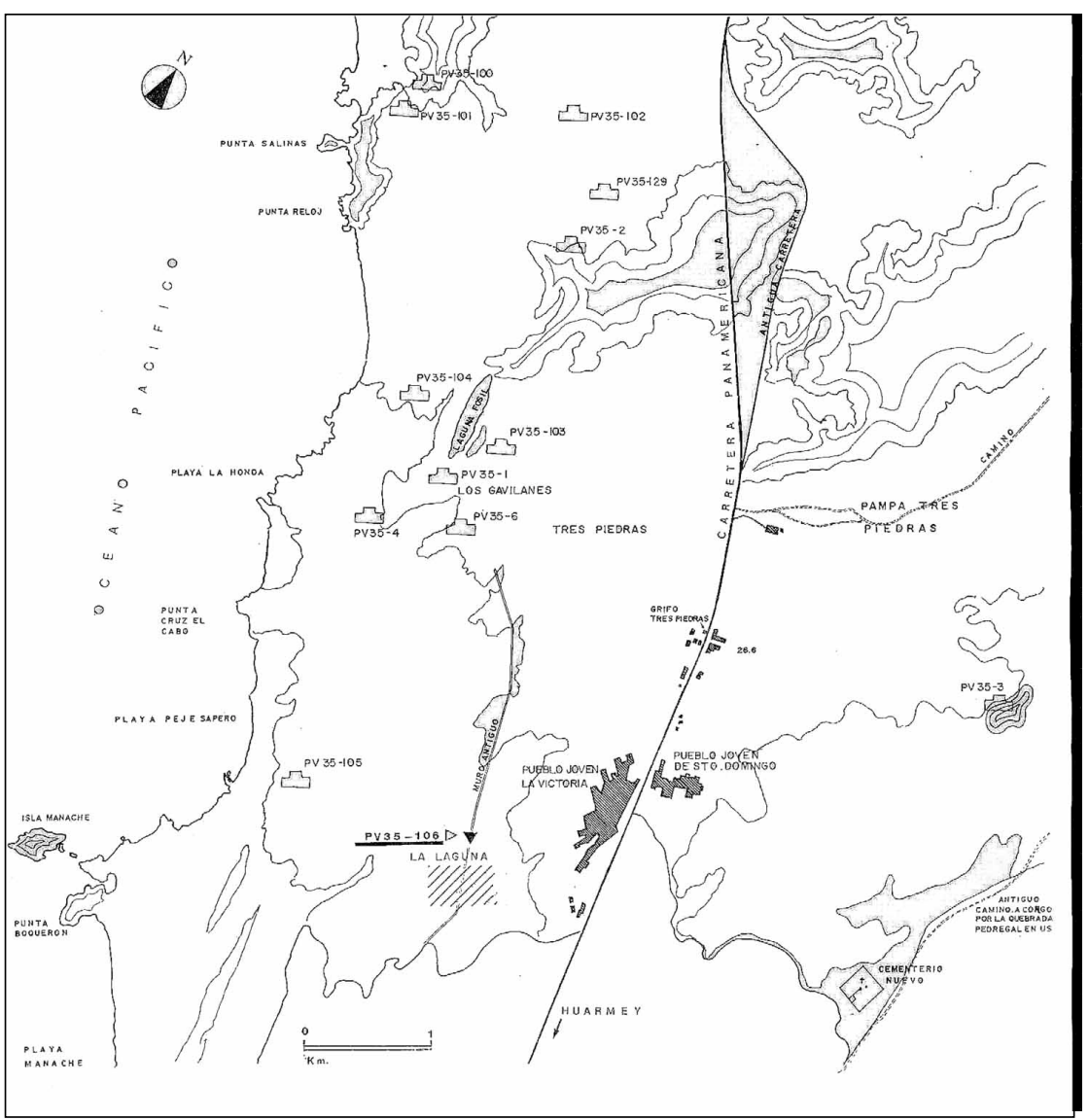

Fig. 1 - Mapa de ubicación.

\section{DESCRIPCIÓN Y UBICACIÓN DEL YACIMIENTO}

El sitio está ubicado cerca del Pueblo Joven La Victoria y cuando efectuamos los trabajos, la zona noreste limitaba prácticamente con la última casa de éste. Hasta ese momento el yacimiento no había sufrido ningún tipo de deterioro. (Fig. 1).

Es una zona árida, situada inmediatamente detrás de la pequeña cadena de cerros que separan en dicho sector de costa la línea de playa de tierra adentro (vide Bonavia,1982a: mapa 4). Su altura sobre el nivel del mar es de $25 \mathrm{~m}$. Por las evidencias de superficie, suponemos que el yacimiento ocupa aproximadamente un área de $57000 \mathrm{~m}^{2}$, que mide aproximadamente $380 \mathrm{~m}$ de largo en sentido Oeste-Noroeste/Este-Sureste y $150 \mathrm{~m}$ de ancho en la dirección opuesta.

Un muro enigmático cruza el yacimiento en sentido Sur-Suroeste/Nor-Noroeste, dividiéndolo en dos partes. Éste tiene inicio en el borde del valle de Huarmey y llega hasta las vecindades de Los Gavilanes (PV35-1); en algunos sectores está bien conservado y en otros destruido. Si bien no ha sido posible fecharlo, creemos que es prehispánico. Aparentemente su construcción no ha dañado mayormente el yacimiento, 
pues éste ha sido cubierto por una capa de arena eólica y el muro ha sido levantado sobre la superficie, sin cimientos. No cabe la menor duda que éste es muy posterior al yacimiento en estudio. (Para la ubicación de este muro vide Bonavia, 1982a: mapa 2, 14-15 y fotografía $99,444-445)$.

En la superficie en algunos lugares se veían manchas de coloración negruzca que indicaban restos de basura. Ello se hacía evidente en aquellos lugares en los que la capa superficial de arena eólica había sido desplazada por el viento. Pero en términos generales lo único que quedaba en superficie era una importante cantidad de artefactos líticos. No había ninguna evidencia que de alguna manera pudiera ser interpretada como resto arquitectónico.

\section{TRABAJOS EFECTUADOS}

Si bien esta es la primera vez que se publica la información completa relativa a este yacimiento, es de señalar que él ha sido mencionado en el catastro de sitios arqueológicos que se hizo en el valle de Huarmey (Bonavia, 1982a: 443), en la monografía que se ha publicado sobre Los Gavilanes (Bonavia, 1982a: 402) y en algunos artículos (Bonavia et al., 1993: 426-429, 432; Bonavia, 1996: 172-176; Chauchat \& Bonavia, 1998: 432-433).

La investigación se llevó a cabo en febrero de 1977. Por razones prácticas se ha dividido el yacimiento en dos zonas, una denominada A y que corresponde a la que está al lado este-sureste del muro y otra, denominada B que se sitúa hacia el oeste-noroeste con respecto a éste.

En primer lugar se hizo una recolección de todo artefacto que se veía sobre la superficie, sin ningún criterio de selección. Es de notar, insistimos, que sólo había artefactos líticos. Dado que después de un minucioso análisis se veía claramente que no había zonas de mayor condensación de éstos, no consideramos necesario efectuar la recogida en forma más sistemática.

Luego escogimos al azar tres lugares del yacimiento, uno en la Zona B y dos en la A, para efectuar unos pozos de prueba. En vista que no se disponía de mucho tiempo y era absolutamente necesario realizar este trabajo por el peligro de destrucción del sitio y también porque sabíamos, por la experiencia de trabajar en la zona, que la roca madre no podía estar a mucha profundidad, decidimos excavar tres pozos de $1 \mathrm{~m}$ por $1 \mathrm{~m}$. Si bien estábamos conscientes de todas las limitaciones que significa excavar en áreas tan pequeñas, en este caso no teníamos otra alternativa. Y dado que se trata de una sola ocupación continuada — como se verá más adelante — y de basura densa, creemos que, sin ser completa, de todos modos la muestra es significativa. Como suponíamos, en la Zona B la roca madre está a $48 \mathrm{~cm}$ de profundidad (Pozo No 3 ) y en la Zona A, en un punto a $48 \mathrm{~cm}$ (Pozo No 1) y en el otro (Pozo No 2) a $80 \mathrm{~cm}$ de la superficie. En la Zona A el Pozo $\mathrm{N}^{\circ} 1$ se hizo a $3 \mathrm{~m}$ del muro ya mencionado y el Pozo $\mathrm{N}^{\circ} 2$ en el centro del área arqueológica, a $40 \mathrm{~m}$ del muro. El Pozo $\mathrm{N}^{\circ} 3$ de la Zona B está también a $3 \mathrm{~m}$ del muro. Tenemos la impresión que en dicha zona está la mayor concentración de basura.

En los tres pozos se encontró basura compacta con restos quemados. Hubo relativamente pocos remanentes de moluscos y otros animales, pocos residuos botánicos, 
grandes cantidades de carbón, relativamente pocas piedras y casi todas quemadas. Una buena cantidad de ellas mostraba la fractura típica producida por inmersión en agua fría después del recalentamiento (termofractura). Hubo pocos artefactos y todo estaba mezclado con cenizas.

Durante las excavaciones entre el material botánico sólo pudimos identificar fragmentos de mate.

No cabía ninguna duda que la basura representaba una sola y continua ocupación del sitio. En la estratigrafía no había ningún indicio de interrupciones. En los tres pozos la secuencia fue la misma: en la parte superior una capa de arena eólica relativamente delgada (entre 9 y $16 \mathrm{~cm}$.), luego la capa compacta de restos arqueológicos sin diferencias de estratos $\mathrm{y}$, finalmente, al fondo la roca madre. Es por eso que no consideramos necesario incluir el dibujo de las secciones respectivas.

\section{CRONOLOGÍA ABSOLUTA}

En vista que la industria característica de este yacimiento era nueva para nosotros y no la hemos encontrado en ningún otro sitio del valle de Huarmey y sus vecindades, creímos importante obtener por lo menos una fecha radiocarbónica. Para ello escogimos una muestra de carbón, completamente seca, obtenida en el Pozo $\mathrm{N}^{\mathrm{o}} 2$ a $30 \mathrm{~cm}$. de profundidad. Fue sacada de un lugar donde había una concentración de cenizas y otros restos orgánicos quemados.

La datación obtenida ha sido de $6430 \pm 175$ años (GX-5081) que con la calibración respectiva (Universidad de Oxford, 2000) (1) y con la probabilidad del $95,4 \%$ nos da un rango temporal entre cal. 5750 y 4950 años a.C., es decir un promedio de 5350 años a.C. Se ha informado sucintamente sobre este fechado en nuestra monografía sobre Los Gavilanes (Bonavia, 1982a: 402).

\section{MATERIALES}

\section{1. Material lítico}

\section{1. 1. Tipología}

El primer problema con el que nos hemos enfrentado al analizar el material de este yacimiento, ha sido su originalidad. En el sentido que era la primera vez que encontrábamos artefactos de estas características en el área de Huarmey. Pero es más, al buscar material correspondiente en otras áreas de los Andes Centrales, hemos podido encontrar algunos utensilios parecidos a los nuestros sólo en dos lugares que discutiremos más adelante. Pero éstos no muestran de ninguna manera la riqueza de variedades de la industria de PV35-106. Además ellos no han sido bien descritos desde el punto de vista tipológico y técnico. Por eso hemos creído necesario elaborar una tipología morfológica que nos pudiera servir de base para nuestro estudio y para trabajos futuros. Es necesario señalar que si bien hemos seguido las normas de la tipología francesa, estamos completamente de acuerdo con Chauchat (1982: 76; Chauchat et al.,1992: 50) en el sentido que

(1) Todas las fechas radiocarbónicas han sido calibradas con el programa OxCal v3.5 Radiocarbon Acelerator Unit del Laboratory of Archaeology and Ancient Arts de la Universidad de Oxford (versión de junio de 2000). 
“... la tipología lítica como un todo está sometida a interpretaciones de contexto. Ella no puede ser una ciencia exacta en la que la determinación y la clasificación de un utensilio se desprende automáticamente de criterios tecnológicos y morfológicos elaborados de una vez por todas, sea la que sea la finura y la precisión de esos criterios. De esto se desprende que pueden existir diferentes clases de tipos según el contexto." (el subrayado es nuestro). La tipología es como sigue (vide Cuadro 1 y Diagrama 1).

\section{1.- Piezas astilladas típicas}

Han sido elaboradas exclusivamente a partir de guijarros, buscando de preferencia los delgados y de forma alargada. Éstas han sido obtenidas por talla bipolar aplicada inicialmente y luego reavivando las cicatrices con talla bifacial. En algunos casos el golpe bipolar inicial ha provocado el desprendimiento de grandes lascas, del tamaño de todo el guijarro, y en otros sólo desprendimientos parciales. Este fenómeno se puede observar en uno y en ambos lados de las piezas. El golpe bipolar inicial se ha producido siempre en los dos extremos, considerados sobre el eje más largo del guijarro. (Es de notar que para los efectos de este estudio, todas las referencias que se hagan a los artefactos sobre guijarros, serán con respecto al eje más largo de éste. Para las piezas astilladas no se ha utilizado ninguna terminología especial [v.g. vide Brézillon, 1977: 288; Merino, 1994: 124-125], es por eso que denominamos extremos cada uno de los lados opuestos con cicatrices sobre el eje más largo del artefacto. Cuando se ha tenido que hacer referencia concreta a las extremidades, en forma arbitraria se ha definido como basal la inferior y apical [que es sinónimo de extremo superior] a la superior. Se ha evitado de utilizar los términos superior e inferior, pues ellos se emplean para definir las caras de las lascas [lege Brézillon, 1977: 58]).

Las partes activas han sido utilizadas para un trabajo de machacado más que como cuchillo. Éstas son rectas o ligeramente cóncavas. Hay sólo algunas piezas con huellas de machacado lateral suave. (Fig. 2).

\section{1. Piezas astilladas típicas con astillamiento y retoque bilateral}

Son piezas iguales a las astilladas típicas, sólo que después del astillamiento por golpe bipolar en los extremos, se ha repetido la misma operación sobre los bordes laterales. Prácticamente en todos los casos este astillamiento se ha producido sobre una sola cara del artefacto; hay un solo caso en el que el efecto es inverso. (Fig. 3).

\section{2. Piezas astilladas típicas con golpe lateral}

Se trata de piezas astilladas típicas a las que se les ha producido lateralmente una cicatriz cortante, ya sea al lado derecho o al izquierdo. En la mayoría de casos esta parte activa lateral es insignificante, pero en algunos parece haber sido retocada. (Fig. 4).

\section{3. Piezas astilladas con retoque a un extremo}

Son guijarros que han sido escogidos en función de las mismas características que para hacer piezas astilladas típicas. La única diferencia es que una vez producido 





Diagrama 1 - Distribución porcentual de la tipología lítica (se ha incluido a las lascas usadas por ser útiles a posteriori).
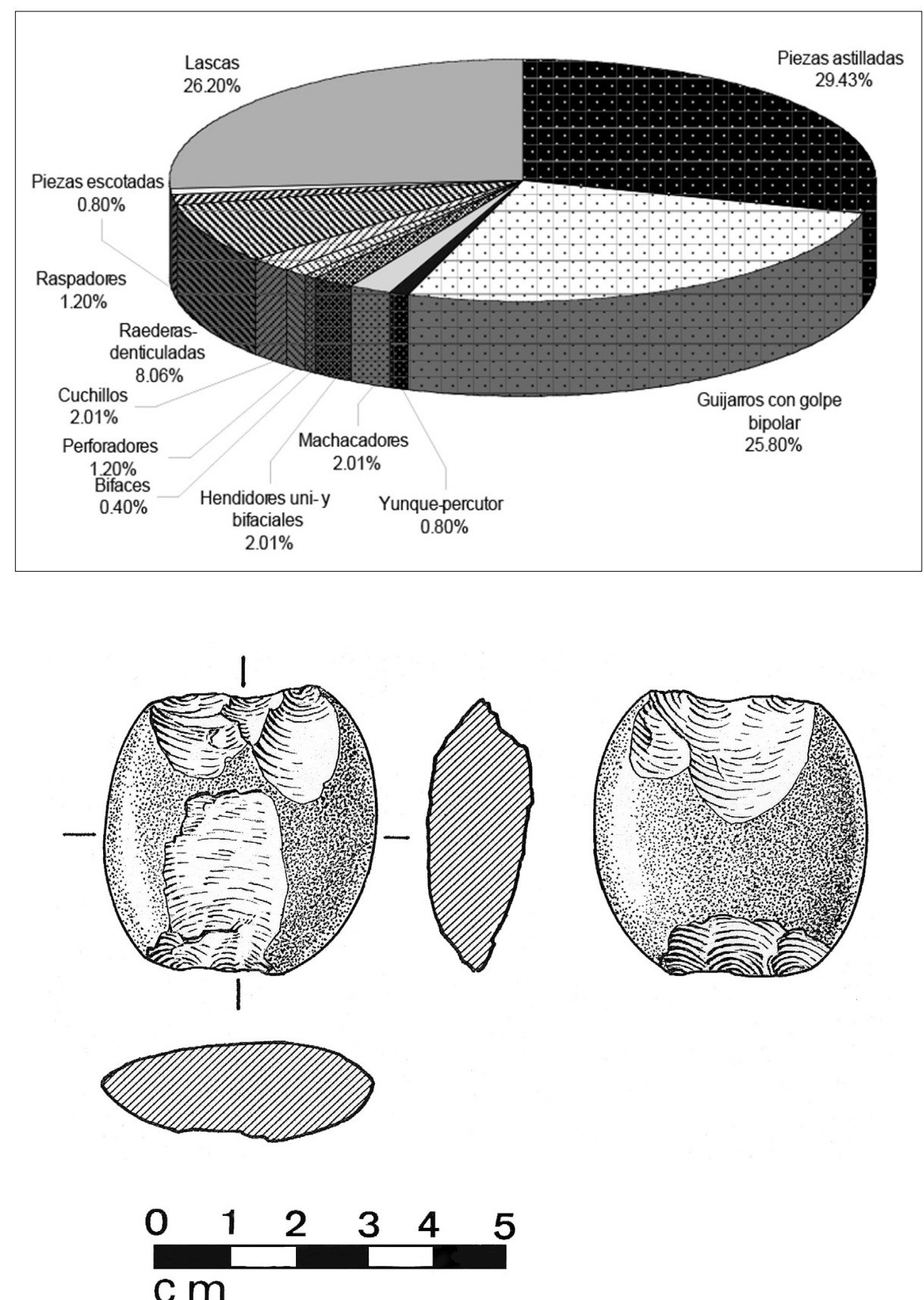

Fig. 2 - Piezas astilladas típicas. 

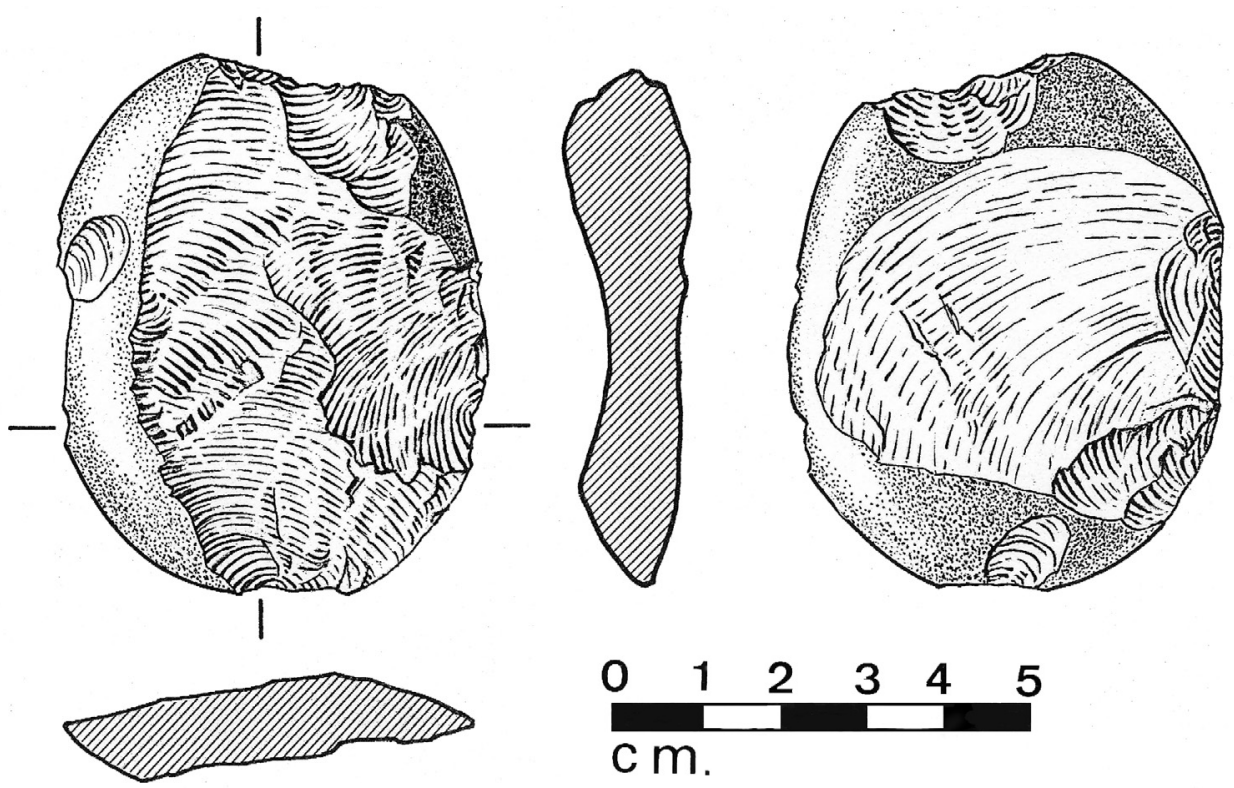

Fig. 3 - Piezas astilladas típicas con astillamiento y retoque bilateral.
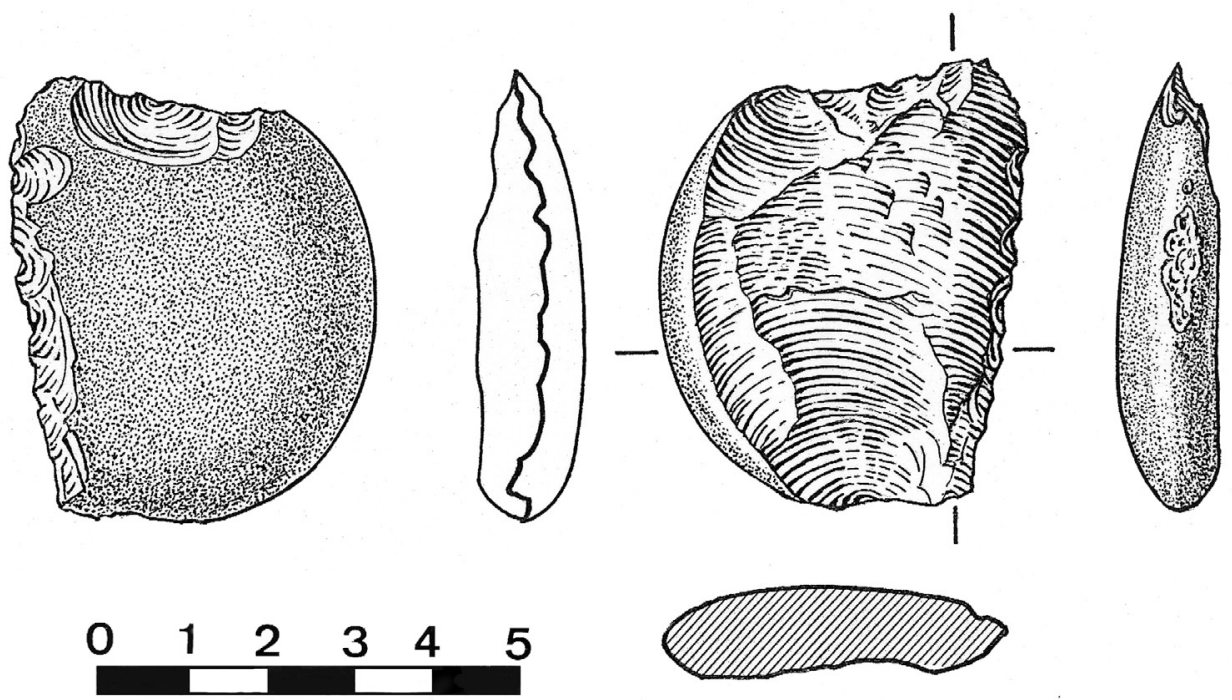

$\mathrm{c} \mathrm{m}$.

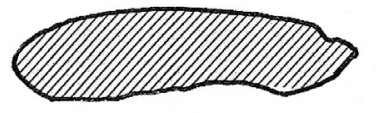

Fig. 4 - Piezas astilladas típicas con golpe lateral. 
el astillamiento en los dos puntos opuestos del guijarro (buscando siempre el eje más largo), se ha utilizado sólo una parte para ampliar la parte activa (arbitrariamente considerada como parte apical de la pieza), por medio de un retoque bifacial. A la cicatriz basal, aparentemente, no se le ha dado uso (Fig. 5).
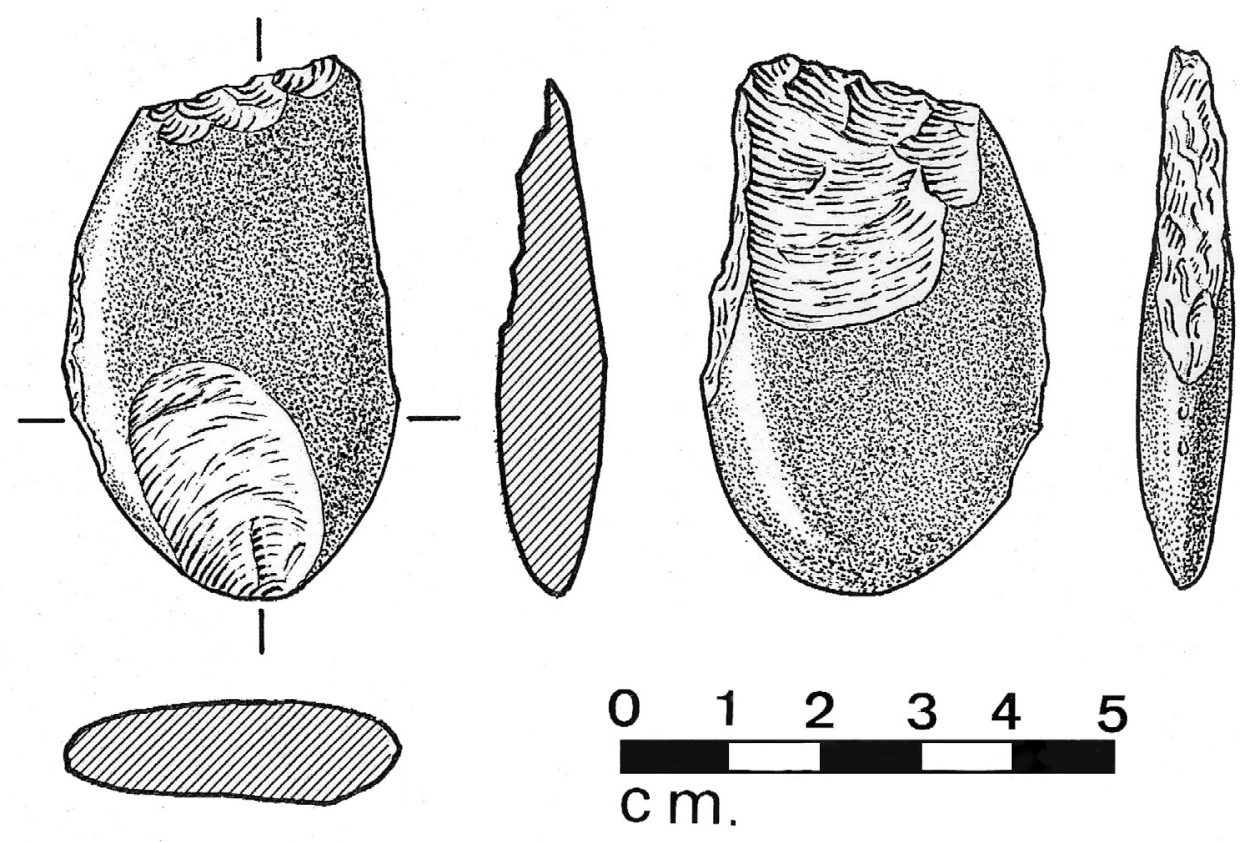

Fig. 5 - Piezas astilladas con retoque a un extremo.

\section{2.- Guijarros con golpe bipolar}

Se trata de guijarros alargados o más o menos redondos, pero muy grandes. Son del mismo tipo que se ha utilizado para las piezas astilladas.

En la gran mayoría el golpe bipolar ha provocado el desprendimiento total de la mitad del guijarro. Sólo ocasionalmente hay desprendimiento en las dos caras. Da la impresión que han sido piezas desechadas y que originalmente se trata de la parte inicial del proceso para producir artefactos astillados que por ser imperfectos, fueron abandonados. En efecto en las piezas astilladas típicas, los desprendimientos no son tan grandes (Fig. 6).

\section{1. Guijarros con golpe bipolar y astillamiento en la parte apical}

Son piezas que reúnen las mismas características de las anteriores. Han recibido un golpe bipolar muy fuerte, pero éste ha producido sólo una cicatriz en la parte apical. Es probable que en este caso también se trata de especímenes fallados al tratar de hacer piezas astilladas. (En este caso hemos empleado el término apical con el mismo criterio seguido para las piezas astilladas.) (Fig. 7). 

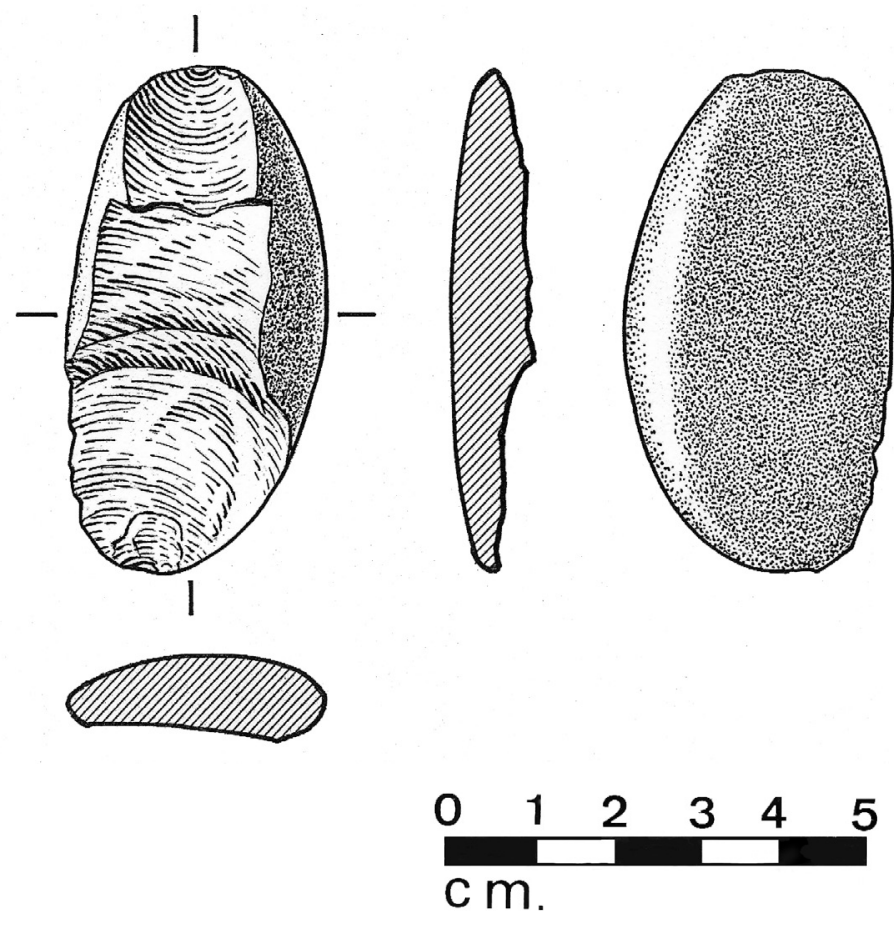

Fig. 6 - Guijarros con golpe bipolar.
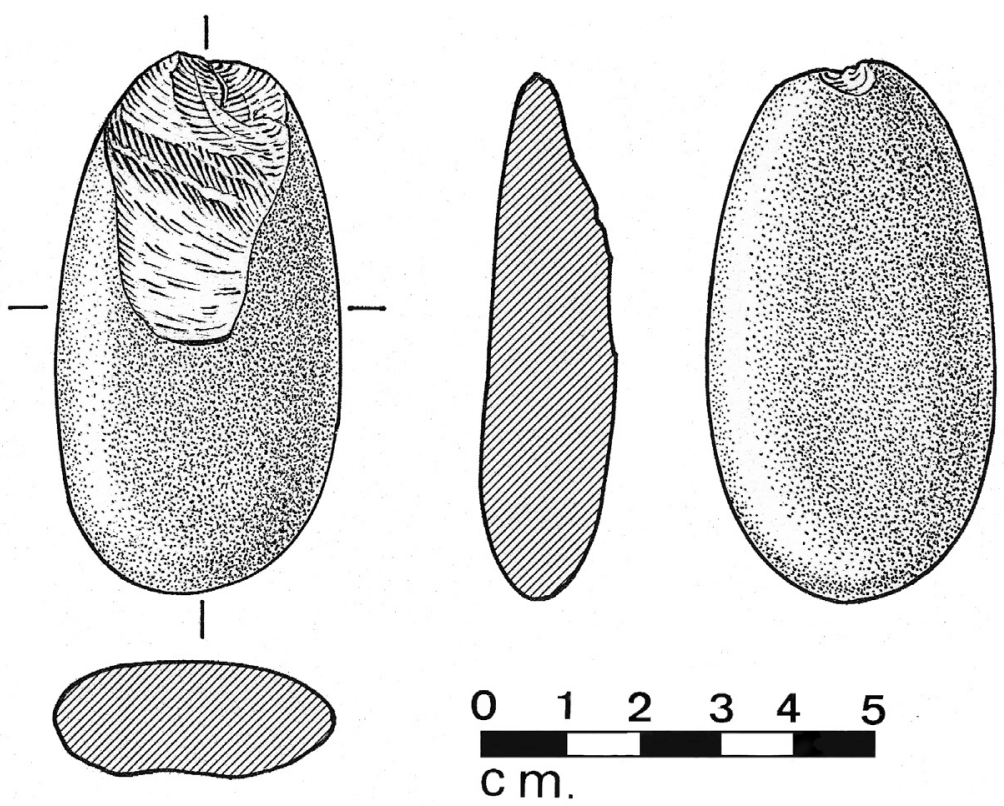

Fig. 7- Guijarros con golpe bipolar y astillamiento en la parte apical. 


\section{2. Guijarros con golpe bipolar y lateral}

Son guijarros que reúnen las mismas características del tipo anterior. Muestran un golpe bipolar sobre el eje más largo, con desprendimientos de grandes lascas típicas. Luego sobre los bordes laterales se ha aplicado también un golpe bipolar, probablemente más suave, que ha producido un desprendimiento de lasca a un solo lado. Éstos son tan típicos como los anteriores. El desprendimiento lateral puede estar sobre la cara del primer lascado o sobre la otra y a la derecha o a la izquierda con respecto al lascado primario. Si bien hay piezas de todos los tamaños, predominan las grandes y gruesas. A juzgar por su morfología general no se trata de artefactos, sino simplemente de núcleos para obtener lascas (Fig. 8).

\section{3. Guijarros con golpe bipolar lateral}

Se trata de guijarros de la misma naturaleza de los del tipo anterior. El golpe bipolar que se ha aplicado a los lados, ha producido en tres casos el desprendimiento de una lasca pequeña, mientras que en uno hay desprendimiento de una lasca grande cuya cicatriz va de lado a lado. En este caso el eje de lascado es sobre la parte más angosta del guijarro. Creemos que son núcleos de los que se ha obtenido lascas (Fig. 9).

\section{4. Guijarros con golpe bipolar vertical y lateral}

Es una variante de los guijarros con golpe bipolar y lateral (Tipo 2. 2). En efecto, siempre sobre el mismo tipo de guijarros, se ha producido un desprendimiento de grandes lascas. La diferencia estriba en que el lascado lateral ha producido indistintamente desprendimientos sobre una cara u otra. Sólo en un caso el desprendimiento es alterno. Por sus características generales, parece tratarse de núcleos para la obtención de lascas (Fig. 10).

\section{Yunque-percutor}

Son guijarros grandes y oblongos, que han sido utilizados al mismo tiempo como yunques y como percutores.

Para la función de percutores se ha usado los dos extremos (determinados por el eje más largo), así como las partes laterales. Estos mismos artefactos han sido empleados como yunques para apoyar los guijarros para la talla bipolar (Fig. 11).

\section{Machacadores}

Para la función de machacar se ha empleado guijarros pequeños, alargados. El machacado se efectuó sólo en uno de los extremos de las piezas (Fig. 12). (Para una definición más completa de este tipo, vide Bonavia [1982a: 82; 1992: 84]. Hay que tener presente, sin embargo, que hay pequeñas diferencias de este tipo en función del material sobre el que fueron empleados.)

\section{Hendidores unifaciales}

(Para evitar interpretaciones equivocadas, señalamos que hemos adoptado la terminología castellana propuesta por Merino [1994: 53] y que corresponde en la 

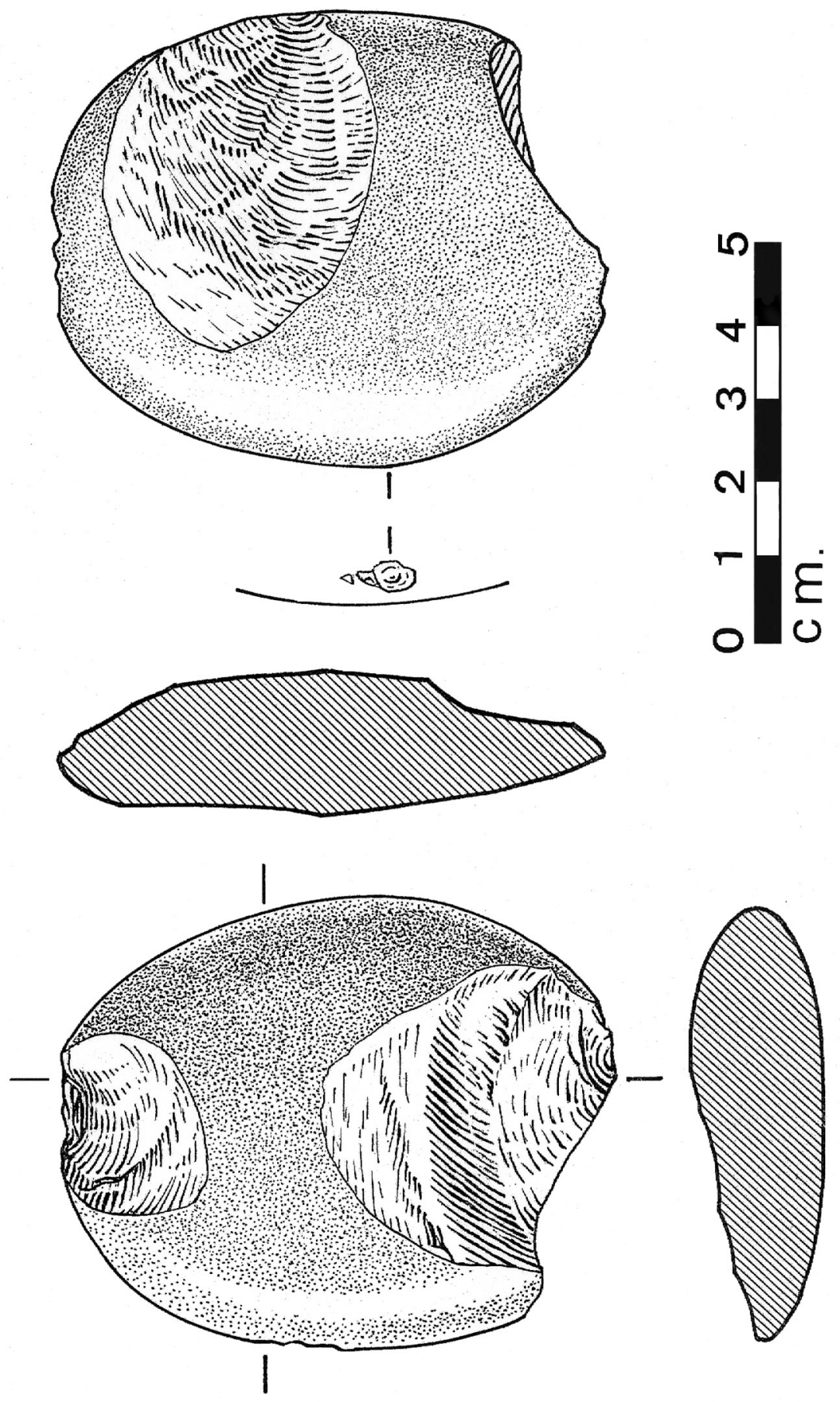

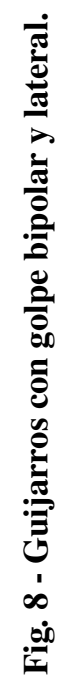



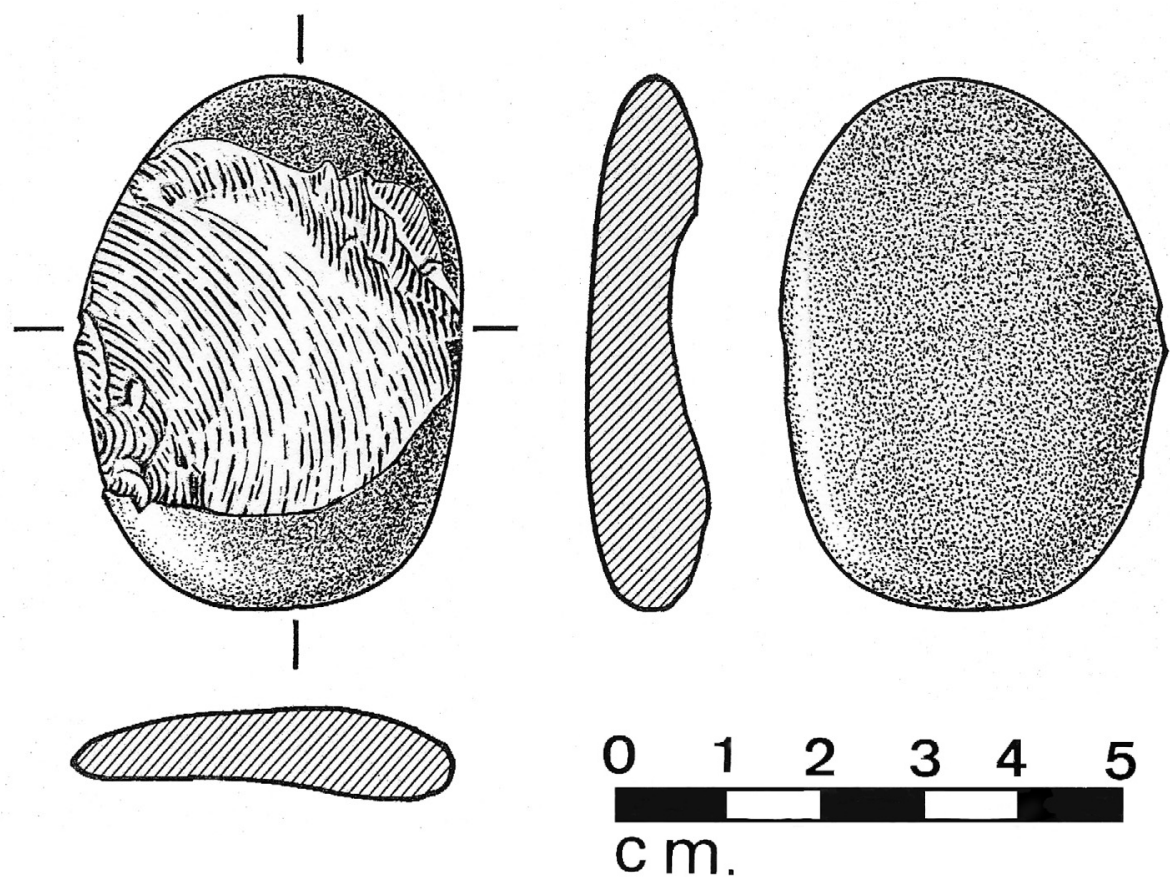

Fig. 9 - Guijarros con golpe bipolar lateral.
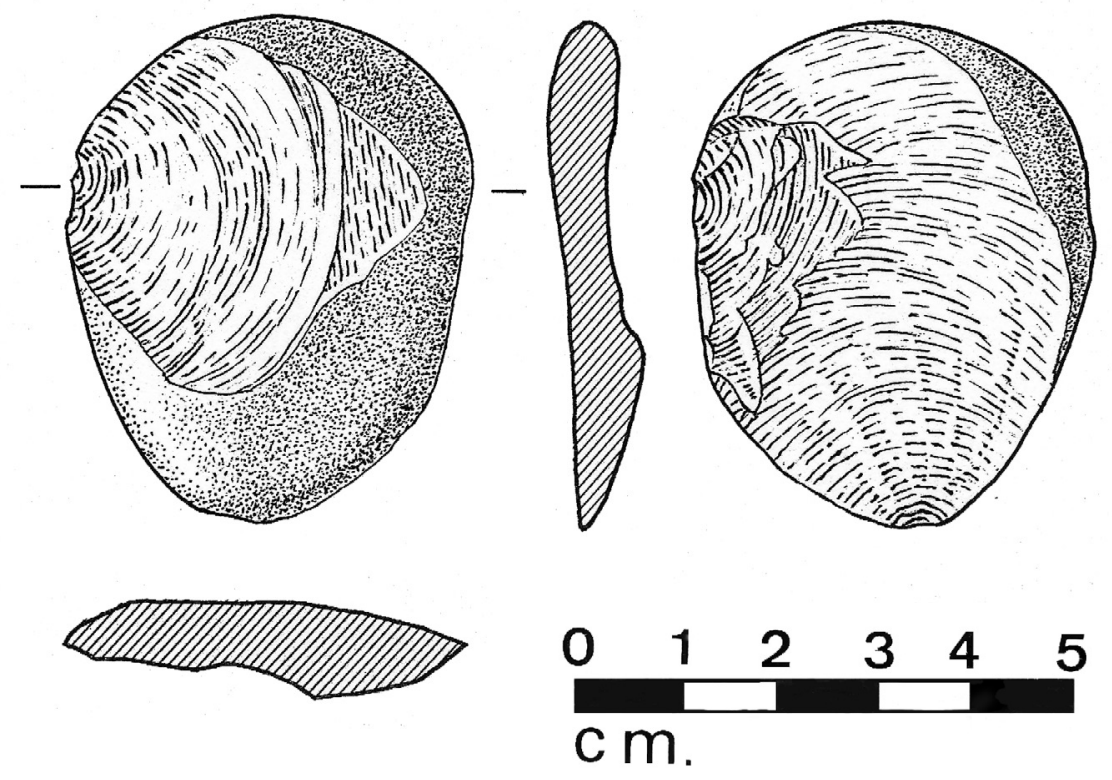

Fig. 10 - Guijarros con golpe bipolar vertical y lateral. 


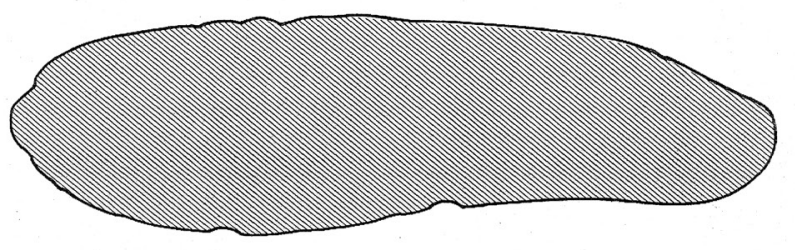

ま
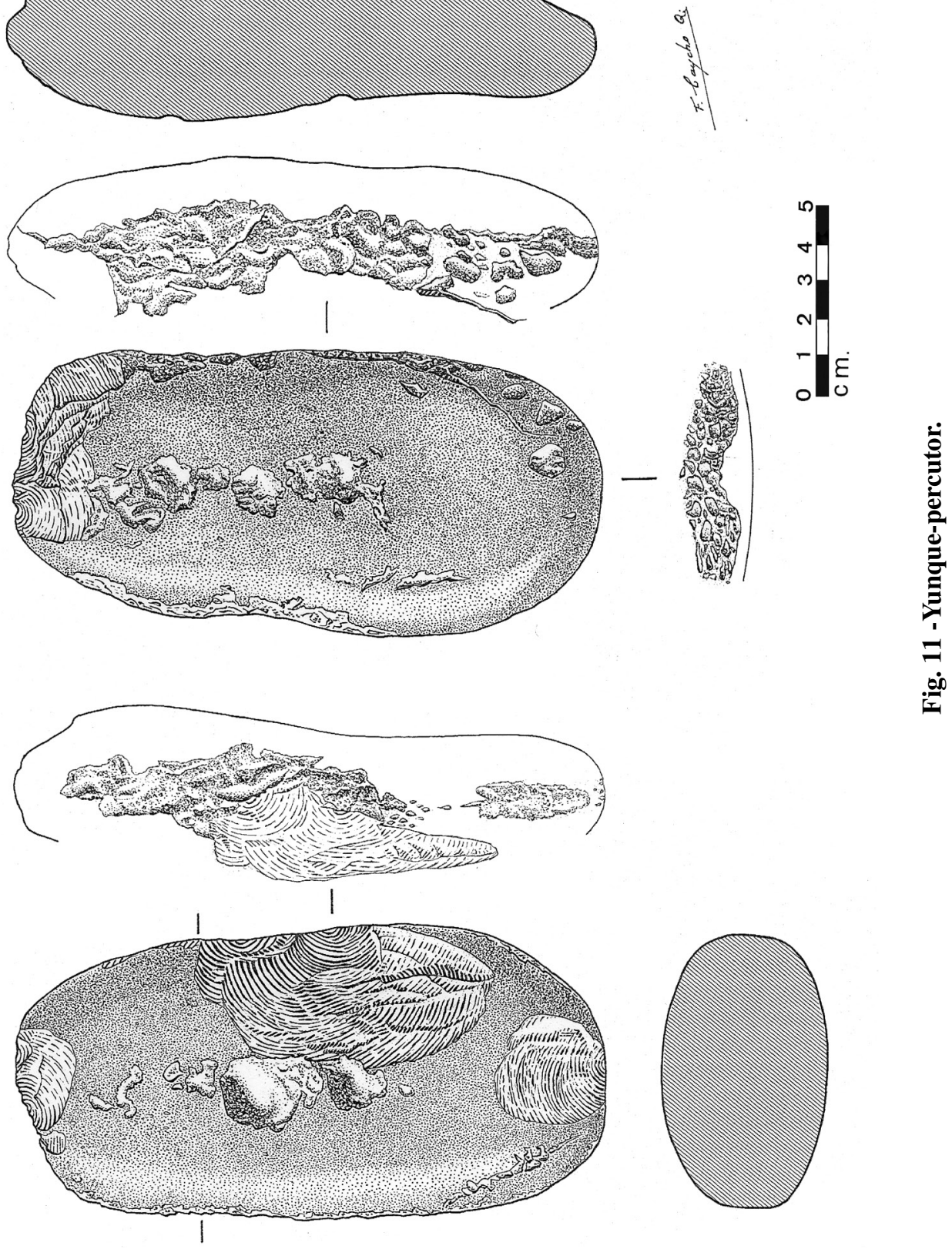


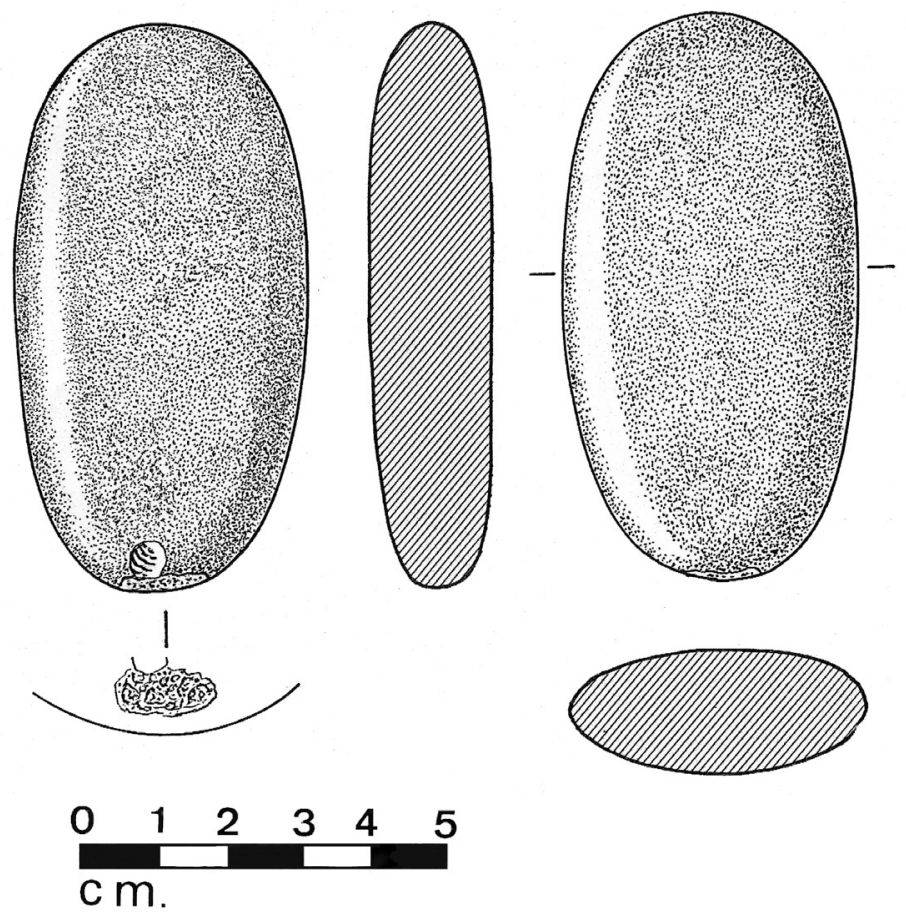

Fig. 12 - Machacadores.

terminología inglesa a chopper [vide Kozlowski \& Ginter, 1975: 4; Brézillon, 1977: 194]). Son hendidores unifaciales típicos que no necesitan descripción. (Fig. 13)

\section{Hendidores bifaciales}

(Siguiendo la terminología de Merino [1994: 53] corresponde a chopping-tool de la terminología inglesa [vide Kozlowski \& Ginter, 1975: 4; Brézillon, 1977: 194]). En este caso también se trata de piezas típicas cuya descripción sobraría (Fig. 14).

\section{Bifaz}

Hay una sola pieza y merece ser descrita. Es un bifaz pequeño, trabajado probablemente por percusión dura. La parte basal es redondeada y la apical puntiaguda. Evidentemente se ha aprovechado de una piedra de forma natural apropiada, lográndose una pieza bastante regular. Se trata probablemente de un ejemplar que no es típico. (Para los artefactos en general empleamos el término apical como opuesto a basal, para evitar el uso de inferior y superior por las razones ya explicadas [vide supra].) (Fig. 15).

\section{Perforadores o bec}

Para la definición de este tipo hemos seguido a Chauchat (1982: 94; Chauchat et al., 1992: 60). Son artefactos elaborados a partir de lascas de guijarros, gruesas o 


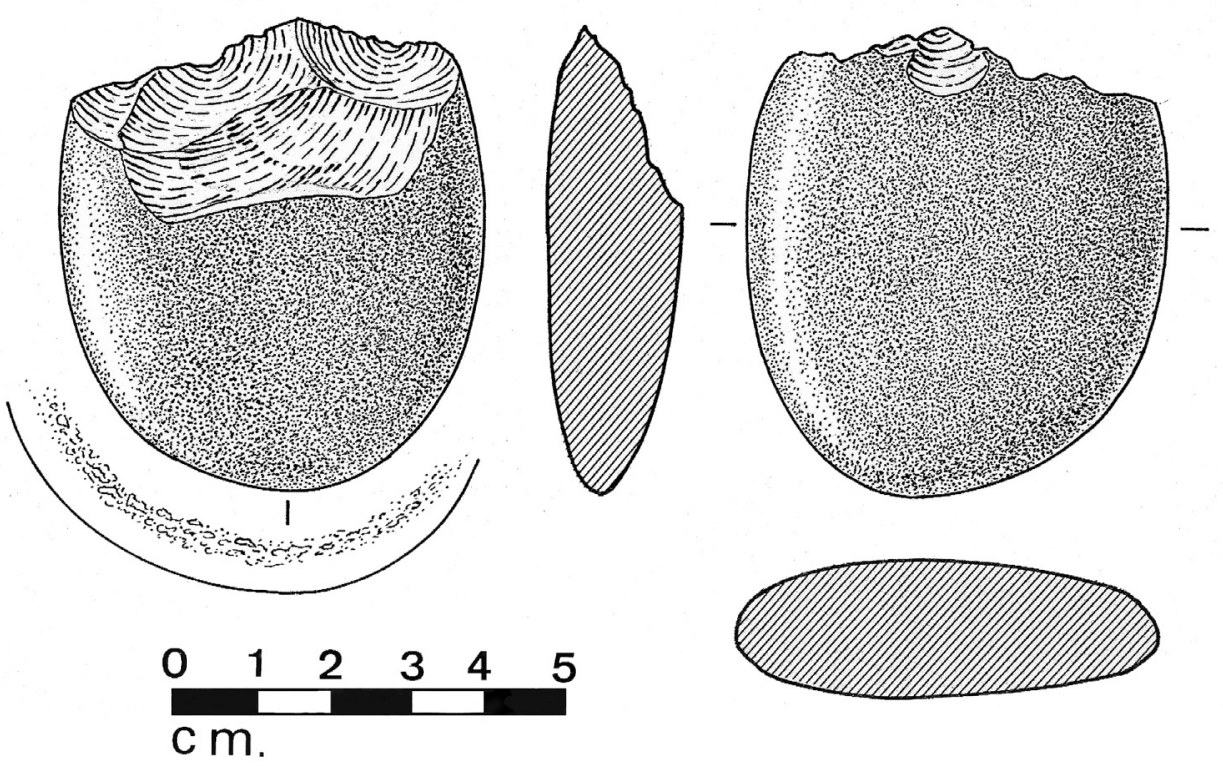

Fig. 13 - Hendidores unifaciales.
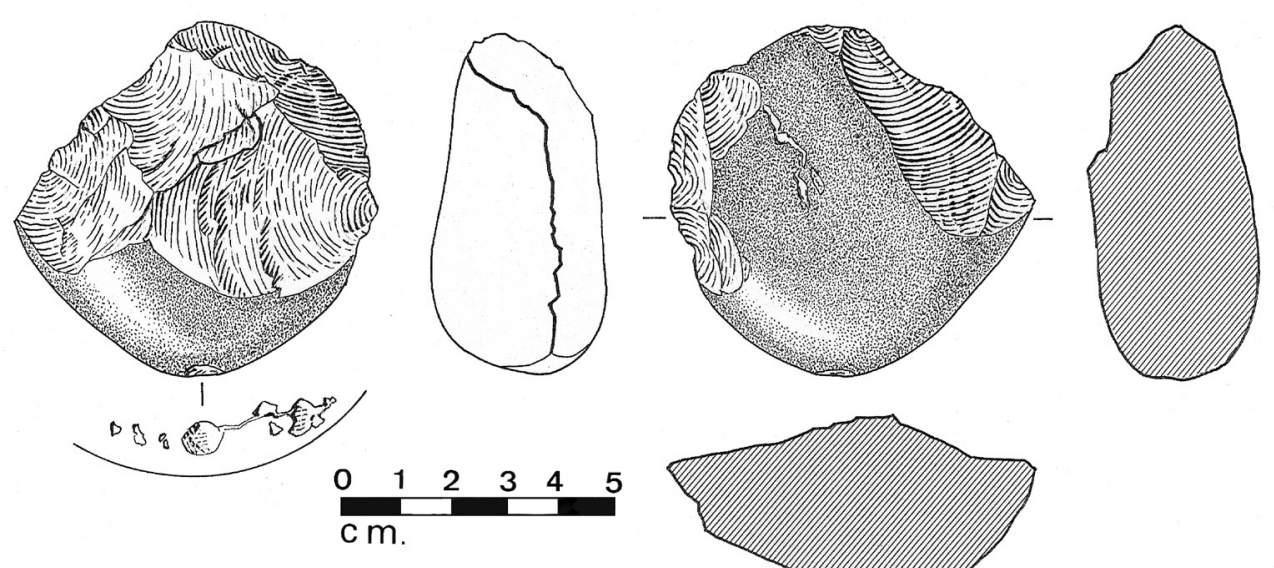

Fig. 14 - Hendidores bifaciales. 

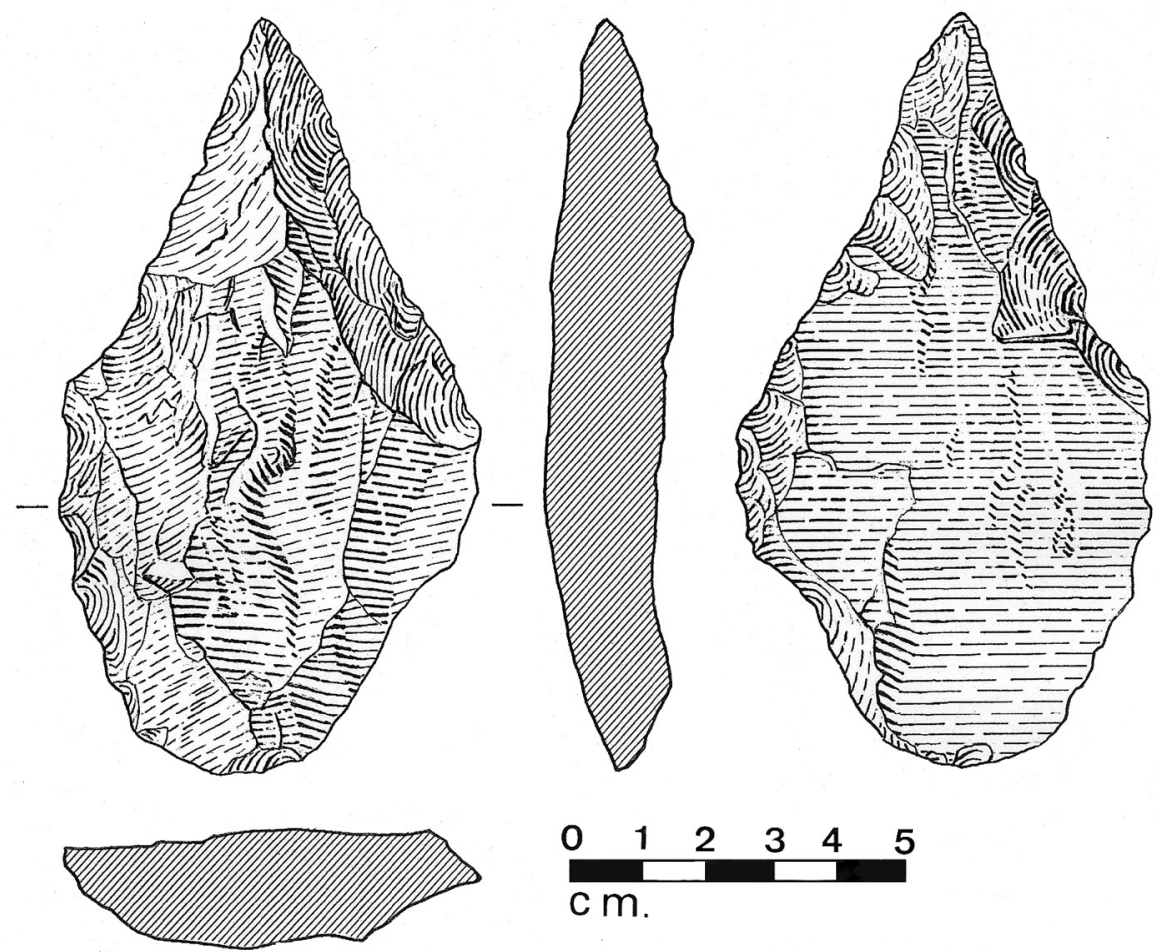

Fig. 15 - Bifaz.

delgadas. Para mayores detalles vide infra. (Preferimos no traducir el término bec, en cuanto se presta a confusiones, lege Merino [1994: 111, 118]) (Fig. 16).

\section{Cuchillos}

Se ha incluido en este tipo artefactos que no son típicos, pero que han sido elaborados con la misma técnica y, se supone, para la misma función. Son piezas sobre las que se ha conseguido un borde cortante por medio de talla bifacial bastante regular.

La parte activa no tiene la misma forma en todos los casos. Puede ser recta, convexa, circular o en ángulo recto, en cuyo caso ambas aristas son trabajadas.

Se ha tomado siempre la precaución que en lado opuesto a la parte activa central, exista una zona lisa que permita el fácil manejo del artefacto (Fig. 17).

\section{Raederas denticuladas}

Se ha creado este tipo compuesto, pues si bien se trata de denticulados, pensamos que han sido usados como raederas, al juzgar por las huellas que hemos observado al microscopio. Todas han sido hechas sobre lascas grandes y gruesas. La parte activa se ha creado con golpes precisos, que han desprendido pequeñas lascas del tal modo que los bordes de las cicatrices de éstas se tocan. En algunos casos para lograrlo se ha partido 

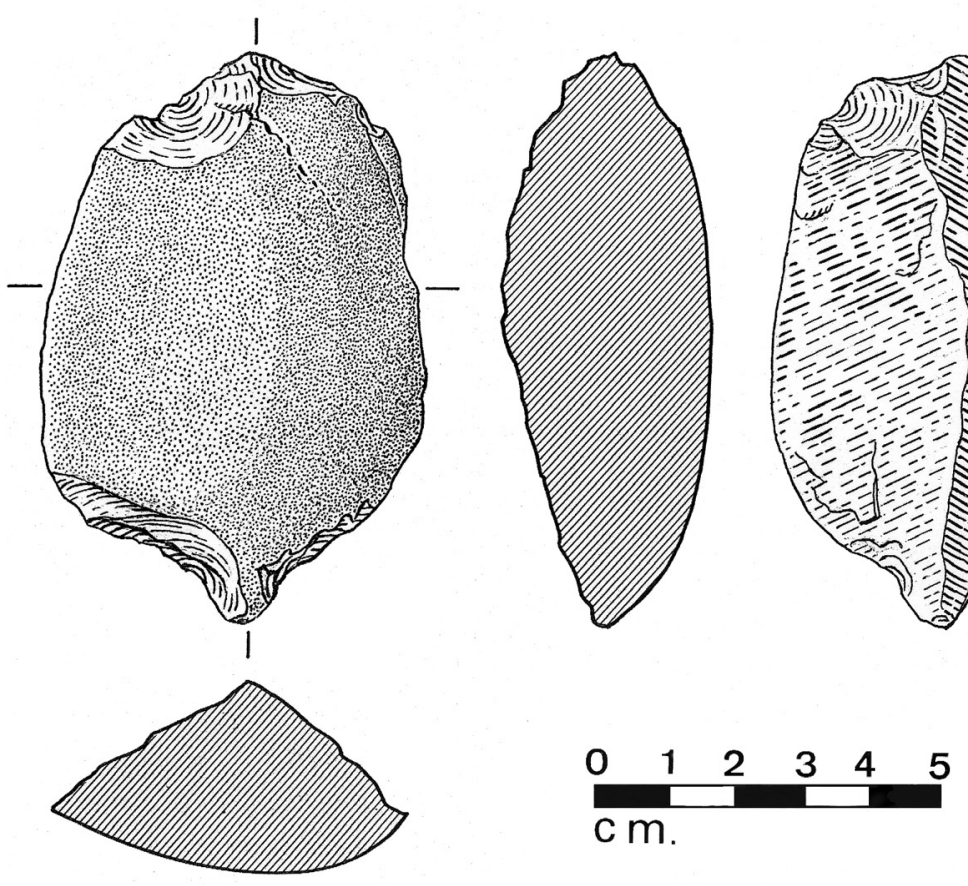

Fig. 16 - Perforadores o bec.
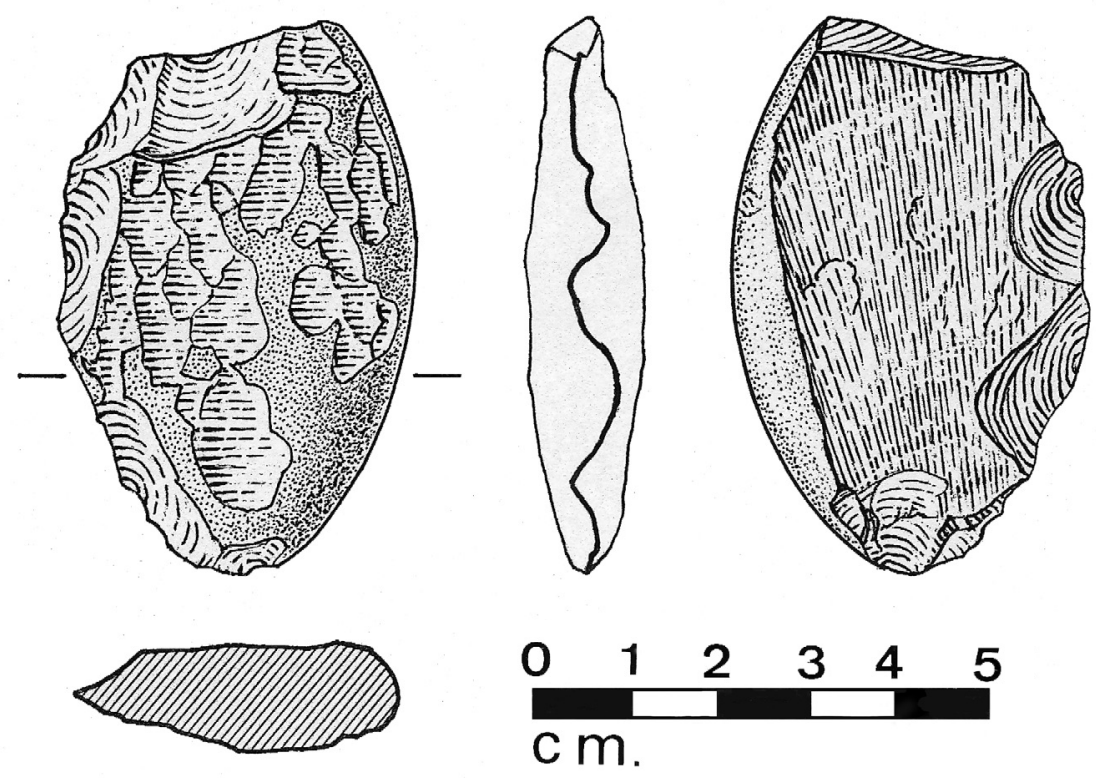

Fig. 17 - Cuchillos. 
de la cara ventral y en otros de la dorsal. El denticulado no es igualmente marcado en todas las piezas. La parte activa ocupa generalmente un lado de la lasca, en forma recta o convexa, sólo en algunos ejemplares aparecen dos zonas alejadas. En la mayoría de casos las cicatrices son abruptas (Fig. 18).

\section{Raspadores}

Son raspadores nucleiformes que no necesitan descripción. Tienen retoque escamoso (Fig. 19). (Claude Chauchat, comunicación personal, 13 de agosto de 2001 y Santiago Uceda, in litteris, 8 de agosto de 2001, han sugerido que para este tipo sería más correcto utilizar el término "denticulado en un extremo". Si bien en sentido estricto ello es correcto, esta definición nos parece demasiado amplia y se presta a confusiones. Por eso preferimos mantener la que hemos propuesto).

\section{Piezas escotadas}

Son típicas y consideramos que no necesitan ser definidas (Fig. 20).

\section{Varios}

Se ha creado esta categoría para poder incluir en ella las piezas atípicas, que son básicamente fragmentos de guijarros.

Lascas. Las lascas son importantes en esta industria, por ello hemos creído necesario hacer un análisis prolijo (vide Cuadro 2). Desde el punto de vista morfológico
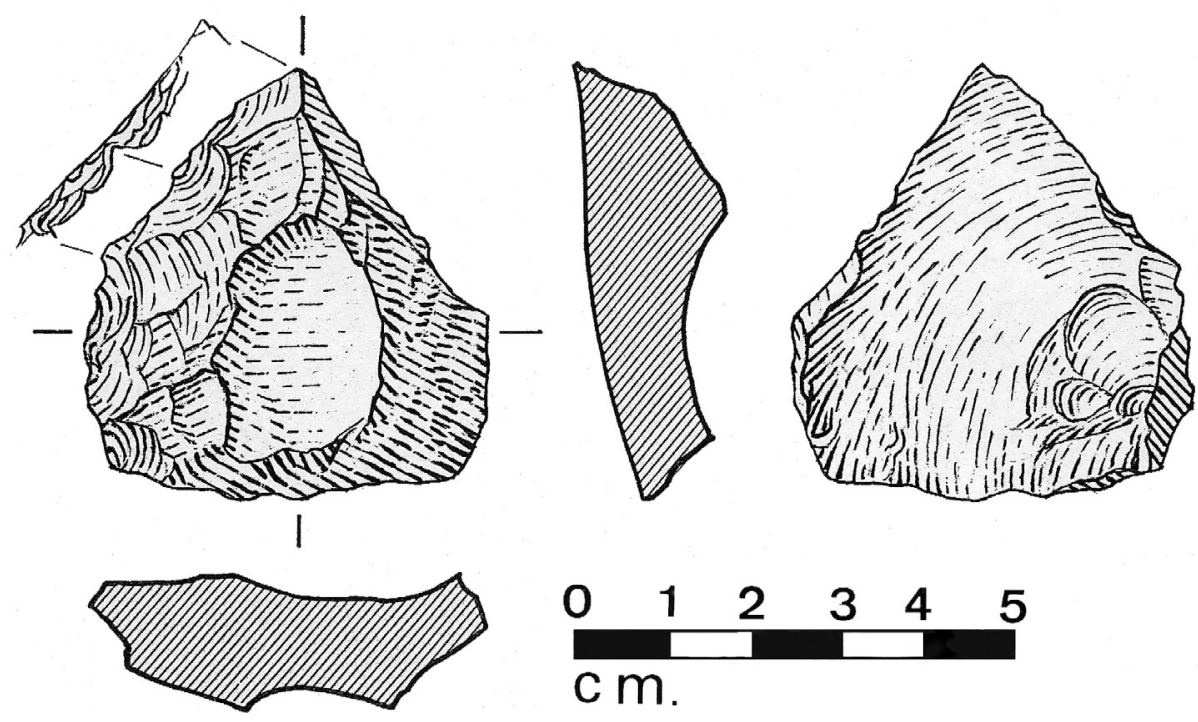

Fig. 18 - Raederas denticuladas. 

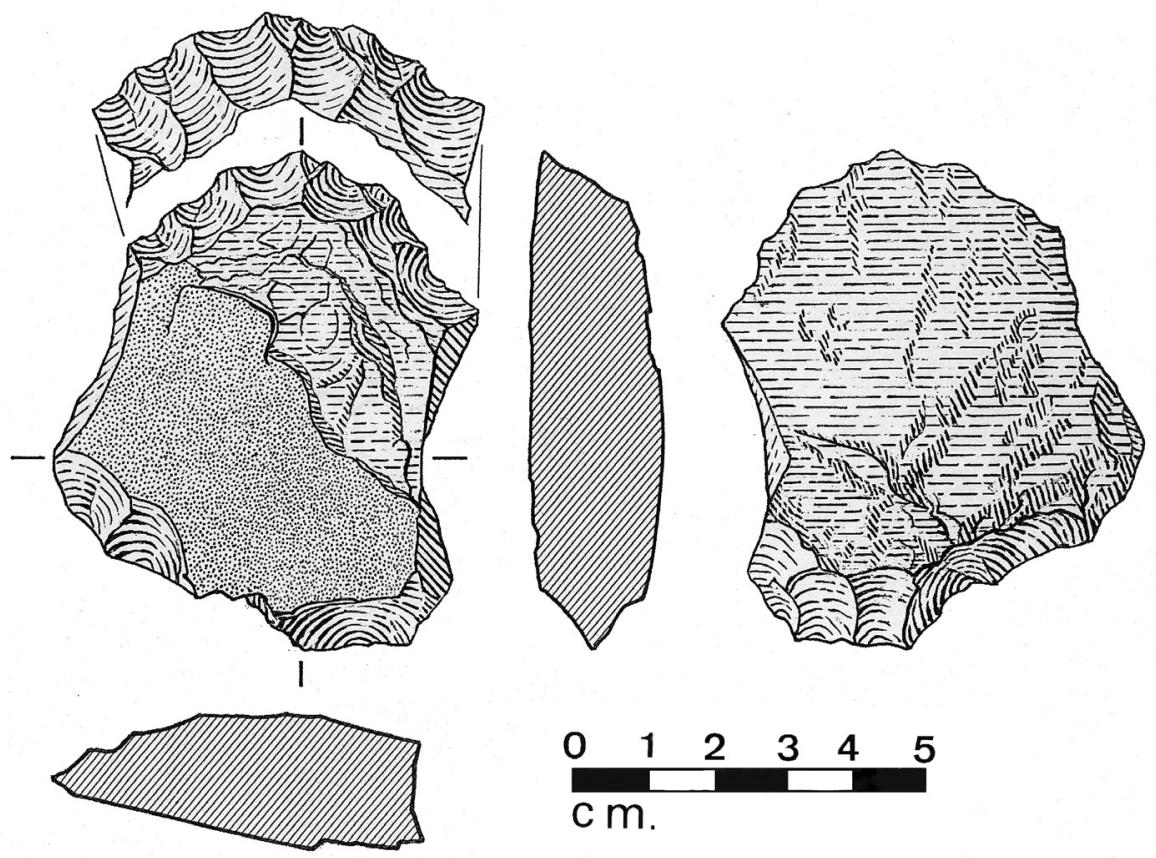

Fig. 19 - Raspadores.
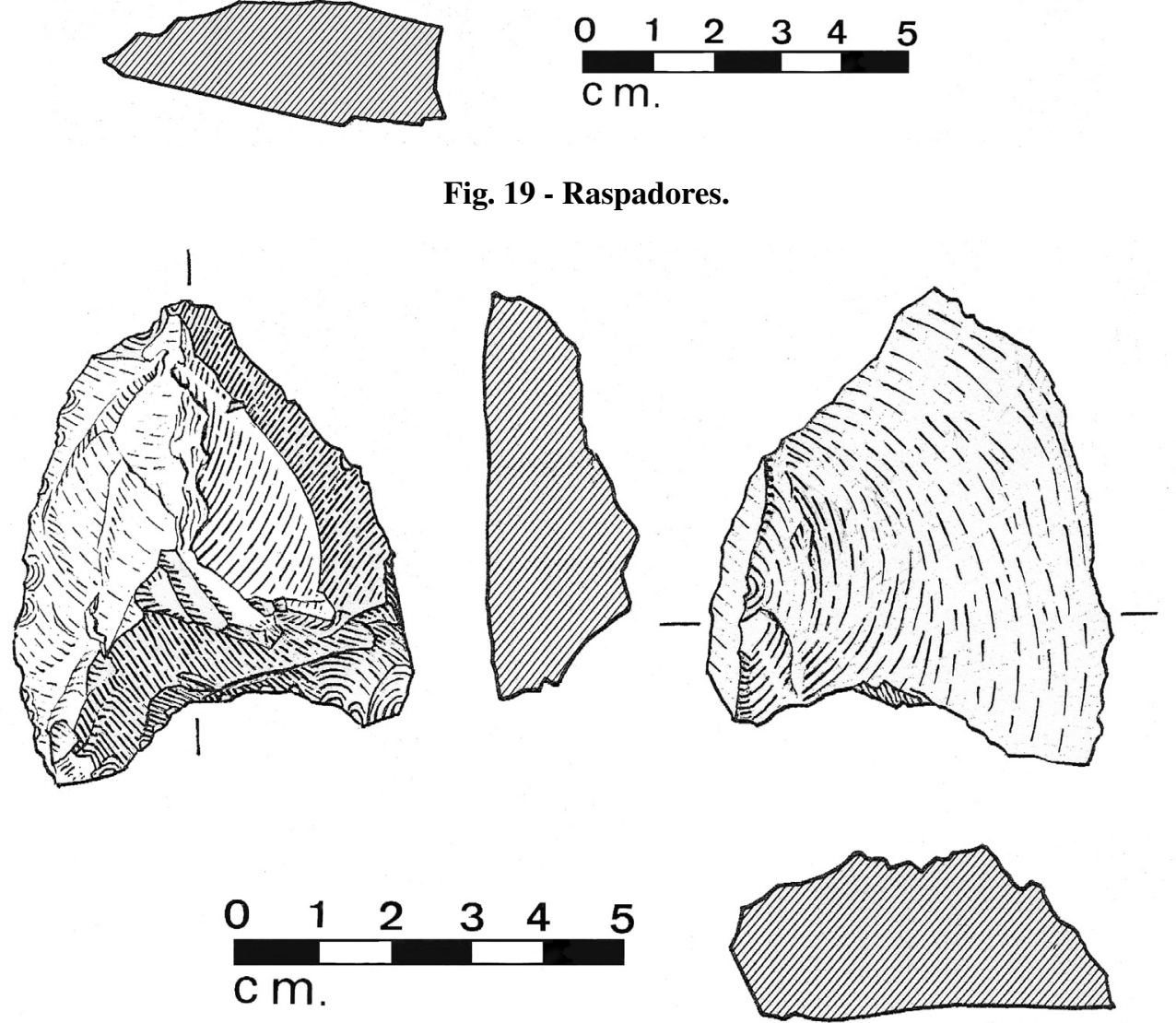

Fig. 20 - Piezas escotadas. 


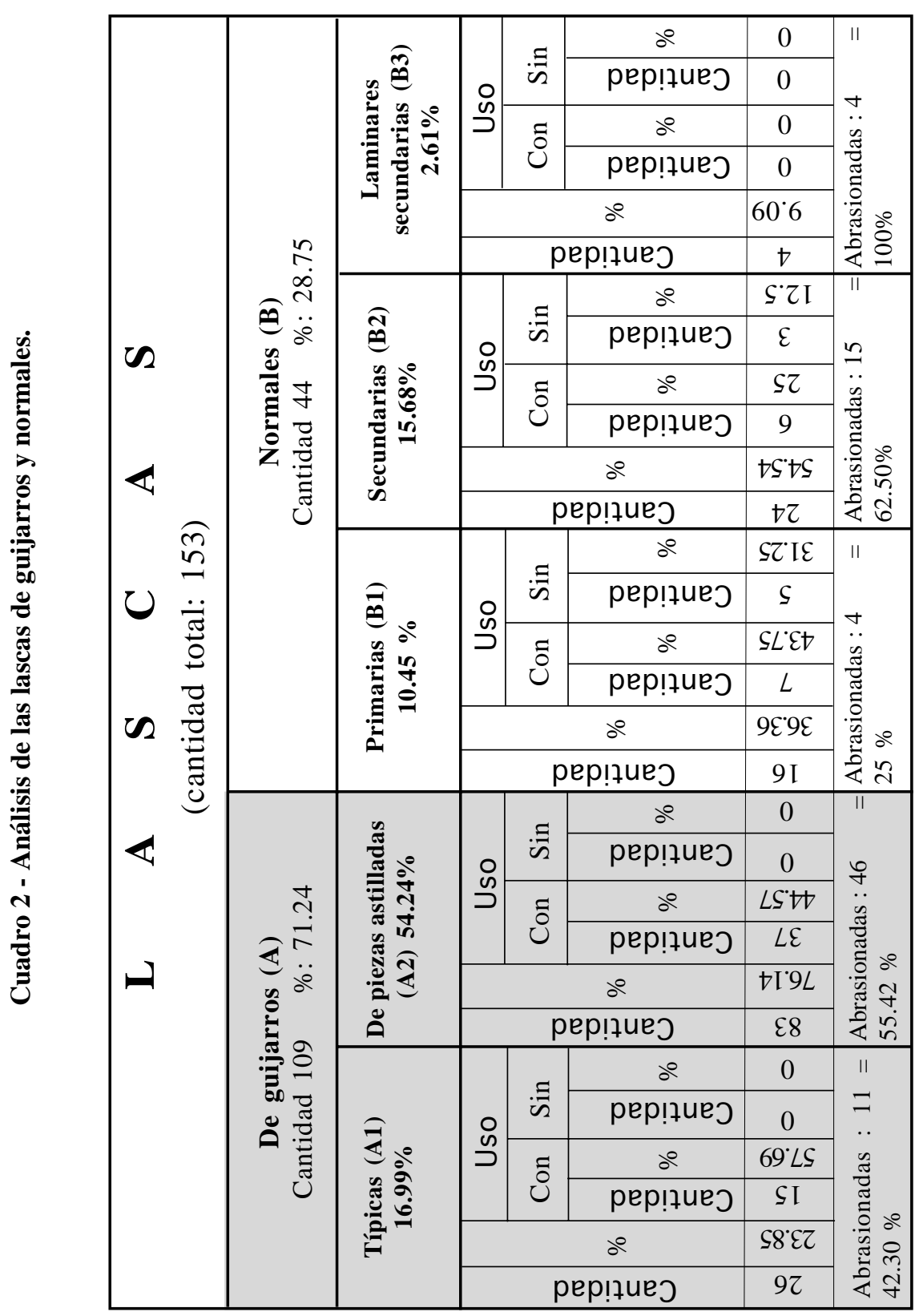


las hemos separado en dos subtipos: las normales (B) y las obtenidas a partir de guijarros (A).

Las lascas de guijarros (A) a su vez las hemos subdividido en típicas (A1) y de piezas astilladas (A2). Las típicas (A1) tienen el punto de fractura muy marcado, la mayoría no tienen bulbo y han sido logradas con un golpe vertical fuerte. Son gruesas y regulares. Pueden ser primarias o secundarias (Fig. 21).

Las lascas obtenidas a partir de la elaboración de las piezas astilladas (A2) son de todo tamaño, aunque predominan las pequeñas. Ninguna es muy grande. Son lascas que han quedado como consecuencia del trabajo de piezas astilladas. Todas son primarias por haber sido parte de cantos rodados. La mayoría, vistas en corte, son ligeramente arqueadas. La gran mayoría conserva el córtex en la cara dorsal, en algunos casos éste presenta una cicatriz por astillamiento. El punto de fractura en ambos lados es muy claro y marcado. En algunos casos el bulbo es prominente y las ondas muy marcadas y prominentes también. En la gran mayoría, sin embargo, el bulbo es casi ausente. En forma predominan las alargadas sobre las redondeadas. Se trata de piezas muy típicas e inconfundibles. A menudo tienen una ruptura reflejada en la parte distal. (Fig. 22).

Las lascas normales (B) son típicas y no necesitan mayor descripción. Las hemos subdividido en primarias (B1; Fig. 23), secundarias (B2; Fig. 24) y lascas laminares secundarias (B3; Fig. 25). Para la definición de "lascas laminares" remitimos al lector a nuestros trabajos tipológicos anteriores (Bonavia, 1982a: 96; 1992: 87). Cuando
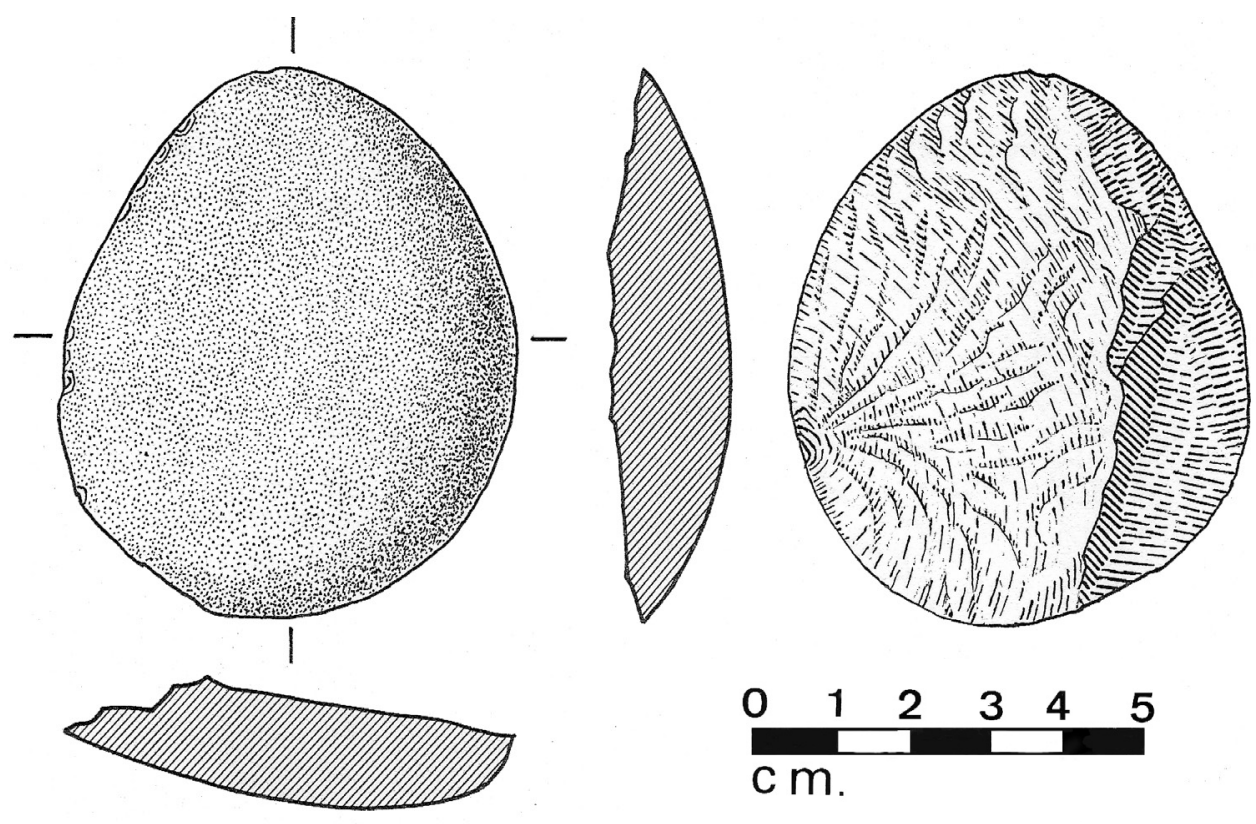

Fig. 21 - Lascas de guijarros. 

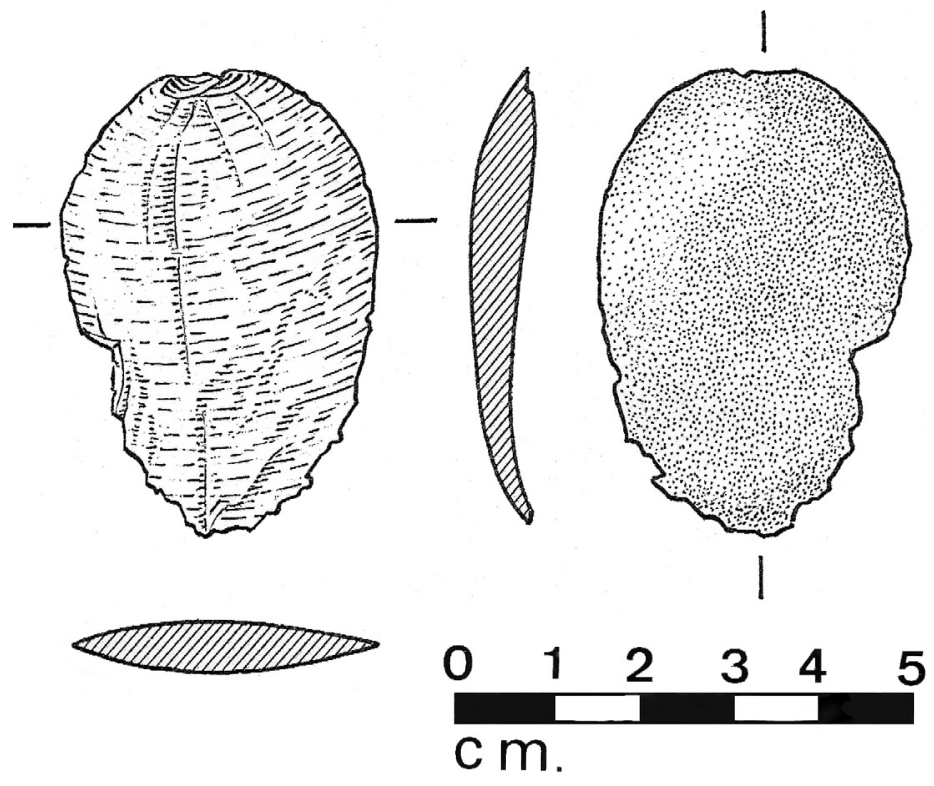

Fig. 22 - Lascas obtenidas a partir de la elaboración de piezas astilladas.
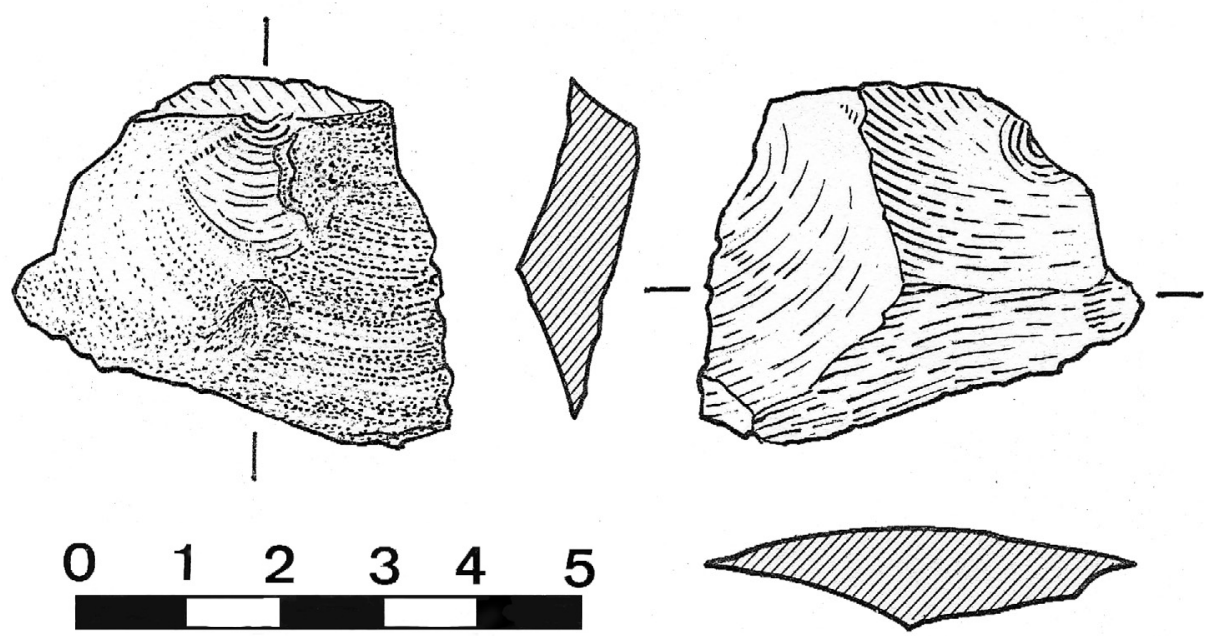

$\mathrm{cm}$.

Fig. 23 - Lascas normales primarias. 

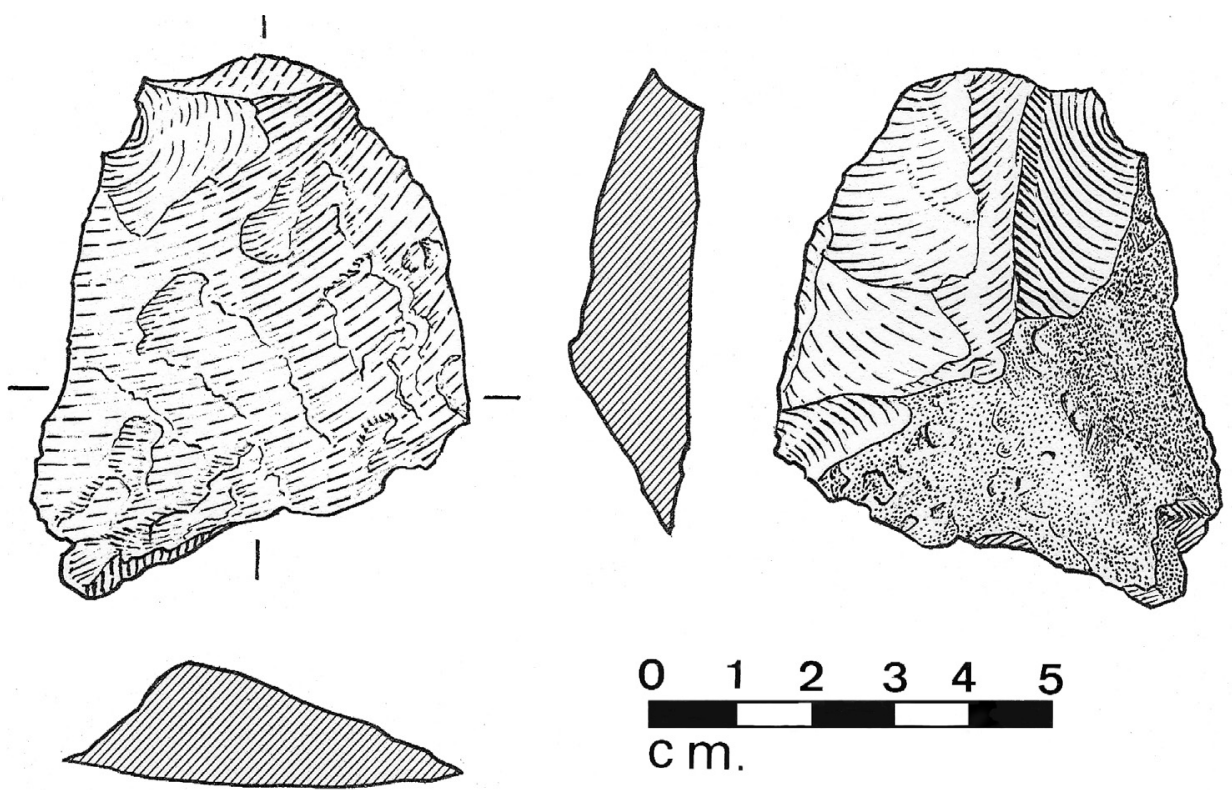

Fig. 24 - Lascas normales secundarias.
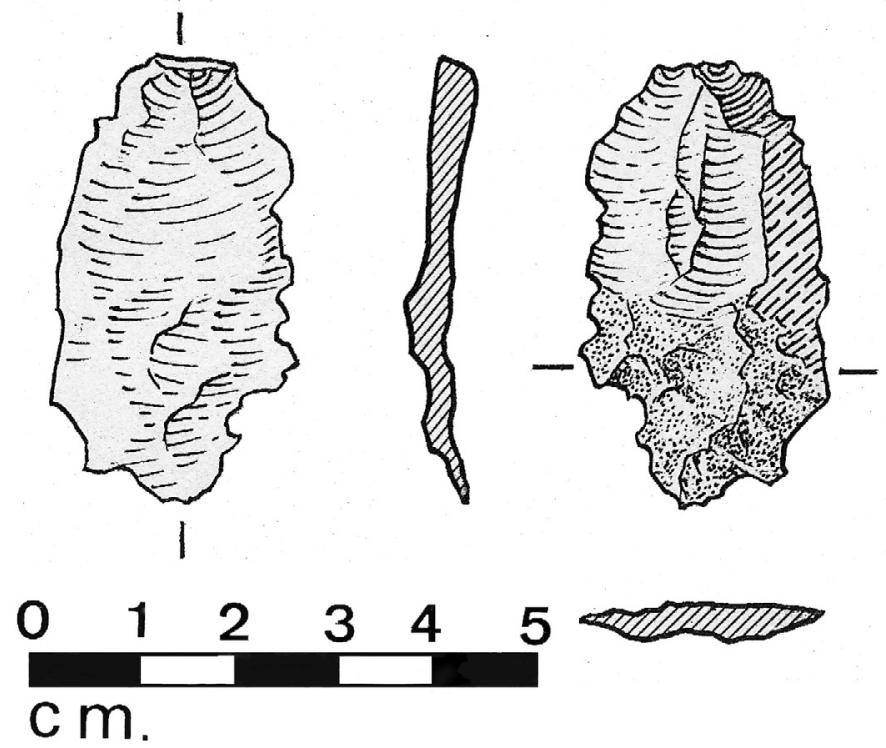

Fig. 25 - Lascas laminares secundarias. 
nosotros propusimos el término, no teníamos conocimiento que él fue usado por B. Bagolini a fines de la década de los años 60 para una industria holocénica del norte de Italia [vide Merino, 1994: fig. 375, 261 y 457]).

\section{INVENTARIO Y CARACTERÍSTICAS DEL MATERIAL LÍTICO}

El material lítico de este yacimiento procede de la superficie y de las excavaciones realizadas. Para su análisis, sobre la base de nuestra tipología morfológica, hemos efectuado una tipología funcional con la finalidad de tratar de tener un conocimiento más exacto sobre las actividades de los habitantes del sitio (vide Bordes, 1970; Bordes et al., 1972).

La mayor parte de las piedras utilizadas para la elaboración de artefactos son rocas volcánicas porfiríticas, a veces vesciculares. La mayoría son probablemente andesitas y algunas poseen cuarzo. Hay un pequeño porcentaje de toba silicificada, cuarzo de filón, meta cuarcita y algunos fragmentos de jaspe, probablemente de origen volcánico.

\section{1. Material de superficie}

En la superficie hemos recogido 336 piedras trabajadas de los diferentes tipos que se pueden ver en el cuadro 1. Es todo lo que en ese momento había en la superficie y a pesar que visitamos el sitio con anterioridad, no notamos cambios. Por la información que tenemos, hemos sido los primeros en efectuar trabajos en la zona. Y este tipo de material no llama la atención de la gente, de modo que consideramos que verdaderamente la muestra es representativa. La tipología que hemos elaborado ha sido hecha a base de este conjunto de piezas. Para un resumen del análisis, remitimos al lector a los cuadros 1 y 2 y a los diagramas 1 y 2 .

En total se encontró 37 piezas astilladas típicas, que representan el 20,21\%. Es prácticamente nada lo que se puede añadir, a más de lo que ya se ha dicho en la parte tipológica. Sólo cabe decir que hay 4 piezas $(10,81 \%$ de esta categoría) que tienen huellas de machacado lateral suave. Del análisis microscópico se desprende que hay 22 utensilios $(59,45 \%)$ con huellas de uso y $6(16,21 \%)$ sin ellas. Pero hay 9 piezas $(24,32 \%)$ que están abrasionadas por efecto eólico y sobre las que cualquier indicio de esta naturaleza ha desaparecido.

El largo varía entre $5,6 \mathrm{~cm}$ y $2,5 \mathrm{~cm}$, siendo el promedio $4,13 \mathrm{~cm}$. El ancho oscila entre $6,5 \mathrm{~cm}$ y $0,8 \mathrm{~cm}$ con un promedio de $3,32 \mathrm{~cm}$. El espesor máximo es de 1,9 cm y el mínimo 0,4 cm, con un promedio de 1,08 cm. El ancho de la parte con cicatrices, considerando en forma arbitraria una como apical y la otra basal, es en el primer caso entre $5 \mathrm{~cm}$ y $0,4 \mathrm{~cm}$ con un promedio de $2,4 \mathrm{~cm}$, y en el segundo entre $3,5 \mathrm{~cm}$ y $0,2 \mathrm{~cm}$, con un promedio de $1,62 \mathrm{~cm}$. El ángulo de la parte apical del artefacto con cicatrices oscila entre $80^{\circ}$ y $25^{\circ}$ y el de la parte basal entre $70^{\circ}$ y $25^{\circ}$ con un promedio de $49^{\circ}$.

Hay 6 piezas astilladas típicas con astillamiento y retoque bilateral $(3,27 \%)$. De ellas $5(83,33 \%)$ tienen huellas de uso (tomando en cuenta que hay una [16,66 \%] que está abrasionada). El largo varía entre $6 \mathrm{~cm}$ y $4,3 \mathrm{~cm}$, con un promedio de $5,46 \mathrm{~cm}$. El 
Diagrama 2 - Distribución porcentual del uso en el utillaje lítico.

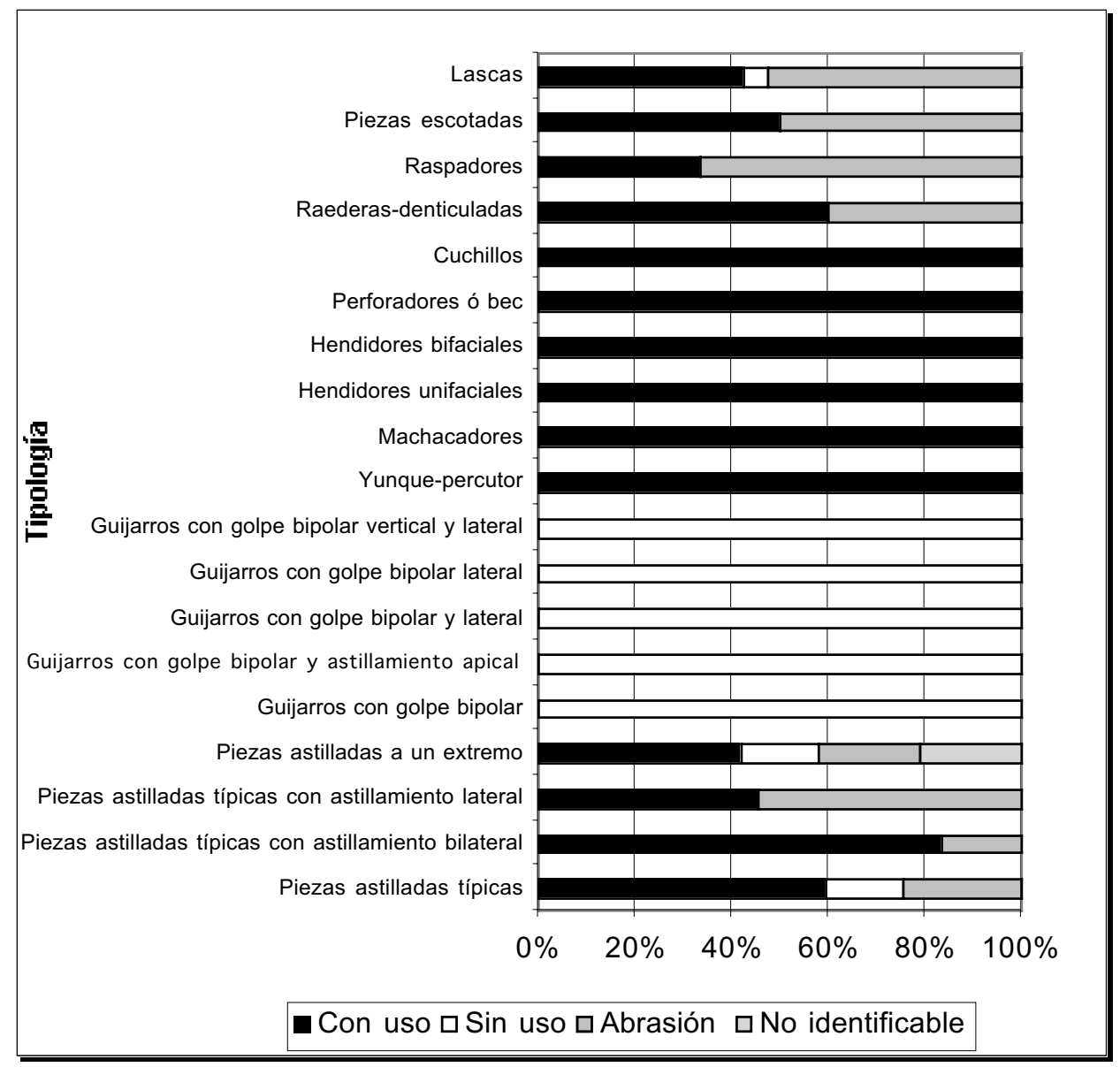

ancho máximo es de 5,6 cm. y el mínimo de $2,6 \mathrm{~cm}$, con un promedio de 4,43 cm y el espesor varía entre $1,7 \mathrm{~cm}$ y $0,8 \mathrm{~cm}$, con un promedio de $1,18 \mathrm{~cm}$. El ancho de la parte activa apical oscila entre $3 \mathrm{~cm}$ y $1,5 \mathrm{~cm}$ con un promedio de $2,26 \mathrm{~cm}$ y el de la basal con cicatrices entre $2,5 \mathrm{~cm}$ y $1,1 \mathrm{~cm}$ con un promedio de $1,76 \mathrm{~cm}$. El ancho de la parte derecha con cicatriz (colocando ésta hacia el observador) varía entre $4,5 \mathrm{~cm}$ y $1 \mathrm{~cm}$, con un promedio de $2,45 \mathrm{~cm}$ y el de la parte activa izquierda entre $3 \mathrm{~cm}$ y $1,5 \mathrm{~cm}$ con un promedio de $2,24 \mathrm{~cm}$.

Los ángulos de las partes con cicatrices en el orden apical, basal, derecha e izquierda varían entre un máximo de $90^{\circ}, 80^{\circ}, 70^{\circ}$ y $65^{\circ}$ y un mínimo de $45^{\circ}, 50^{\circ}, 45^{\circ}$, $50^{\circ}$ con un promedio de $65^{\circ}, 63^{\circ}, 62^{\circ}$ y $67^{\circ}$ respectivamente.

Las piezas astilladas típicas con golpe lateral son $11(6,01 \%)$ y de ellas 5 $(45,45 \%)$ tienen huellas de uso y $6(54,54 \%)$ son abrasionadas. Las medidas máximas 
de estas piezas, en el orden largo, ancho, espesor en su mayor tamaño son de $7 \mathrm{~cm}$, $5,2 \mathrm{~cm}, 1.7 \mathrm{~cm}$ y en su tamaño menor $3,3 \mathrm{~cm}, 2,1 \mathrm{~cm}$ y $0,6 \mathrm{~cm}$ con un promedio respectivamente de $9,8 \mathrm{~cm}, 3,5 \mathrm{~cm}$ y $1,1 \mathrm{~cm}$. El ancho máximo de las partes apical y basal con cicatrices son $4 \mathrm{~cm}$ y $1,7 \mathrm{~cm}$ y el mínimo de 1,3 y $0,4 \mathrm{~cm}$, con un promedio en cada caso de $2,6 \mathrm{~cm}$ y $1,3 \mathrm{~cm}$. El ancho de la parte activa lateral varía entre $5,2 \mathrm{~cm}$ y $0,5 \mathrm{~cm}$, con un promedio de $2,5 \mathrm{~cm}$.

Las medidas máximas de los ángulos de las partes apical, basal y lateral con cicatrices son de $80^{\circ}$ en los tres casos, mientras que las medidas mínimas son de $40^{\circ}, 30^{\circ}$ y $40^{\circ}$, con un promedio de $60^{\circ}, 56^{\circ}$ y $56^{\circ}$ en cada caso.

Encontramos 19 piezas astilladas con retoque a un extremo $(10,38 \%)$, de las cuales $8(42,10 \%)$ tienen huellas de uso, $3(15,78 \%)$ no las tienen y $4(21,05 \%)$ están abrasionadas. (4 piezas [21,05\%] están en tal mal estado que no se pudo hacer ningún reconocimiento). Las medidas máximas de largo, ancho y espesor son de $5,9 \mathrm{~cm}, 5,3 \mathrm{~cm}$ y $1,3 \mathrm{~cm}$ con un promedio de 4,3 cm, 3,2 cm y $0,9 \mathrm{~cm}$ en cada caso. El ancho máximo de la parte activa es de 5,2 cm y el mínimo de $1,3 \mathrm{~cm}$ con un promedio de $2,2 \mathrm{~cm}$, mientras que el ángulo de la parte activa oscila entre $65^{\circ}$ y $45^{\circ}$ con un promedio de $50^{\circ}$.

Tenemos 23 guijarros con golpe bipolar (12,56\%), cuyo largo varía entre $6,1 \mathrm{~cm}$ y $2,6 \mathrm{~cm}$ con un promedio de $4,7 \mathrm{~cm}$. El ancho oscila entre $5,2 \mathrm{~cm}$ y 1,4 cm, con un promedio de $2,9 \mathrm{~cm}$ y el espesor entre $2,2 \mathrm{~cm}$ y $0,4 \mathrm{~cm}$ con un promedio de $1 \mathrm{~cm}$. Hay que señalar que no se ha tomado en cuenta 3 fragmentos que no se pueden medir. En ninguno de ellos se ha detectado huellas de uso.

Hemos encontrado $10(5,94 \%)$ guijarros con golpe bipolar y astillamiento en la parte apical. Su largo varía entre $6,8 \mathrm{~cm}$ y $3 \mathrm{~cm}$, con un promedio de $5,3 \mathrm{~cm}$. Su ancho oscila entre $4,7 \mathrm{~cm}$ y $2,2 \mathrm{~cm}$, con un promedio de $3,7 \mathrm{~cm}$ y con un espesor entre $2,3 \mathrm{~cm}$ y $0,9 \mathrm{~cm}$, con un promedio de $1,4 \mathrm{~cm}$. Ninguno tiene huellas de uso.

Los guijarros con golpe bipolar y lateral suman $23(12,56 \%)$ y respectivamente las medidas máximas de largo, ancho y espesor son de $8 \mathrm{~cm}, 6,2 \mathrm{~cm}$ y $1,9 \mathrm{~cm}$, siendo el promedio respectivamente de $4,6 \mathrm{~cm}, 3,7 \mathrm{~cm}$ y $1,1 \mathrm{~cm}$. En esta categoría hay 3 piezas fragmentadas que no se pueden medir y que por eso no han sido tomadas en cuenta para los fines estadísticos. Ninguno ha sido usado.

Los guijarros con golpe bipolar lateral son solamente 4 (representan el 2,18\%). Las medidas máximas de largo, ancho y espesor son $7 \mathrm{~cm}, 5,6 \mathrm{~cm}$ y $1,9 \mathrm{~cm}$, mientras que las mínimas son $3,5 \mathrm{~cm}, 2,8 \mathrm{~cm}$ y $1 \mathrm{~cm}$, siendo los promedios respectivos de $5,1 \mathrm{~cm}$, $4 \mathrm{~cm}$ y $1,4 \mathrm{~cm}$. En ninguno se ha podido reconocer huellas de uso.

También los guijarros con golpe bipolar vertical y lateral son 4 (2,18\%), siendo su largo máximo de $6,6 \mathrm{~cm}$, mientras que el ancho y el espesor son respectivamente $4,2 \mathrm{~cm}$ y 1,2 cm. El largo, el ancho y el espesor mínimos son de 4,5 cm, 3,7 cm y 1,2 cm, siendo los promedios $5,5 \mathrm{~cm}, 3,9 \mathrm{~cm}$ y $0,9 \mathrm{~cm}$. Tampoco fueron usados.

Pudimos hallar sólo 2 yunques-percutores $(1,09 \%)$. Para ello se ha utilizado guijarros grandes y oblongos, de roca probablemente sub-volcánica fanerítica de grano fino. Es interesante que para esta función se ha escogido este material que no tiene fractura concoidal. Uno mide $15,7 \mathrm{~cm}$ de largo por $7,5 \mathrm{~cm}$ de ancho y 4,3 cm de espesor y pesa $980 \mathrm{gr}$. El segundo mide $14 \mathrm{~cm}$ de largo por 7,7 $\mathrm{cm}$ de ancho y 5,4 cm de espesor y pesa 885 gr. 
Las huellas de percusión en los bordes son muy marcadas, habiendo dejado inclusive algunas cicatrices grandes, lo que muestra uso continuo por largo tiempo y con considerable fuerza. Al mismo tiempo, sobre las superficies de ambas caras más grandes de los guijarros y sobre todo en la parte central, han quedado muy claras las huellas marcadas y profundas de una percusión intensa. Son llamativas unas concavidades irregulares, profundas, que señalan el lugar donde se apoyaba los guijarros que eran golpeados por el percutor para lograr el típico efecto del golpe bipolar.

Entre los materiales de superficie, encontramos 5 machacadores $(2,73 \%)$. A juzgar por las huellas que han quedado en ellos, el machacado no parece haber sido fuerte ni muy prolongado. Dos ejemplares se rompieron longitudinalmente, probablemente durante su uso, y a un tercero le ha quedado una cicatriz grande en uno de los extremos (justamente aquél donde se produjo el machacado). Para esta tarea se escogió guijarros alargados de diferentes tipos, algunos delgados y otros gruesos. El peso de estos machacadores es: 95 gr, 40 gr, 100 gr, 50 gr y 20 gr respectivamente.

Los hendidores unifaciales encontrados son 4 (representan el 2,48\% del conjunto). Como se dijo al hacer la tipología, son piezas típicas; sólo en dos de ellas la cicatriz no forma un ángulo muy agudo. Tres presentan la particularidad de mostrar huellas de machacado intenso en la parte basal. En los bordes de la parte activa, si bien todos muestran huellas de uso, uno de ellos tiene además huellas de golpes suaves, probablemente sobre algo no muy duro. Toda la superficie de estos artefactos muestra una gran cantidad de estrías. Consideramos que en este caso el peso es más significativo que las medidas de los intrumentos. Este es de 45 gr, 75 gr, 90 gr y 105 gr en cada caso.

Hay un solo hendidor bifacial (0,54\%), típico, que pesa 60 gr y que en el borde activo muestra huellas de uso.

En el caso del único bifaz que tenemos $(0,54 \%)$, es poco lo que se puede decir, más de lo expresado en la parte dedicada a la tipología. Cabe hacer hincapié que se trata de una pieza atípica, que inclusive tiene un lado mucho más regular que el otro. Ha sido hecha de toba silicificada. Mide 11,6 cm de largo, 6,1 $\mathrm{cm}$ de ancho y 1,9 $\mathrm{cm}$ de espesor en la parte más gruesa. En los bordes muestra huellas de uso.

Los perforadores o bec encontrados son sólo 3 (1,63\%). Han sido elaborados a partir de lascas de guijarros. Para lograr la parte activa puntiaguda, en un caso se ha golpeado en forma alterna desde las caras cortical (dorsal) y la ventral de la lasca. En otro los golpes han partido de la parte cortical y en el tercero de la ventral. En todos ellos se trata de golpes certeros que no han necesitado un retoque posterior. Los tres ejemplares muestran huellas de uso en la punta y zonas vecinas. En un caso el movimiento parece haber sido por frotación circular, pero en los otros dos se trataría más bien de un trabajo de palanca con golpes no muy fuertes. El más típico ha sido hecho en meta cuarcita, que entre las rocas comunes es una de las más duras. El largo de los tres ejemplares es de $8,2 \mathrm{~cm}, 8 \mathrm{~cm}$ y $5,2 \mathrm{~cm}$, mientras que el ancho es de 5,3 cm, 7,6 cm y $5,5 \mathrm{~cm}$ y el espesor es de $2,9 \mathrm{~cm}, 2 \mathrm{~cm}$ y $1,3 \mathrm{~cm}$. El peso es respectivamente de $140 \mathrm{gr}$, 60 gr y 50 gr.

Entre estos artefactos hay 5 cuchillos $(2,73 \%)$ que han sido ya descritos. Cabe añadir que en dos casos se ha partido de lascas grandes de guijarros, en uno de una pieza astillada rota utilizándose el borde lateral, en otro del extremo de un guijarro plano, 
partido por la mitad y, finalmente, en el último ejemplar a partir de una lasca gruesa. Siendo difícil la medición, se ha preferido indicar el peso. Este es de 55 gr, 180 gr, $95 \mathrm{gr}, 45 \mathrm{gr}$ y $45 \mathrm{gr}$ en cada caso. Todos muestran la parte activa muy lustrosa y no hay huellas de golpes. Esto deja suponer que fueron utilizados para cortar alguna materia relativamente blanda, con movimiento de vaivén y probablemente por tiempo prolongado.

En el caso de las raederas denticuladas, que son 20 y representan el 10,92\% del total del utillaje de este yacimiento, es poco lo que se puede añadir, a más de lo ya dicho. Cabe sólo indicar que son 14 los casos en los que se ha partido de la cara ventral para obtener el artefacto y en los 6 restantes desde la dorsal. La parte activa se encuentra siempre sobre el lado opuesto al punto de percusión de la lasca. Como ya se ha dicho, en algunos casos el denticulado es marcado y en otros no. El promedio está entre los dos extremos. 12 de estos artefactos (60\%) tienen huellas de uso y en los 8 restantes $(40 \%)$ es imposible darse cuenta, por la marcada abrasión que presentan. El largo de estos utensilios varía entre $10 \mathrm{~cm}$ y $3,6 \mathrm{~cm}$, siendo el promedio $6,9 \mathrm{~cm}$. El ancho oscila entre $9,2 \mathrm{~cm}$ y $4,5 \mathrm{~cm}$. Y el ancho máximo es de $3,2 \mathrm{~cm}$ y el mínimo $1,1 \mathrm{~cm}$ con un promedio de $2 \mathrm{~cm}$.

Los tres raspadores típicos $(1,63 \%)$ son pequeños y han sido elaborados a partir de lascas secundarias. Su peso es respectivamente de 45 gr, 45 gr y 25 gr. La parte activa tiene un largo que en cada caso es de $3,5 \mathrm{~cm}, 4 \mathrm{~cm}$ y $4 \mathrm{~cm}$ y el ángulo de ésta mide $65^{\circ}$, $60^{\circ}$ y $70^{\circ}$ respectivamente. Sólo en uno se ha podido ver huellas de uso ya que las otras piezas son abrasionadas.

Hemos encontrado sólo 2 especímenes escotados (1,09\%), de los que uno es típico y el otro atípico, pero ambos han sido hechos sobre lasca secundaria. El ancho de la parte activa, tomado en los dos puntos extremos que delimitan la escotadura, es de 4 y $3 \mathrm{~cm}$. Sólo en un ejemplar se ha podido identificar huellas de uso ya que la otra pieza está muy afectada por la erosión eólica.

Finalmente en la categoría "Varios" hemos incluido tres fragmentos atípicos de guijarro. Dos de ellos son muy erosionados y uno muestra huellas de machacado en los bordes.

Consideramos que las lascas son una categoría importante, no sólo por la cantidad encontrada sino, como se verá más adelante, por la función que cumplieron. Por eso merece la pena incluir una serie de detalles. En total se ha encontrado 153 que representan el 45,53 \% del total del utillaje de PV35-106. Para la síntesis de la información que se expondrá en seguida, nos remitimos al cuadro 2.

Como se ha señalado en la parte referente al aspecto tipológico, las lascas han sido separadas en dos grandes subcategorías: las que se han obtenido a partir de guijarros (A) y aquellas que se consideran como normales (B). Las primeras representan el 71,24 \% del total de lascas (109 ejemplares) y las segunda 28,75\% (44 piezas).

Nos referiremos primero a las lascas de guijarro. Éstas han sido subdivididas a su vez en tres subcategorías. Las primeras son las típicas (denominadas con la sigla A1), que dentro de su subcategoría representan el 23,85\% (26 ejemplares). Es importante señalar que casi todas $(93,15 \%)$ son primarias y sólo una pequeña minoría $(6,85 \%)$ son secundarias. De éstas $15(57,69 \%)$ tienen uso y han sido empleadas como artefactos. Corresponden a lo que Bordes (1970) ha definido como útiles a posteriori. De 11 
$(42,30 \%)$ no podemos saberlo, pues están fuertemente abrasionadas por la acción eólica. Hay tres ejemplares difíciles de definir y que no han sido tomados en cuenta.

El largo de estas lascas varía entre $8,5 \mathrm{~cm}$ y $2,1 \mathrm{~cm}$. El ancho entre $11 \mathrm{~cm}$ y $3.5 \mathrm{~cm}$, con un promedio de $5,7 \mathrm{~cm}$ y el espesor entre $2,9 \mathrm{~cm}$ y $0,8 \mathrm{~cm}$, con un promedio de $1,4 \mathrm{~cm}$.

La segunda subcategoría son las lascas de piezas astilladas, que en cantidad de 83 representan el 76,14\%. Todas ellas son primarias y a menudo muestran una ruptura reflejada en la parte distal. 37 de ellas $(44,57 \%)$ muestran huellas de uso, pero 46 $(55,42 \%)$ están abrasionadas. El largo de estas lascas oscila entre $5,9 \mathrm{~cm}$ y $16 \mathrm{~cm}$, con un promedio de $3,7 \mathrm{~cm}$; mientras que el ancho varía entre $4,4 \mathrm{~cm}$ y $1,3 \mathrm{~cm}$, con un promedio de $3,14 \mathrm{~cm}$. Las medidas extremas del espesor son $1 \mathrm{~cm} \mathrm{y} 0,2 \mathrm{~cm}$, siendo el promedio $0,5 \mathrm{~cm}$.

Hay 12 ejemplares que son fragmentos de lascas, que no pudieron ser medidos y que no han sido incluidos en la estadística. Sin embargo 2 de ellos tienen huellas de uso, 5 no las tienen y el resto está abrasionado. Hay también 14 piezas dudosas que no hemos podido incluir con cierto margen de seguridad en esta subcategoría y que preferimos excluir del análisis estadístico.

Las lascas normales (B), como se recordará, han sido subdivididas en tres subcategorías: las primarias (B1), las secundarias (B2) y las laminares secundarias (B3). Las primeras (B1) en número de 16, representan el 36,36\%, las segundas (B2) que son 24 el 54,54\% y las últimas (B3) en cantidad de 4 son tan sólo el 0,09\%. De las lascas primarias (B1) el 43,75 \% muestran huellas de uso, el 31,25\% no las tienen y el $25 \%$ restante son piezas abrasionadas. Se debe señalar que el uso en forma mayoritaria aparece en el borde activo distal.

El ancho máximo de estas lascas varía entre $5,5 \mathrm{~cm}$ y 2,4 , con un promedio de $3,7 \mathrm{~cm}$; el ancho entre $7,2 \mathrm{~cm}$ y $2 \mathrm{~cm}$, siendo el promedio $4,1 \mathrm{~cm}$; el espesor entre $2,2 \mathrm{~cm}$. y $0,5 \mathrm{~cm}$, con un promedio de $1,2 \mathrm{~cm}$. El ángulo máximo de fractura es de $125^{\circ}$ y el mínimo de $95^{\circ}$, con un promedio de $109^{\circ}$ y el ángulo distal varía entre $65^{\circ}$ y $35^{\circ}$ con un promedio de $47^{\circ}$.

Es de señalar que se trata de lascas típicas, obtenidas con percutor duro. Hay 6 (25\%) secundarias (B2) que muestran huellas de uso, 3 (12,5\%) que nos las tienen y $15(62,5 \%)$ que están abrasionadas. Como ya se dijo son típicas y obtenidas en este caso también con percutor duro. El largo de estas lascas varía entre un máximo de $6 \mathrm{~cm}$ y un mínimo de $1,7 \mathrm{~cm}$, con un promedio de $3,4 \mathrm{~cm}$, mientras que el ancho tiene una variación entre $8,4 \mathrm{~cm}$ y $2,2 \mathrm{~cm}$ con un promedio de $4 \mathrm{~cm}$. El espesor oscila entre $2,8 \mathrm{~cm}$ y $0,5 \mathrm{~cm}$, con un promedio de $1,2 \mathrm{~cm}$. El ángulo de fractura tiene un máximo de $125^{\circ}$ y un mínimo de $85^{\circ}$ con un promedio de $103^{\circ}$; mientras que el ángulo distal oscila entre $80^{\circ}$ y $25^{\circ}$ con un promedio de $47^{\circ}$.

Y finalmente tenemos las lascas laminares secundarias (B3) que son todas típicas y todas abrasionadas, de modo que es imposible darse cuenta si tuvieron o no huellas de uso. Las medidas máximas de largo, ancho y espesor son respectivamente $5,2 \mathrm{~cm}$, $2,5 \mathrm{~cm}$ y $0,6 \mathrm{~cm}$ y las mínimas $3,3 \mathrm{~cm}, 1,3 \mathrm{~cm}$ y $0,3 \mathrm{~cm}$, con un promedio de $4,3 \mathrm{~cm}, 1,8$ $\mathrm{cm}$ y $0,4 \mathrm{~cm}$. A su vez los ángulos máximos de fractura y distal son de $100^{\circ} \mathrm{y} 50^{\circ} \mathrm{y}$ los mínimos de $95^{\circ}$ y $20^{\circ}$, con promedios de $96^{\circ}$ y $34^{\circ}$.

El cuadro general de las lascas se puede ver en el diagrama 3. 


\section{Diagrama 3 - Distribución porcentul de las lascas utilizadas.}

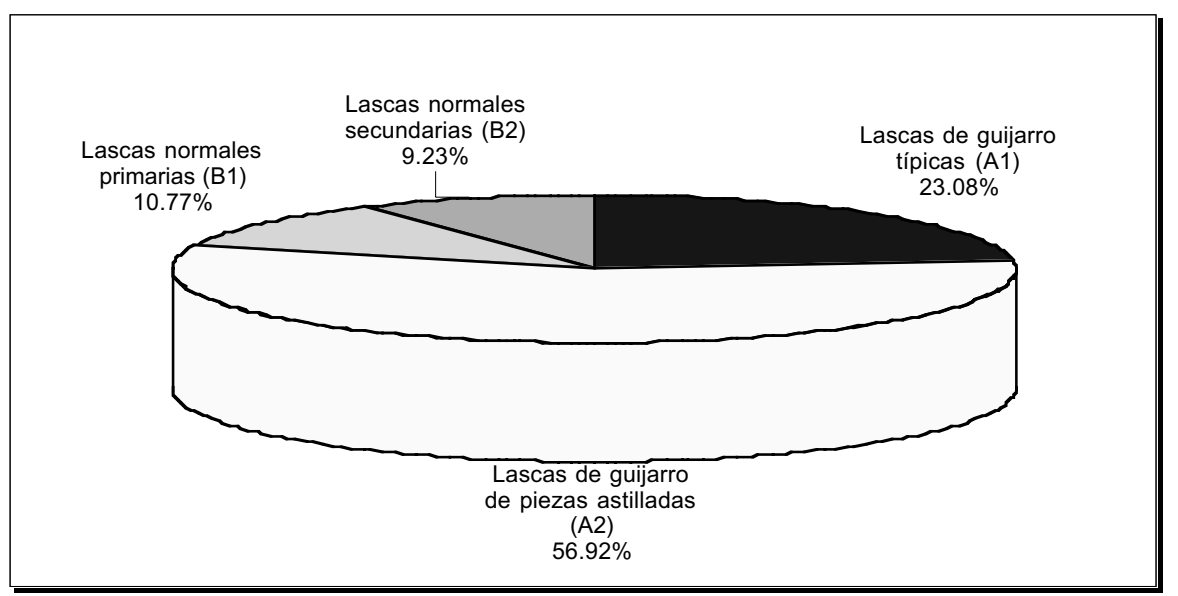

\section{2. Material excavado}

En términos generales en las excavaciones se encontró poco material lítico. Hubo en total 54 artefactos que, salvo dos excepciones que mencionaremos en su debido momento, reúnen las características de los utensilios descritos a base de la colección de superficie.

\section{2. 1. Pozo $N^{o} 1$}

Al excavarse el Pozo $\mathrm{N}^{\circ} 1$ se encontró 23 artefactos, que se reparten de la siguiente forma. Hubo dos piezas astilladas típicas (que representan el 8,69\% del utillaje excavado en este pozo). Ambas son usadas y con restos de una materia rojiza en las fisuras, cerca del borde activo. Una de ellas muestra huellas de machacado intenso sobre un borde lateral. El largo mide $5,1 \mathrm{~cm}$ y $6 \mathrm{~cm}$ respectivamente; el ancho $4 \mathrm{~cm}$ y $3,2 \mathrm{~cm}$, elespesor $1,7 \mathrm{~cm}$ y $1 \mathrm{~cm}$. El ancho de la parte activa apical es de $2,8 \mathrm{~cm}$ y $2,1 \mathrm{~cm}$, mientras que el de la parte basal es de $1,8 \mathrm{~cm}$ y $2,1 \mathrm{~cm}$. El ángulo de la parte activa apical mide $70^{\circ}$ y $55^{\circ}$, mientras que el de la basal es de $55^{\circ}$ y $50^{\circ}$.

Encontramos 2 piezas $(8,69 \%)$ astilladas con retoque a un extremo. Una es pequeña y la otra grande. La más grande tiene gran cantidad de materia rojiza en los intersticios. El largo de esta piezas es de $4,2 \mathrm{~cm}$ y $3,4 \mathrm{~cm}$, mientras que el ancho es de $4,4 \mathrm{~cm}$ y $2,2 \mathrm{~cm}$, con un espesor de $0,9 \mathrm{~cm}$ y $0,5 \mathrm{~cm}$. El ancho de la parte activa es de $3,5 \mathrm{~cm}$ y $1 \mathrm{~cm}$ y el ángulo de la misma $40^{\circ}$ y $65^{\circ}$.

Hallamos un solo guijarro con golpe bipolar (4,34\%); mide $6 \mathrm{~cm}$ de largo, $4,6 \mathrm{~cm}$ de ancho y $1,7 \mathrm{~cm}$ de espesor. También hay un ejemplar de guijarro con golpe bipolar y lateral (4,34\%) que mide $5,7 \mathrm{~cm}$ de largo, 4,6 cm, de ancho y 1,4 cm de espesor.

El único yunque-percutor $(4,34 \%)$ encontrado fue hecho a partir de un guijarro roto que mide $10 \mathrm{~cm}$ de largo por $9,5 \mathrm{~cm}$ de ancho y $5,5 \mathrm{~cm}$ de espesor. Pesa $775 \mathrm{gr}$. Tiene huellas típicas de golpe bipolar en ambos lados y, además, huellas de un machacado 
intenso en el lado fracturado. También se encontró un machacador (4,34 \%) de 275 gr, que originalmente fue un guijarro alargado que fue partido en dos. Se ha aprovechado la parte fracturada como núcleo y se ha sacado dos lascas pequeñas. Luego se ha utilizado la pieza para machacar. Sobre el lado más puntiagudo hay huellas de un machacado intenso y llevado a cabo con fuerza, mientras que al lado opuesto lo hay también, pero muestra menos intensidad en la acción.

Se halló un solo hendidor bifacial (4,34\%) típico, que pesa 100 gr y un perforador atípico $(4,34 \%)$ de $7,5 \mathrm{~cm}$ de largo por $5 \mathrm{~cm}$ de ancho y 3,3 cm de espesor, que pesa 105 gr. Hallamos asímismo dos cuchillos (8,69 \%), ambos atípicos. Uno sobre un fragmento grueso de piedra. Se le ha incluido en esta categoría por su función, pero el borde cortante podría ser clasificado como denticulado. Además en un extremo tiene una pequeña raedera denticulada. Pesa 45 gr. El otro es una gruesa lasca secundaria rota, cuyo borde activo también es muy denticulado. Pesa 120 gr.

De esta excavación proceden también 4 raederas denticuladas $(17,39 \%)$, dos sobre lasca de guijarro (de las cuales una es consecuencia de un golpe bipolar) y dos sobre fragmentos normales. Éstas tienen un retoque muy abrupto $\left(75^{\circ}\right.$ y $70^{\circ}$ respectivamente, con respecto a la base plana). En un caso se trata de un artefacto múltiple, ya que tiene una pequeña escotadura a un lado. El largo varía entre $6,5 \mathrm{~cm}$ y $3,5 \mathrm{~cm}$, con un promedio de $5,3 \mathrm{~cm}$, mientras que el ancho oscila entre $7,5 \mathrm{~cm}$ y $2,7 \mathrm{~cm}$ con un promedio de $5,6 \mathrm{~cm}$. A su vez el espesor está entre $2,3 \mathrm{~cm} \mathrm{y} 0,8 \mathrm{~cm}$, con un promedio de $1,8 \mathrm{~cm}$. Las cuatro tienen huellas de uso.

En la categoría de "Varios" hemos colocado dos fragmentos de guijarros rotos en forma intencional y una piedra que tiene algunos retoques a un lado (13,04\%).

Hubo además 12 lascas. 8 de guijarro (A; 66,66\%), de las cuales $3(37,5 \%)$ son típicas (A1) y $5(62,5 \%)$ son lascas de piezas astilladas (A2). Todas ellas muestran huellas de uso.

Las lascas típicas tienen el largo que varía entre $7 \mathrm{~cm}$ y $3,7 \mathrm{~cm}$, con un promedio de $4,9 \mathrm{~cm}$; el ancho oscila entre $7,2 \mathrm{~cm}$ y $3 \mathrm{~cm}$ con un promedio de $4,7 \mathrm{~cm}$ y el espesor entre $1,7 \mathrm{~cm}$ y $0,9 \mathrm{~cm}$ con un promedio de $1,3 \mathrm{~cm}$.

Mientras que las lascas de piezas astilladas tienen un largo que va entre $5,3 \mathrm{~cm}$ y $1 \mathrm{~cm}$ con un promedio de 3,7 ; el ancho entre $3,8 \mathrm{~cm}$ y $2,1 \mathrm{~cm}$ con un promedio de 2,8 $\mathrm{cm}$ y un espesor que varía entre $0,6 \mathrm{~cm}$ y $0,3 \mathrm{~cm}$ con un promedio de $0,4 \mathrm{~cm}$.

En total hubo 4 lascas normales (B;33,33\%), de las cuales 3 son secundarias (B2; $75 \%)$ y $1(25 \%)$ es laminar secundaria (B3).

En las lascas secundarias el largo varía entre un máximo de $4,5 \mathrm{~cm}$ y un mínimo de $2,1 \mathrm{~cm}$ con un promedio de $3 \mathrm{~cm}$, mientras que el ancho oscila entre $4,6 \mathrm{~cm}$ y $2,5 \mathrm{~cm}$ con un promedio de $3,4 \mathrm{~cm}$; y el espesor entre $1 \mathrm{~cm}$ y $0,5 \mathrm{~cm}$ con un promedio de $0,6 \mathrm{~cm}$. El ángulo de fractura oscila entre $125^{\circ}$ y $105^{\circ}$ con un promedio de $111^{\circ}$, y el ángulo distal entre $40^{\circ}$ y $25^{\circ}$ con un promedio de $30^{\circ}$. Dos de estas lascas tienen huellas de uso $(66 \%)$ y una (33\%) está abrasionada.

La lasca laminar secundaria tiene un largo de $6,4 \mathrm{~cm}$, un ancho de $2,7 \mathrm{~cm}$ con un espesor de $1,4 \mathrm{~cm}$. El ángulo de fractura mide $115^{\circ}$ y el distal $20^{\circ}$. Esta lasca ha sido retocada en ambos lados a partir de la cara dorsal, de modo que se ha formado, en ambos 
lados también, una serie de denticulados. El uso es muy marcado. Encontramos además una lasca pequeña, muy atípica, que no merece mayor descripción.

En esta excavación, además de todos estos utensilios, hemos hallado uno más, que no está representado entre los ejemplares de superficie y para el que hemos tenido que crear una categoría adicional. Es un núcleo cepillo $(4,34 \%)$ que en realidad es un núcleo cuyo borde de fractura ha sido utilizado como cepillo. Es una pieza gruesa que se parece mucho a los núcleos cepillos hallados y descritos para Los Gavilanes (Bonavia, 1982a: 91-92, dibujo 7; 1992: 85). Muestra huellas de uso por golpes suaves. Conserva aún una proporción de córtex. Su peso es de 300 gr (Fig. 26).

Hay también 3 núcleos (13,04\%), uno de los cuales es de guijarro. Los tres son de formas muy irregulares. Han sido usados para sacar pequeñas lascas. No tienen muchas cicatrices y éstas muestran uso de percutor duro. No hay indicios de preparación de plano de fractura y muchas partes tienen aún el córtex. El peso de estos núcleos es respectivamente de 255 gr, 360 gr y 165 grs (Fig. 27 y 28).

\section{2. 2. Pozo $N^{o} 2$}

En el Pozo N 2 se encontró un total de 6 artefactos. Hay una pieza astillada típica con golpe lateral $(16,66 \%)$. No es completa, pues se partió debido a un golpe muy fuerte que recibió sobre una cara. Es por eso que no se puede saber su largo original. Su ancho es de $5 \mathrm{~cm}$ y el espesor de $1,5 \mathrm{~cm}$. La única parte activa que queda completa tiene un ancho de $3,5 \mathrm{~cm}$ y un ángulo de $80^{\circ}$.

Hubo también 2 guijarros con golpe bipolar (33,33\%) que miden 7,2 $\mathrm{cm}$ y $3,7 \mathrm{~cm}$ de largo, por $3,7 \mathrm{~cm}$ y $2,5 \mathrm{~cm}$ de ancho y $1,4 \mathrm{~cm}$ y $0,9 \mathrm{~cm}$ de espesor. Un único machacador $(16,66 \%)$ mide $230 \mathrm{gr}$.

Finalmente hay dos fragmentos de piedra atípicos (que representan el 33,33\% del total) con astillamiento lateral y uso, que hemos incluido en la categoría de "Varios".

En total se halló 8 lascas de las cuales 3 son de guijarros (A; 37,5\%). 2 $(66,66 \%)$ son típicas (A1), ambas primarias y con uso. El largo en un caso no se puede medir pues la lasca no es completa, y en el otro es de $1,5 \mathrm{~cm}$. El ancho mide 3,1 cm y $2,5 \mathrm{~cm}$ y el espesor $0,4 \mathrm{~cm}$ en ambos casos. La tercera (que representa el 33,33\%) es una lasca de pieza astillada (A2) con huellas de uso que, por estar rota, no permite la medición del largo. El ancho es de $3 \mathrm{~cm}$ y el espesor de $0,2 \mathrm{~cm}$.

Las 5 lascas normales $(62,5 \%)$ son todas secundarias (B2) y dos de ellas muestran huellas de uso, dos no las tienen y una está abrasionada. El largo varía entre $4,3 \mathrm{~cm}$ y $2 \mathrm{~cm}$ con un promedio de $2,6 \mathrm{~cm}$. El ancho entre $3,5 \mathrm{~cm}$ y $2,2 \mathrm{~cm}$, con un promedio de $2,7 \mathrm{~cm}$ y el espesor entre 1,2 y $0,5 \mathrm{~cm}$ con un promedio de $0,8 \mathrm{~cm}$. El ángulo de fractura varía entre un máximo de $110^{\circ}$ y un mínimo de $90^{\circ}$ con un promedio de $99^{\circ}$, mientras que el ángulo distal tiene una variación entre $65^{\circ}$ y $25^{\circ}$, con un promedio de $51^{\circ}$.

\section{2. 3. Pozo $N^{o} 3$}

En la excavación del Pozo N $\mathrm{N}^{\mathrm{o}} 3$ se encontró un artefacto de piedra. Es un guijarro con golpe bipolar vertical y lateral que mide $5,5 \mathrm{~cm}$ de largo, por 4,2 $\mathrm{cm}$ de ancho y 

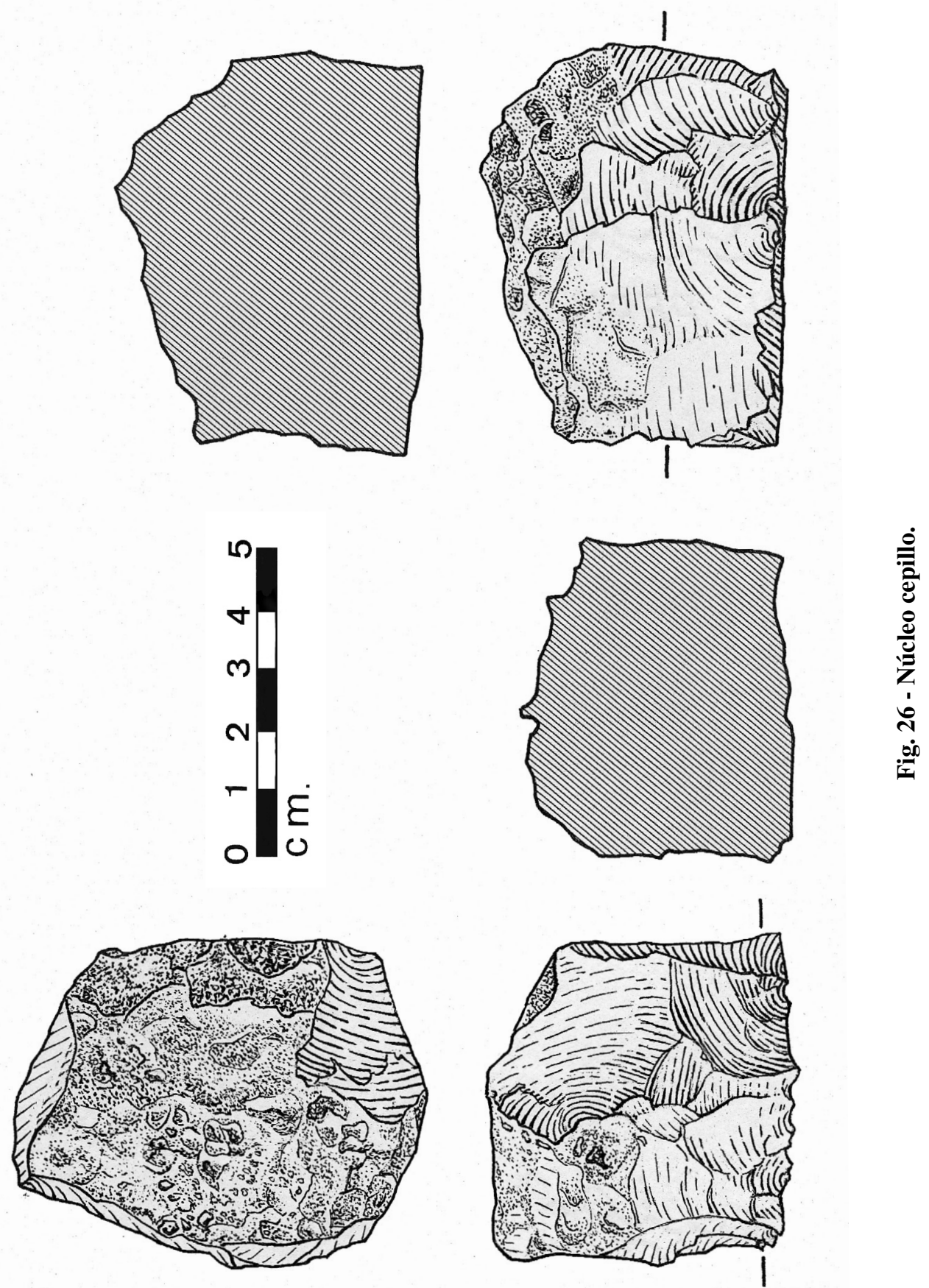

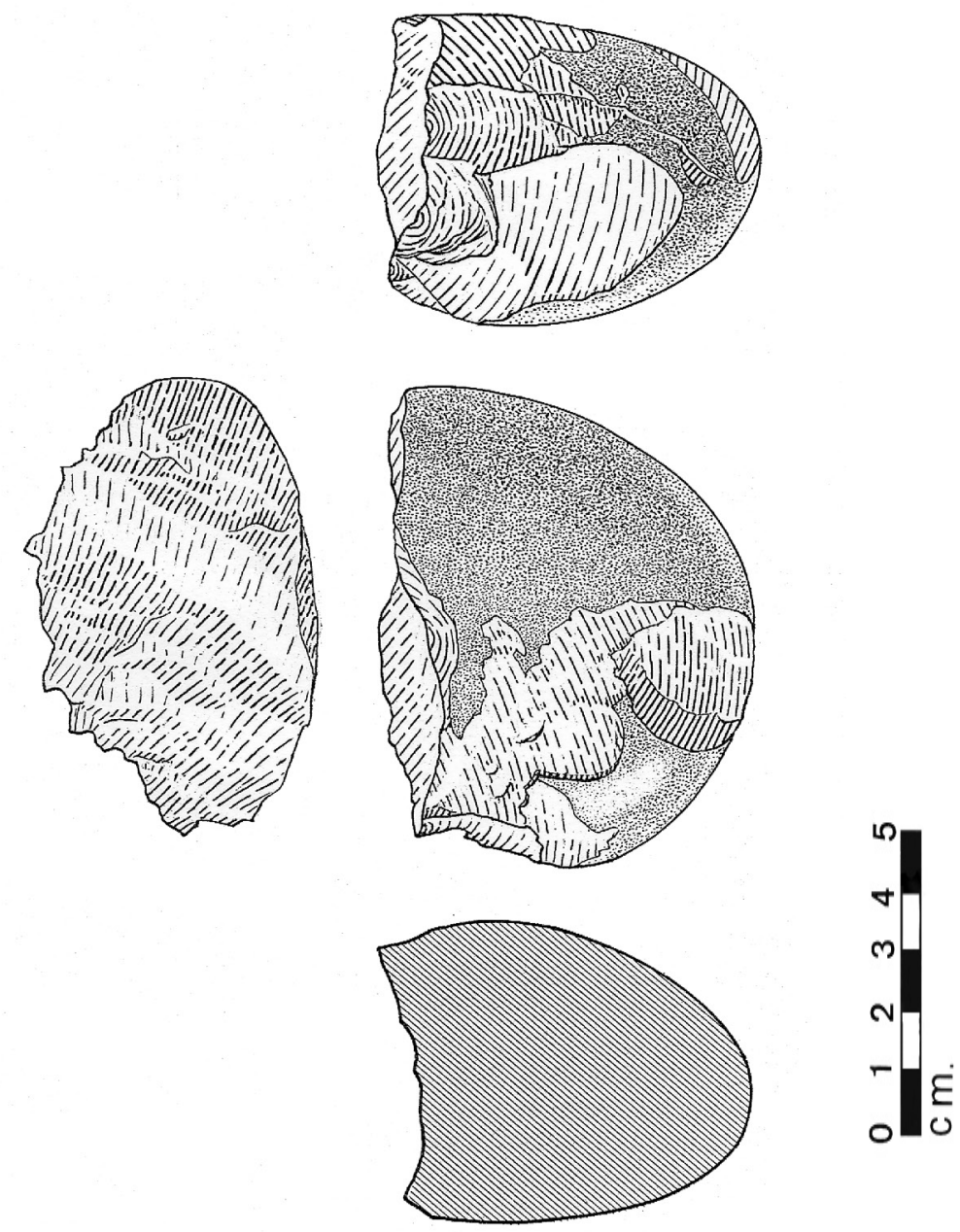

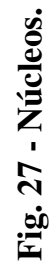

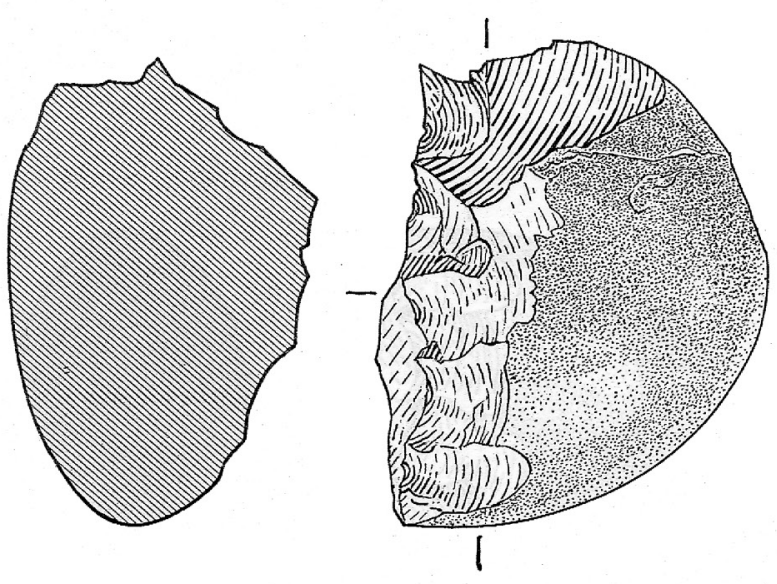



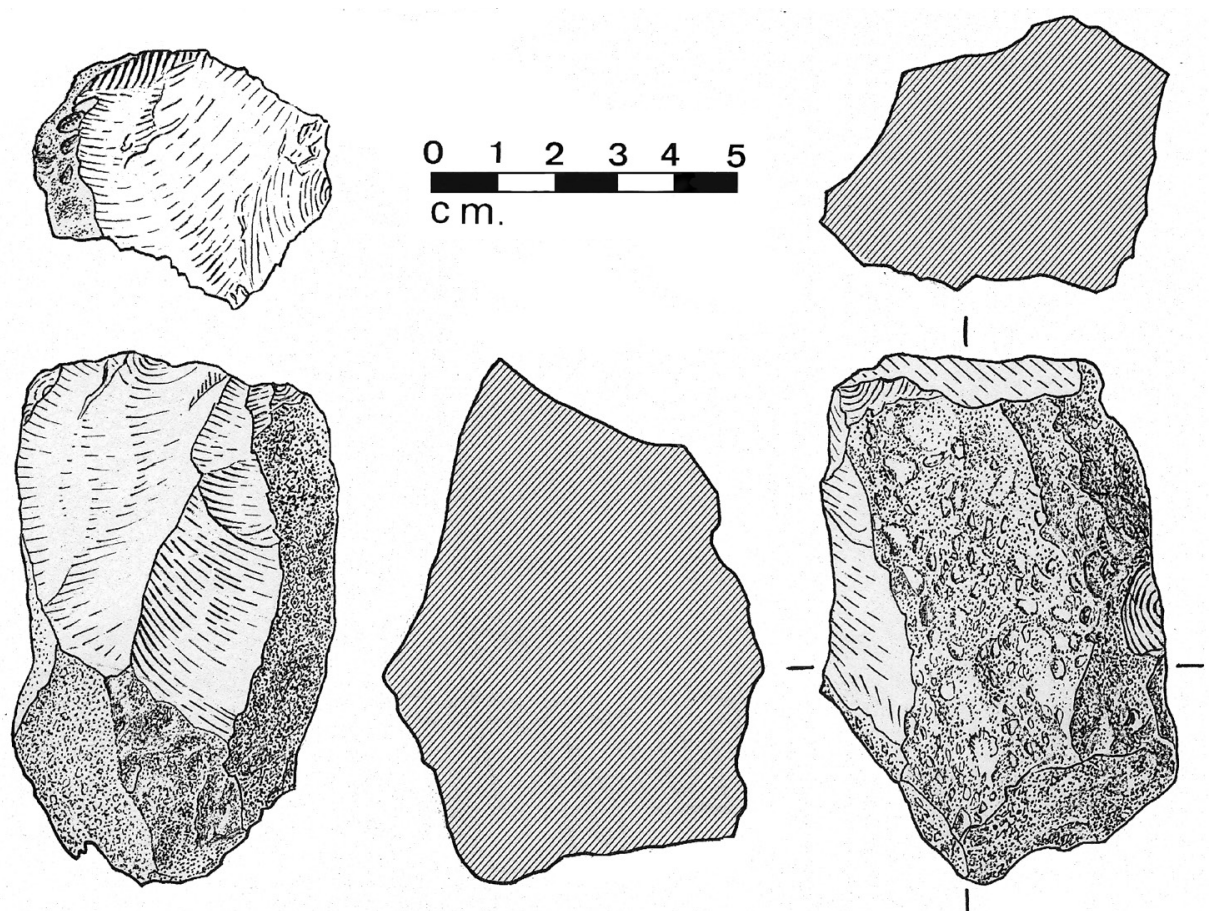

Fig. 28 - Núcleos.

$0,9 \mathrm{~cm}$ de espesor. Todo el resto (14) son lascas, 8 de guijarro (A; 57,14\%) y las 6 restantes son normales $(\mathrm{B} ; 42,85 \%)$. Entre las lascas de guijarros hay una que es típica (A1; $12,5 \%$ ) y tiene huellas de uso; mide $5,5 \mathrm{~cm}$ de largo, 4,2 cm de ancho, 0,9 cm de espesor. Y $7(87,5 \%)$ son lascas de piezas astilladas (A2). De ellas $5(71,42 \%)$ tienen uso y el resto ha sido dífícil de verificar. Sólo se ha podido medir 5, ya que las otras dos están partidas. De las completas el largo varía entre $2,3 \mathrm{~cm}$ y $1,3 \mathrm{~cm}$ con un promedio de $1,5 \mathrm{~cm}$; el ancho entre $2,1 \mathrm{~cm}$ y $1,3 \mathrm{~cm}$ con un promedio de $1,6 \mathrm{~cm}$ y el espesor entre $0,4 \mathrm{~cm}$ y $0,3 \mathrm{~cm}$, siendo el promedio de $0,3 \mathrm{~cm}$.

De las 6 lascas normales, todas son secundarias (B). Sólo una (16,66\%) muestra huellas de uso. Se ha podido medir sólo 5 de estas lascas, ya que hay una que está fragmentada. El largo oscila entre un máximo de $3,5 \mathrm{~cm}$ y un mínimo de $1,6 \mathrm{~cm}$, con un promedio de $2,8 \mathrm{~cm}$; el ancho entre $4 \mathrm{~cm}$ y $2,7 \mathrm{~cm}$ con un promedio de $3,3 \mathrm{~cm}$ y el espesor entre $0,8 \mathrm{~cm}$ y $0,5 \mathrm{~cm}$, con un promedio de $0,6 \mathrm{~cm}$. El ángulo máximo de fractura es de $115^{\circ}$ y el mínimo de $100^{\circ}$, siendo el promedio de $86^{\circ}$; mientras que el ángulo distal varía entre $55^{\circ}$ y $35^{\circ}$ con un promedio de $41^{\circ}$. Son probablemente desechos de talla.

\section{RESTOS BOTÁNICOS}

Casi todos los restos de plantas que se han analizado no son carbonizados, aunque algunos muestran signos de mineralización en su estructura celular. Dado su 
estado de conservación, para el efecto de las identificaciones generalmente ha sido suficiente el análisis macroscópico, pero para poder distinguir la corteza de Lagenaria de la de Cucurbita, se ha utilizado un microscopio de disección con un aumento de 7$30 X$.

Las determinaciones se han hecho comparando los materiales arqueológicos con las colecciones del Laboratorio de Etnobotánica del Museo de Antropología de la Universidad de Michigan.

La cantidad de material botánico procedente de este yacimiento es muy pequeña. Los únicos restos que se pueden identificar claramente corresponden a la familia Cucurbitaceae. Es así que hay una pequeña cantidad de corteza de Cucurbita sp. y Lagenaria siceraria. Hay también hojas de Poaceae que no se pudo identificar.

Dos tubérculos muy pequeños en forma de bulbos ( $\mathrm{ca} .1 \mathrm{~cm}$ de diámetro) son tan menudos que parece improbable que ellos representen una especie que pueda haber tenido un gran valor dietético, y su tamaño virtualmente excluye la posibilidad que se trate de restos de especies cultivadas. Uno de ellos está carbonizado, de modo que no puede ser identificado por sus granos de almidón, ya que éstos revientan cuando se calientan. La morfología de la superficie del otro no es similar a ninguna otra especie de tubérculos modernos cultivados (Vide Cuadro 3).

\section{RESTOS ANIMALES}

Los resultados del análisis de los restos animales de este sitio, han sido incluidos para fines comparativos en nuestro libro sobre Los Gavilanes, pero sin mayores comentarios (vide Bonavia, 1982a: cuadro 21, 198-199; cuadro 24, 385). Se debe señalar que los resultados que se presentan aquí son un poco diferentes a los que aparecen en el mencionado libro. Es que cuando él se escribió no se consideró necesario tomar en cuenta los fragmentos que no pudieron ser identificados a nivel de género por lo menos y una especie (Acmala viridula) que no tiene valor significativo y que no se ha encontrado en otros yacimientos de la zona. Aquí hemos preferido presentar la información completa. Es importante ahora ver estos resultados en el contexto total de

Cuadro 3 - Restos vegetales.

\begin{tabular}{|l|l|l|}
\hline ESPECIES & FAMILIAS & $\begin{array}{l}\text { PARTES DE LA } \\
\text { PLANTA }\end{array}$ \\
\hline Cucurbita sp. & Cucurbitaceae & Corteza \\
Lagenaria siceraria & Cucurbitaceae & Corteza \\
Desconocida & Poaceae & Hojas \\
Tubérculos no identificados & Desconocida & Raíces \\
& & \\
\hline
\end{tabular}


los hallazgos. Para los detalles sobre la metodología seguida para el estudio de estos materiales, remitimos al lector al mencionado trabajo (Bonavia, 1982a: 214-216). Para fines estadísticos se ha considerado juntos los restos de Mollusca, Arthropoda, Echinodermata y un Chordata (Ascidiacea).

\section{1. Mollusca, Arthropoda, Echinodermata}

Los Moluscos identificados son como sigue (en la lista se consigna el porcentaje en función del peso de la concha):

Semimytilus algosus (choro playero, chorito) $\quad 1,13 \%$

Choromytilus chorus (choro) $\quad 1,70 \%$

Aulacomya ater (choro, choro común, mejillón) $\quad 1,56 \%$

Perumytilus purpuratus (chorito) $\quad 0,78 \%$

Aequipecten purpuratus (concha de abanico, señorita) $\quad 6,04 \%$

Mesodesma donacium (macha) $\quad 0,42 \%$

Fissurella crassa $\quad 0,99 \%$

Fissurella limbata $\quad 2,84 \%$

Fissurella maxima (blanco) $\quad 1,92 \%$

Fissurella peruviana $\quad 0,35 \%$

Fissurellidae $\quad 0,71 \%$

Scurria parasitica $\quad 0,38 \%$

Tegula atra $\quad 0,42 \%$

Tegula tridentata $\quad 0,42 \%$

Crepipatella dilatata (pique) $\quad 0,35 \%$

Polinices sp. $\quad 0,07 \%$

Thais chocolata (caracol) $\quad 6,11 \%$

Thais haemastoma $\quad 0,21 \%$

Concholepas concholepas (chanque, pata de burro) $\quad 1,92 \%$

Prunum curtum $\quad 0,14 \%$

Enoplochiton niger (barquillo) $\quad 33,78 \%$

Acanthopleura equinata (barbón) $\quad 1,63 \%$

Chitonidae $\quad 0,99 \%$

Acmala viridula $\quad 0,09 \%$

Fragmentos no identificados $\quad 9,85 \%$

El único Artrópodo encontrado es Balanus sp. (vulgarmente conocido como pico de loro) en una proporción del 0,92 \% y el único Equinodermo es Arbacia spatuligera (conocido como erizo rojo o erizo colorado) en una propiorción del 21,37\%. 


\section{2. Chordata}

\section{2. 1. Ascidiacea}

De los Cordados se ha identificado una sola especie de ascidia, Pyura chilensis, conocida vulgarmente como ciruelo de mar. La identificación ha sido hecha a base de las túnicas duras, llamadas test, que protegen y fijan a estos animales. Para la estadística, el peso del test ha sido comparado con el peso de concha de los Moluscos, Artrópodos y Equinodermos y representa el 2,27\%.

\section{2. 2. Pisces, Aves, Mammalia}

Se ha identificado ejemplares de dos Familias, dos Géneros y una Especie de Peces; una Familia y dos Géneros de Aves y una Orden de Mamífero. (Para mayores detalles sobre los métodos empleados vide Wing \& Reitz, 1982). En total se ha encontrado 265 huesos de los cuales se ha identificado 58, repartidos como sigue.

De los Peces hay 126 huesos que no han podido ser identificados, el resto corresponde a:

Carcharhinidae

Trachurus sp.

Seriolella

Pomadasydae

Sciaena deliciosa (lorna)
2 huesos

10 huesos

1 hueso

1 hueso

1 hueso

De las Aves hay 8 huesos que no han podido ser identificados y el resto es de:

\section{Phalacrocorax sp.}

Sula sp.

Scolopacidae
5 huesos

3 huesos

5 huesos

Finalmente hay 73 huesos de Mamíferos que no han podido ser identificados más allá de su Clase y 30 que corresponden a Pinnipedia.

Podemos sintetizar toda esta información de la siguiente manera:

$\begin{array}{lll}\text { Chondrichtys (Peces cartilaginosos) } & 2 \text { huesos } & 0,75 \% \\ \text { Osteichthys (Peces óseos) } & 139 \text { huesos } & 52,45 \% \\ \text { Aves } & 21 \text { huesos } & 7,92 \% \\ \text { Mammalia } & 103 \text { huesos } & 38,86 \%\end{array}$

\section{DISCUSIÓN}

Con la poca información que tenemos se hace difícil reconstruir la geografía de la época, pero es casi seguro que el grupo humano que ocupó el yacimiento tuvo una visión de su ambiente y del valle vecino muy diferente del actual. 
Por los estudios que hemos realizado en la zona con la ayuda de especialistas (vide Bonavia, 1982a: 256), sabemos que alrededor del año 4000 a.C. el nivel del mar debió estar aproximadamente a $4 \mathrm{~m}$ por encima del nivel actual de playa. Ello significa que si hoy el yacimiento se encuentra a 25 m.s.n.m., en el momento en el que éste fue habitado por sus primeros pobladores que estamos estudiando, debió estar aproximadamente a 21 m.s.n.m. Este cambio de altura del nivel del mar no debió influir en nada sobre el aspecto general de la zona ocupada por el yacimiento, pues éste está separado de la playa por la cadena de pequeños cerros que se ha mencionado al principio de este estudio. Lo que sin duda fue diferente, es el aspecto de la playa misma.

Sin embargo un hecho importante relacionado con el nivel del mar, es el de la napa freática. Aún hoy ésta es alta en la zona de Huarmey y en la parte baja del valle son muy comunes los pozos de tajo abierto que, en algunos lugares, alcanzan 1,50 m de profundidad, siendo el valor promedio de 5,20 m (ONERN, 1972: 244-247, cuadro $\mathrm{N}^{\circ}$ 20). Nosotros hemos constatado que justamente en el Pueblo Joven La Victoria, dentro de cuyos términos está el yacimiento, hay pozos cuyo nivel de agua está dentro de los límites señalados. Por efecto de la diferencia de densidad entre el agua dulce y el agua del mar, cuando el nivel de éste último estuvo más alto, la napa freática en esta parte baja del valle debió ser mucho más alta también. De modo que no sólo el hombre la pudo aprovechar para abastecerse de agua, sino que la extensión de los pantanos en toda la zona que está comprendida entre la margen derecha del río Huarmey hasta por lo menos la actual zona de Tres Piedras, debió ser diferente a la actual.

Hoy los bordes del valle en la parte baja, que marcan el límite entre el desierto y las tierras cultivadas, son artificiales y resultado del riego. Originalmente la vegetación más densa debió extenderse como una faja a los bordes de ambas márgenes del río Huarmey, lo que en línea recta significa aproximadamente un kilómetro de distancia entre ésta y el sitio en estudio. Pero en lo que hoy es la zona cultivada y buena parte de los terrenos que bordean la Carretera Panamericana, entre el río y la mencionada localidad de Tres Piedras, debieron existir grandes extensiones de pantanos y la laguna fósil que está al norte de Los Gavilanes (vide Bonavia, 1982a: mapa 2, 14-15, fotografía $1,16)$, casi seguramente estaba aún con agua. Sin embargo la zona del yacimiento mismo (PV35-106), por ser más alta, debió ser desértica como lo es en la actualidad (para una discusión mayor de este asunto, el lector podrá encontrar información en Bonavia, 1982a: 256-257). No hay que olvidar que los habitantes de PV35-106 vivieron en las épocas tempranas del Holoceno, justo a fines del Optimum Climaticum cuando el nivel del mar estaba bajando y ello jugaba un rol fundamental sobre las lagunas costeras, como se ha señalado. Tan es así que hacia fines del Precerámico la laguna que estaba cerca de Los Gavilanes y que comenzó a formarse en estos tiempos, ya estaba seca. De modo que el grupo humano que ocupó el sitio que estamos estudiando, no tuvo problemas para abastecerse de agua, ni siquiera tuvo que ir hasta el río mismo para conseguirla y, además, en los pantanos pudo encontrar una serie de recursos vegetales $\mathrm{y}$ animales.

El material lítico merece algunos comentarios. En primer lugar se podría criticar la gran cantidad de tipos que se ha creado en la tipología. Pero hay que comprender que es la primera vez que se clasifica una industria de esta naturaleza, de modo que hemos 
partido del principio que es mejor pecar por exceso que por falta. En este sentido hemos hecho nuestra la posición de Bordes et al. (1972: 22), aceptando que es posible que algunos tipos sean superfluos, pero la experiencia demuestra que es más fácil juntar sobre el papel tipos vecinos que rehacer las series, buscando tipos no identificados.

En segundo lugar consideramos importante insistir, para evitar malentendidos, sobre algo que en parte ya está dicho al principio de este escrito. La primera clasificación que hemos hecho de esta industria ha sido creando tipos a base morfológica y, sobre ella, hemos elaborado la tipología funcional (Bordes, 1970: 202; Bordes et al., 1972: 24). No creemos necesario insistir sobre este punto, en todo caso el que quiera podrá hacerlo revisando los trabajos que hemos mencionado.

El lector se podrá haber dado cuenta que en la estadística (Diagrama 1) hemos incluido a los útiles a posteriori, es decir a las lascas usadas, que obviamente no figuran en la tipología. Como se recordará, nuestra recogida de material lítico de superficie ha sido lo más exhaustiva posible. Con ello no podemos afirmar que ha sido total, pues en la arena ello es imposible salvo que la capa de ésta en toda la superficie estudiada fuera pasada por la zaranda, lo que hubiera significado un trabajo muy grande. Y durante las excavaciones cada pieza lítica ha sido analizada cuidadosamente, guardándose todas aquellas que tenían huellas de algún tipo de trabajo. Para ello se ha utilizado una lupa de 7X. En el laboratorio hemos analizado al microscopio (Wild M44 de 64X y un sistema de iluminación lateral de intensidad regulable) todo el material. Es por ello que consideramos que esta categoría es válida (lege Bordes, 1970: 201).

La única objeción que se podría hacer, es que dado lo reducido de nuestras excavaciones cabe dudar si la muestra es representativa. Pensamos que sí lo es, en cuanto entre el material excavado hemos encontrado sólo un tipo (el de núcleo cepillo) que no está presente entre el material de superficie, y que está compuesto por una sola pieza que consideramos como útil a posteriori y que por eso no ha sido incluido en la lista tipológica.

Dos tipos para cuya definición hemos tenido un especial cuidado, son los denticulados y las piezas escotadas, que no por nada Bordes (1970: 201) llamó "útiles equívocos". En el caso de los denticulados hemos preferido crear una categoría mixta, la de las raederas-denticuladas, pues no estamos muy seguros que fueron hechos ex professo como tales, es decir como denticulados, ya que su función fue más bien como raederas.

En el caso de las piezas escotadas, hemos tratado de seguir el consejo de Bordes (1970: 201) averiguando, hasta donde ha sido posible, si se trató efectivamente de un artefacto creado intencionalmente o de un útil a posteriori. En este sentido el análisis ha sido cuidadoso, en cuanto sabemos que la escotadura puede inclusive ser natural. Dado que ésta es regular y parece tener retoques alternos, consideramos que estamos en presencia de piezas típicas.

Si se observa el cuadro 1, se podrá ver los resultados de nuestra tipología funcional. El primer tipo, es decir el grupo de las piezas astilladas (1, 1.1, 1.2 y 1.3) son artefactos (Diagrama 4). Los tipos que corresponden al grupo de los guijarros con golpe bipolar (2, 2.1, 2.2, 2.3 y 2.4) los podemos considerar como núcleos que han quedado como resultado de sacar lascas (Diagrama 4). Y, finalmente, los siguientes tipos (del 3 


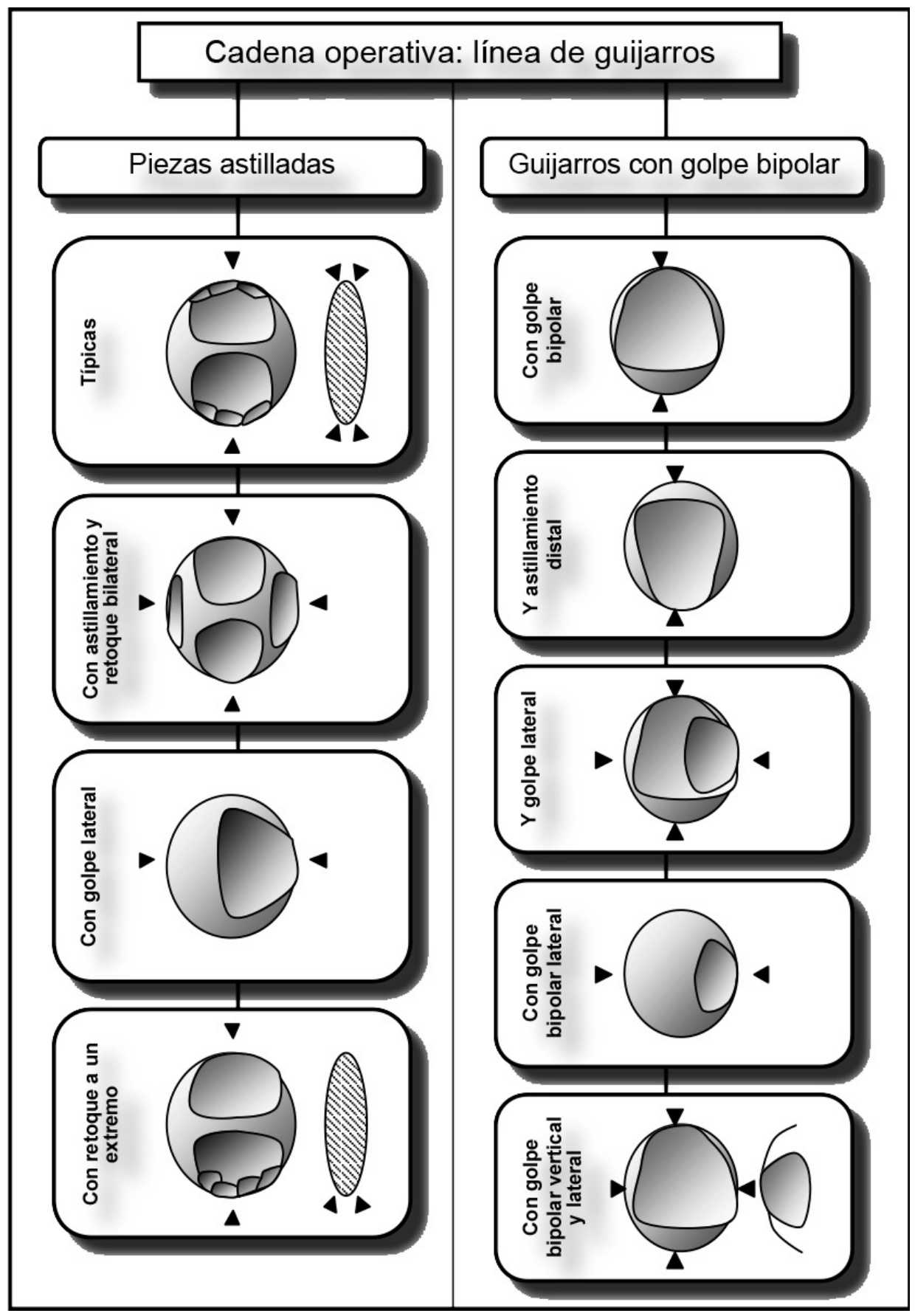

Diagrama 4 - Esquema diacrítico de los tipos piezas astilladas y guijarros con golpe bipolar, con sus respectivos subtipos. 
al 12) creemos que todos son artefactos. Para poder darse cuenta de las razones que nos llevan a estas conclusiones, bastará ver el resultado del análisis que permite señalar uso o no uso de cada uno de los tipos. Los resultados en este caso son muy interesantes y significativos (Vide Cuadro 1 y Diagrama 2).

En este sentido el examen de las lascas es muy importante y para ello nos referimos al cuadro 2. Con sus datos se explican de por sí las razones por las que estamos en presencia de útiles a posteriori. En el caso de las lascas de guijarro, las típicas muestran huellas de uso en 57,69 \% de los casos y, si consideramos que el restante $42,30 \%$ son piezas abrasionadas, no sería muy atrevido afirmar que prácticamente todas estas lascas tuvieron la función de artefactos. El mismo razonamiento es válido para las lascas de piezas astilladas, de las que el $44,57 \%$ muestra huellas de uso y el restante $55,42 \%$ son piezas abrasionadas.

En el caso de las lascas normales el cuadro es ligeramente diferente. Es así que de las primarias, el 43,75\% muestra huellas de uso, el 31,25\% no las tienen y el restante $25 \%$ son piezas abrasionadas. Las lascas secundarias han sido usadas en una proporción del $25 \%$, el 12,5\% no tienen huellas de uso y son abrasionadas en una proporción muy alta, el $62,5 \%$. No tomaremos en cuenta las lascas laminares secundarias, pues hay sólo 4 y todas ellas han sido abrasionadas por acción eólica.

De este análisis se desprende que los habitantes de PV35-106 tenían una preferencia por las lascas de guijarro para ser utilizadas como artefactos y prácticamente hacían lascas de este tipo exclusivamente para ello. Mientras que en el caso de las lascas normales, si bien un alto porcentaje también fue utilizado como artefactos, una apreciable cantidad no lo fue (Vide Diagrama 3 y Cuadro 2).

Es difícil saber con exactitud las razones por las que hubo una especialización de esta naturaleza en este lugar. Pero podemos sugerir por lo menos dos. En primer lugar que en todas las playas y zonas vecinas de la región abundan los guijarros, sin que sin embargo haya una falta de otra materia prima. Y en segundo lugar, y éste a nuestro juicio ha sido el factor decisivo, que las lascas de guijarro por ser ligeramente curvas, se prestan mejor para ciertas tareas específicas, tales como el marisqueo, pero sobre todo para poder sacar la carne de ciertos mariscos como los quitones (Polyplacophora, ya sean barquillos o barbones), los caracoles y los chanques (Thaididae) y el contenido comestible de los erizos de mar (Echinoidea) que son justamente los animales que aparecen mayoritariamente entre la basura de este yacimiento. Esta afirmación se basa en experimentos que hemos hecho cuando trabajamos en la zona.

Esta preferencia no sólo por las lascas de guijarro, sino inclusive por la obtención de las mismas por golpe bipolar, es algo que se ha dado en varias partes del mundo. La técnica se comienza a emplear desde los albores de la humanidad, pues forma parte del Complejo Oldowanense de Tanzania (Ambrose, 2001: 1749). Pero ella ha sido puesta en práctica después y es un caso interesante de convergencia. Citaré sólo algunos ejemplos: el de Australia, la industria de Zhoukoudian en China, en el Pontiniano en Italia, pero hay también fenómenos similares en España, Hungría, Nueva Guinea y Canada (lege Hayden, 1980: 4). En este sentido Breuil \& Lantier (1959: 75-76) son muy explícitos. Ellos escribieron:

"La talla bipolar se ha impuesto al hombre siempre que la materia prima de su utillaje está constituida por muy pequeñas piedras, principalmente 
de pequeños guijarros, marinos o fluviales, redondos u ovalados, para los que la talla sobre yunque o por percusión manual es imposible. Por el contrario, ella es bastante fácil, si se pone al suelo una primera piedra dura, se coloca la piedra para tallar sobre ella, manteniéndola con la mano izquierda, y con otra piedra dura se golpea vigorosamente sobre la extremidad superior".

Bordes era de la misma opinión (Comunicación personal a Hayden, 1980: 4).

$\mathrm{El}$ aspecto funcional de esta industria merece algunos comentarios. Las piezas astilladas muestran en las partes activas básicamente huellas de machacado. Nosotros estamos convencidos que ellas fueron utilizadas para mariscar, concretamente para desprender de las rocas los barquillos y los barbones (Chitonidae). Nuestra afirmación se basa en los siguientes hechos. En primer lugar, como ya se ha señalado, los quitones son entre los moluscos preferidos por los habitantes de PV35-106 y ellos no se pueden recolectar con la mano. Deben ser desprendidos de las rocas con algún artefacto. (Para una discusión amplia sobre el tema, lege Bonavia, 1982a: 248-250). Y entre todos los tipos de utensilios hallados en este sitio el que, por nuestra experiencia, cumple mejor esta tarea son las piezas astilladas. Nuestra hipótesis inicial se vio confirmada en el laboratorio. Pues mientras las piezas astilladas halladas en superficie, vistas al microscopio, son completamente limpias, las que provienen de las excavaciones conservan en sus grietas — como ya lo hemos manifestado- restos de una materia rojiza. Con la experiencia que tenemos, podemos afirmar con absoluta seguridad que se trata de restos de carne de quitón, que corresponde al cinturón que bordea las placas y con el que el instrumento entra en contacto al momento de ser desprendido el animal de las rocas (Bonavia, 1982a: 248-250). Es normal que estos restos hayan desaparecido de los materiales de superficie, expuestos a la alta humedad ambiental y a los efectos abrasivos de la arena y del viento. Con esto no queremos decir que las piezas astilladas no hayan sido utilizadas para alguna otra tarea, pero posiblemente la más importante fue la del marisqueo. Es interesante señalar que ca. 2000 años después, esta tradición se pierde en la zona y se comenzará a usar para esta actividad unos artefactos muy especializados, conocidos como discos "tipo Culebras" (vide Bonavia, 1982a: 84-87, 245-250,291-294). Esto se ve muy claramente en los diagramas 5 y 6 en los que se puede comparar las industrias de Los Gavilanes y de PV35-106.

Las piezas astilladas han sido motivo de discusión desde principios del siglo pasado, en el sentido si son artefactos o desechos de talla. Es así que mientras algunos arqueólogos las consideraron en su tipología, otros decidieron eliminarlas (lege Mazière, 1984). Chauchat et al. (1985) han analizado el asunto refiriéndose al caso peruano, concretamente a su presencia en el Paijanense. Hay que señalar sin embargo que, en este caso, los núcleos son piedras y no guijarros como los de PV35-106. Pero estamos de acuerdo que "... la pieza astillada es el resultado de un proceso técnico para obtener un objeto cortante" (Chauchat et al., 1985: 38). Es necesario insistir que “... el error más común ha sido el de tratar los términos 'núcleo bipolar' y 'pièces esquillées' como si fueran sinónimos, y echar en la misma caja todo lo que ha sido tratado de manera bipolar." como con gran acierto lo advirtió Hayden (1980: 2). En el caso peruano se trata sin duda de artefactos. (Para una discusión más amplia sobre este tema, lege Patterson \& Sollberger,1976; 1977; Haynes,1977; White, 1977; Cresson,1977; Stafford, 1977; Hayden, 1980). 


\section{Diagrama 5 - Diagrama circular de la tipología lítica de PV35-1 (Los Gavilanes)} con reducción de tipos poco representados (de 0 a 1,99\%).

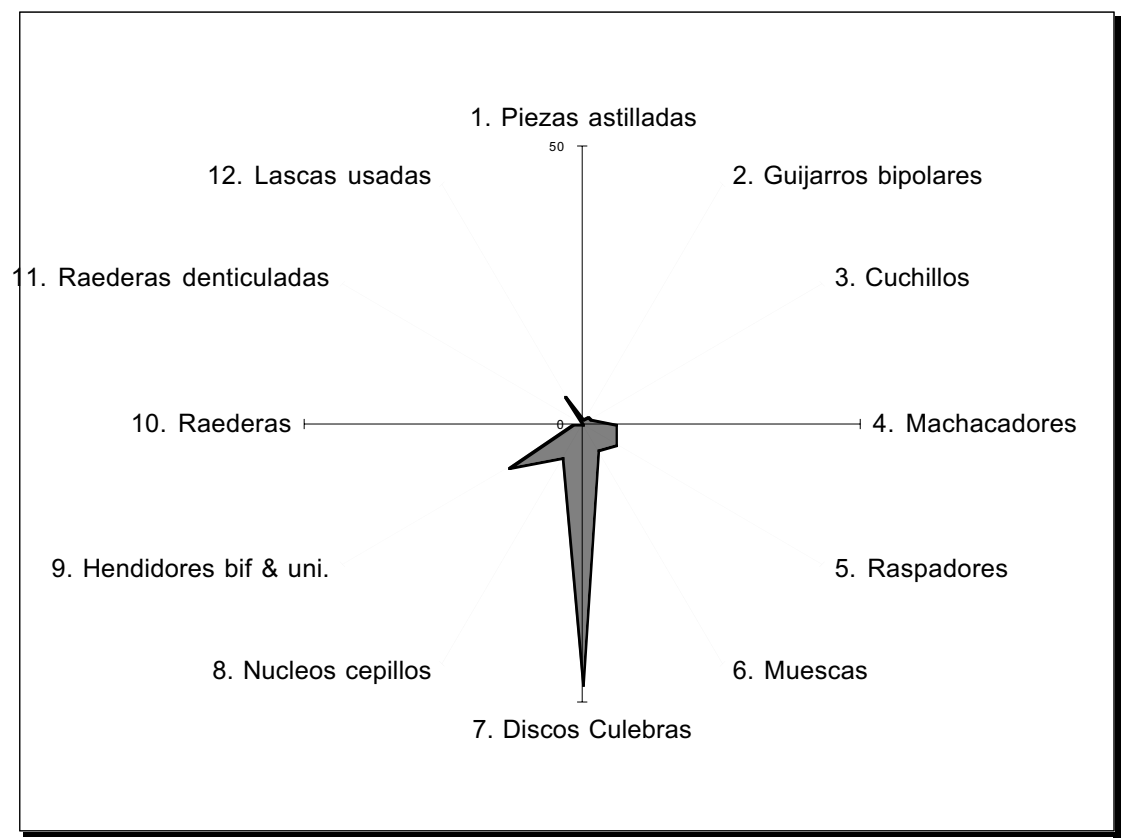

Diagrama 6 - Diagrama circular de la tipología lítica de PV35-106 con reducción de tipos poco representados (de 0 a $1,99 \%$ ).

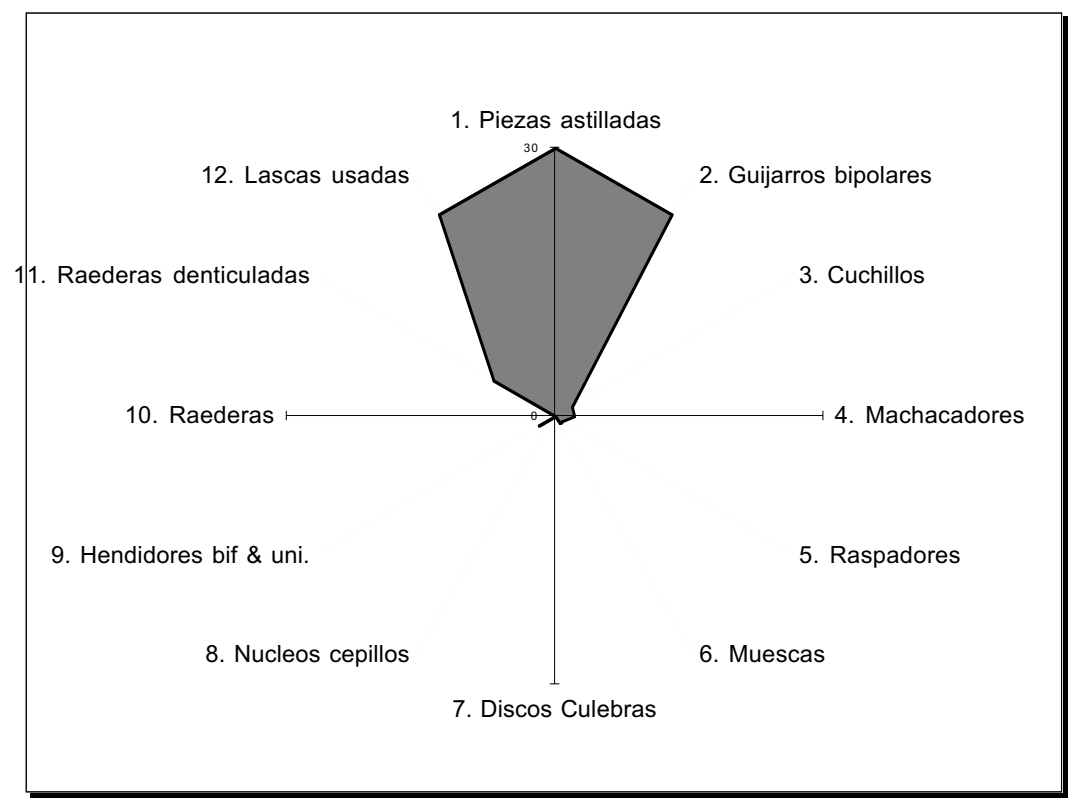


Para el caso de los machacadores es difícil señalar un uso más concreto que el de machacar. Probablemente fueron empleados para golpear cualquier material que fuera necesario. Se ha visto, además, que si en un caso este machacado no ha sido fuerte ni prolongado, en otros ha sido intenso y posiblemente por largo tiempo. Dependía sin duda de la actitud personal del que los usó.

Los hendidores unifaciales no han sido empleados para cortar sino para machacar, en algunos casos con golpes suaves en otros con fuertes. Pero esta actividad debió ejercerse sobre algún material duro, pues en las piezas han quedado estrías que al microscopio se ven muy marcadas. Una posibilidad sería, pero es una simple suposición, que estos artefactos hayan sido utilizados en la búsqueda de raíces y tubérculos y que los golpes y las estrías sean debidos a los impactos que recibieron los implementos al chocar con el cascajo.

En los perforadores o bec el uso es más claro. Las huellas que han quedado señalan trabajo de rotación que ha dejado una superficie brillosa y acción de palanca con pequeñísimos desprendimientos. En el primer caso evidentemente los artefactos han sido empleados para perforar alguna materia blanda, probablemente cuero de algún animal, quizá lobo marino. Mientras que en el segundo es más difícil suponer la función, pero una de ellas pudo haber sido la de abrir moluscos bivalvos.

Un artefacto de muchos usos debió ser la raedera-denticulada, pero posiblemente una de las tareas importantes ha sido para la utilización de la madera. Estamos pensando en trabajos primarios tales como quitar hojas y corteza de pequeñas ramas de arbustos, para aserrar ramas o troncos, etc. Si bien en este caso las huellas no son muy claras, no parecen corresponder a acción sobre un material duro. Lo mismo creemos que se puede decir de las piezas escotadas que pudieron haber cumplido una acción de raspado muy parecida.

Los yunques-percutores son piezas muy interesantes, en cuanto nos han permitido entender muy bien el trabajo de la talla bipolar que ha sido sin duda la función principal de estos implementos. Da la impresión que el individuo que preparaba las lascas con golpe bipolar a partir de guijarros, tenía a su alcance varios de estos yunques-percutores, de modo que mientras uno de ellos cumplía la función de yunque sobre el que se apoyaba el guijarro para el efecto del golpe, con el otro se le golpeaba cumpliendo de esta manera la función de percutor. Los pequeños hoyos que se han creado sobre las superficies planas de estas piedras en los puntos en los que se apoyaba los guijarros, y que son efecto del contragolpe, y por el otro lado las huellas múltiples de golpes en los bordes, están señalando un uso prolongado. Hemos señalado ya que para obtener estos implementos se ha buscado un tipo de piedra que facilitara la función. Suponemos que una vez encontrada, el artesano los cuidaba, pues la formación de los hoyos le facilitaba la tarea, dado que al recibir el guijarro utilizado como núcleo del que se tenía que desprender la lasca el golpe del percutor, no tenía la posibilidad de deslizarse lateralmente (Una buena ilustración de esta técnica se puede ver en Oakley, 1968: [figura] 77, 213).

La parte activa de los cuchillos es muy lustrosa y no muestra estrías. Una de sus funciones, quizá la principal, pudo haber sido para cortar carne (¿de lobo marino?) y deshuesar los peces. 
Pero sin la menor duda el artefacto menos especializado y de uso múltiple ha sido la lasca. Creemos que ella ha sido utilizada prácticamente para cualquier tarea en la que pudiera ser de utilidad. Las huellas en la parte activa no señalan uso muy prolongado, lo que nos hace suponer que muy a menudo cuando se necesitaba iniciar algun trabajo, se preparaba las lascas necesarias. A pesar que ello es obvio, hemos comprobado experimentalmente que ello ofrece la ventaja que la lasca nueva tiene mayor filo en sus bordes y que éste se va perdiendo con el uso. Además es más fácil obtener una lasca nueva que reavivar el filo de una ya usada. La velocidad de pérdida del efecto cortante de la arista depende de la dureza del material sobre el que ésta es usada y de la forma en que se ejerce la acción.

El bifaz podría llamar la atención, pero en realidad es una pieza completamente atípica y muy probablemente fruto del azar. La forma natural de la piedra le debió servir de sugerencia al artesano que lo fabricó. Es difícil señalar una función, pero ésta pudo ser múltiple.

En términos generales se deduce que los artefactos líticos identificados en este yacimiento, corresponden a una economía básica de recolectores especializados, que disfrutaba los recursos marinos y probablemente terrestres. No hay ningún indicio, hasta ahora, de utensilios que pudieran haber sido empleados para pescar.

Queremos ser muy claros en enfatizar que para que cualquier inferencia de tipo funcional pueda ser considerada como cierta, necesita estar apoyada en un trabajo experimental serio que nosotros hemos podido realizar sólo en unos pocos casos. De modo que las nuestras son básicamente sugerencias que podrán ser corroboradas o modificadas en el futuro. Somos muy conscientes del carácter multifuncional que puede tener un utensilio y que los caracteres activos y pasivos no son siempre tan marcados como parece en la teoría. En este sentido es muy importante y sugerente el trabajo de Beaune (1989).

Finalmente debemos hacer hincapié en la considerable cantidad de piedras quemadas que hemos encontrado en las excavaciones y con evidencias claras de termofractura. Es decir que muestran la fractura típica que se produce cuando se introduce una piedra caliente en un líquido frío. No cabe duda que ellas han sido utilizadas para calentar o hacer hervir algún líquido, posiblemente comida. Casi seguramente los recipientes usados para esa tarea fueron los mates.

En el área de la Costa Norcentral, y concretamente en la zona de Huarmey, si bien se encuentra ocasionalmente en la superficie piezas astilladas y guijarros con golpe bipolar, ellos no son comunes y no hemos podido ubicar en todo el valle ni en sus cercanías un yacimiento como PV35-106. El vecino valle de Culebras (al Norte de Huarmey) no ha sido estudiado, de modo que no sabemos si hay o no algún sitio parecido. Sin embargo en uno de los cementerios huaqueados de la parte baja del valle, que hemos denominado PV34-3, hemos encontrado en superficie algunas piezas astilladas. Pero el cementerio corresponde a varias épocas de ocupación, de modo que en este caso el hallazgo no es indicativo.

En el más norteño valle de Casma, hay una industria parecida a la nuestra que ha sido estudiada por Malpass $(1983 ; 1991)$ y por Uceda $(1986 ; 1992 a ; 1992 b)$. En el caso del trabajo de Malpass desafortunadamente es difícil utilizar los datos. El ha hecho la 
clasificación “... usando una combinación de atributos y variables technomic (sic) y estilísticas..." (Malpass, 1983: 59-63) que es confusa y no llega a definiciones precisas. Su tipología (Malpass, 1983: 66 et passim) tampoco es la adecuada. Y los dibujos son deficientes y prácticamente no permiten su utilización con fines comparativos.

A esta industria casmeña Malpass la ha denominado Mongoncillo (nombre que emplea Engel [1973] para la zona de lomas) y la considera como una tradición asociada con puntas de proyectil. Señala que los utensilios son “... básicamente unifaciales y se caracterizaron por tener un alto porcentaje (sobre $40 \%$ ) de instrumentos secundarios, particularmente... pequeños, tales como grabadores [en realidad se trata de perforadores], muescas [piezas escotadas]... denticulados finos, becs y buriles..." (Malpass, 1991: 86). Es difícil llegar a una definición más precisa, ya que Malpass (1983: 119-121) usa las descripciones hechas por Richardson (1973: 199) para Piura y la de Lanning (1967a: 13) para el Ecuador, sin hacer una definición propia. El autor considera que un alto porcentaje de este utillaje ha servido fundamentalmente para hacer otros artefactos que, por ser de material perecible, han desaparecido. Y que la función primaria de esta industria ha sido para la explotación de las lomas, con posibles movimientos migratorios hacia la costa y la sierra (Malpass, 1983: 143-144; 1991: 87).

A los guijarros con golpe bipolar, Malpass los llama núcleos bipolares ("Bipolar cores") y corresponden a su "class 24" (Malpass, 1983: 71-72, 228). Él sin embargo no los ha diferenciado en subtipos, pero por lo que se desprende de su trabajo, en su colección hay sólo una relativamente pequeña cantidad de material que corresponde a nuestro tipo 2 (guijarro con golpe bipolar) y subtipo 2.1 (guijarro con golpe bipolar y astillamiento distal). La descripción general que hace Malpass es bastante parecida a la nuestra, sólo que no ofrece detalles.

Los yunques de Casma, según la descripción de Malpass (1983: 90) son “... piedras delgadas y planas que tienen una pequeña pero clara área picada causada por los impactos de objetos pesados.”. Se dice, además, que “... fueron usados para partir (o) abrir mariscos [el autor dice shellfish, que además de marisco puede significar crustáceo] o como base para la producción de lascas usando la técnica del núcleo bipolar." A juzgar por la ilustración 19 (Malpass, 1983: 246) se trata de un artefacto que si bien aparentemente (el dibujo no permite distinguir detalles) fue empleado como yunque, en un extremo muestra un filo cortante que parece haber sido empleado más como cuchillo que como percutor. Es pues un instrumento muy diferente a nuestro yunque-percutor. Pudo haber sido empleado como yunque para la talla bipolar y quizá la aparente poca profundidad de la zona picada podría explicarse por la pequeña cantidad de objetos con talla bipolar que hay en Casma. Hay sin embargo una contradicción en la explicación del uso de estos implementos que nos da Malpass (1983: 10). El dice que el "área picada" es consecuencia del impacto de objetos "pesados", y ese no es exactamente el caso de los efectos de la talla bipolar. Para nosotros no es muy claro tampoco el uso que se pudo dar a estos "yunques" para "partir (o) abrir mariscos" como afirma el autor (Malpass, 1983: 90).

Insistimos que es muy difícil utilizar esta información, pues la tipología que ha elaborado Malpass es deficiente. Hay inclusive algunos artefactos cuya definición es errónea. Por ejemplo lo que él clasifica como chopper (Malpass, 1983: 230) no es un 
hendidor bifacial, si se acepta su verdadera definición tipológica (e.g. vide Bordes, 1961: 47); así como dudamos mucho que los artefactos mostrados como buriles (Malpass, 1983: 235) en realidad sean tales (Vide Uceda, 1986: 213).

Si seguimos a Malpass podemos decir que si bien es cierto que hay algunos componentes que tipológicamente corresponden a los que aparecen en Huarmey, hay una serie de otros, muy importantes, que no se encuentran, lo que hace que si bien podemos pensar en alguna forma de relaciones, se trataría de industrias diferentes. Es así que los guijarros con golpe bipolar, que en PV35-106 conforman el grupo de tipos mayoritarios (representan el 34,97\% del total del utillaje), en los sitios de Casma en dos casos hay un porcentaje alto $(25 \%$ y $11,5 \%)$ y en todos los demás varían entre $11,1 \%$ y $1,1 \%$, predominando los inferiores al $10 \%$. Hay que considerar, sin embargo, que sólo en PV35-106 se ha encontrado 64 guijarros de estas características, mientras que en Casma en total se ha hallado 82, repartidos en 24 yacimientos (Malpass, 1983: 177-205). Malpass (1983: 133) es muy enfático cuando señala que esta técnica es representativa de Mongoncillo.

Se debe enfatizar la asociación de 10 sitios de la cultura Mongoncillo con puntas de proyectil, aunque el problema no puede ser discutido aquí con la amplitud que se merece. Pero si se observa la figura 12 de Malpass (1983: 124) se nota inmediatamente la incongruencia. Pues, si seguimos lo que allí se muestra, y que no necesariamente nosotros aceptamos, se podrá ver que estas puntas han sido asignadas a una secuencia temporal que se extiende desde los 12000 años a.P. hasta los 3500 años a.P. y, en un caso, al Período Inicial. En efecto hay una amplia variedad de formas que el autor ha tratado de clasificar en función de las pocas e inseguras evidencias que tenemos para el Callejón de Huaylas (Lynch, 1967; 1970; 1980) y las de la Sierra Central, aunque en este caso ha usado exclusivamente la información de Rick (1980). (Lege Uceda, 1986: 284).

Malpass ha fechado la cultura de Mongoncillo comparando su industria con la de los otros yacimientos. Es así que él encuentra semejanzas con Las Vegas del Ecuador (Stothert, 1974; Lanning, 1967a), con los períodos Siches y Honda del Conjunto Amotape en Piura (Richardson, 1973; 1978 [Nota bene: el autor se refiere a la tesis de Richardson, 1969, que nosotros no hemos podido revisar]). También con el material de Lomas de Lachay (Fung, 1968) y con las fases Arenal y Canario de Ancón-Chillón (Lanning, 1963; 1967b; 1967c). Concluye que la fecha que se puede asignar a Mongoncillo es entre 8000 y 4000/5000 años a.P. y especifica que "Comparando las puntas de proyectil de estos sitios, con datos radiocarbónicos de puntas de proyectil [sic] de otras áreas del Perú, indican una similar gama de fechas." (Malpass, 1991: 86-87; lege también, 1983: 119-121).

De todo lo expuesto se desprende que si nos ceñimos a la tipología de Malpass y a las asociaciones de materiales que él plantea, no se ve una clara relación entre Mongoncillo y PV35-106.

Consideramos que el trabajo de Malpass presenta toda una serie de graves deficiencias y errores. En primer lugar porque se investigó sólo en cinco zonas del valle escogidas a base de criterios que son muy discutibles (Malpass, 1983: 14-23; 1991: 80). Luego las zonas seleccionadas no han sido exploradas totalmente sino en forma parcial (Malpass, 1983: 14-23). En tercer lugar la recolección de los materiales ha sido arbitraria 
(Malpass, 1983: 17). La función de los sitios se ha deducido exclusivamente a base de la tipología lítica (Malpass, 1983: 141-144), lo cual definitivamente no es un método seguro. Finalmente, Malpass ha trabajado sólo con colecciones de superficie. Si se analiza su trabajo se ve que sus resultados son muy discutibles. Por ejemplo, en los 38 sitios atribuidos a la cultura Mongoncillo había cerámica (Malpass, 1983: 109-111) y en 12 de ellos había puntas de proyectil de diferentes tipos (Malpass, 1983: fig. 12, 124).

Hay que señalar, en honor a la verdad, que Malpass (1983: 109-110) admite que se trata de ocupaciones mezcladas y que en el caso de Casma las puntas de proyectil no son indicativas (Malpass, 1983: 114). Aunque esto evidentemente es contradictorio con lo que hemos mencionado antes (vide supra).

Posteriormente Uceda ha investigado en Casma y ha revisado los sitios y la información de Malpass y en sus trabajos (Uceda, 1986; 1987; 1992a) mantiene una "ocupación Mongoncillo". La investigación de Uceda es importante, pues es fruto de un trabajo sistemático y en el que se ha empleado una buena clasificación tipológica. Además tiene excelentes ilustraciones. En lo que se refiere a la investigación de Malpass, Uceda llega a tres conclusiones de fundamental importancia: 1) Que se ha trabajado exclusivamente con materiales de superficie, sin hacer ninguna excavación. 2) La recolección del material se hizo al azar, sin ningún criterio metodológico y, finalmente 3) Las unidades que se utilizó fueron mal definidas (Uceda, 1986: 201). Esto corrobora nuestro planteamiento.

Uceda coincide con nuestra opinión que las puntas no muestran una asociación clara con la ocupación Mongoncillo, y define a ésta como una industria fundamentalmente de talla bipolar, con piezas astilladas y perforadores hechos sobre lasca. Los raspadores, los denticulados y los bec se parecen a los de la industria paijanense.

En las redefiniciones de la tipología de la industria de Mongoncillo que hace Uceda (1986: 204), señala los siguientes tipos: lascas retocadas o utilizadas, piezas astilladas, raederas, dos tipos de perforadores, tres de bec, tres de piezas escotadas y dos de denticulados. Vemos que, en términos generales, se trata prácticamente de los mismos tipos de Huarmey. La única diferencia que se podría señalar es que para nosotros los perforadores y los bec conforman un solo tipo. De esto se ve claramente que la aparente falta de relación entre las industrias de PV35-106 y Mongoncillo que se plantea al utilizar la tipología de Malpass, se desvanece cuando se emplea la de Uceda.

Hasta el momento no hay una forma segura de fechar esta industria de Casma. Hemos visto cuáles son las razones por las que Malpass (1983: 119-121; 1991: 86-87) le asigna un lapso temporal que oscila entre 6000 y 3000/2000 años a.C. Pero, insistimos, estas fechas nos parecen totalmente arbitrarias. Además la comparación con las industrias de Las Vegas y del Conjunto Amotape son forzadas. Ellas son más claras con respecto a las de las Lomas de Lachay y las de Ancón-Chillón, sobre todo por la significativa presencia de perforadores.

Uceda (1986) trató de entender este fenómeno y llegó a la conclusión que la única forma de intentar establecer una cronología, es analizando el asunto en un contexto regional. La fecha que él atribuye a la ocupación paijanense de 5040 años a.C. (6990 170 a.P.) (Uceda, 1986: 279; Ziólkowski et al., 1994: 274) se sitúa en el límite inferior de esta ocupación en la zona Ancón-Chillón en la Costa Central (lege Patterson \& Lanning, 
1964: nota 5, 120) mientras que está afuera de las dataciones de los sitios de la zona Moche y Cupisnique-Ascope en la Costa Norte (lege Chauchat et al.: 1992: tabla 51, 340 y tabla 52, 342). Aunque el autor admitió que este fechado no tiene una asociación directa con la industria paijanense.

Ahora bien, en la región de Talara en la que se ha encontrado una industria que, según Uceda se relaciona con Mongoncillo, se ha obtenido fechas que oscilan entre 6000 y 2000 años a.C. (Richardson, 1978: 252; la referencia es a las fases Siches-Estero y Honda). Es decir, se sitúan inmediatamente después de la ocupación paijanense en la zona de La Libertad (concretamente en Cupisnique y La Cumbre). Sin embargo en el caso de Casma esto crea un problema, en cuanto Uceda le asigna al final del Paijanense en la localidad una fecha de aproximadamente 5000 años a.C., de modo que quedaría para Mongoncillo un período muy corto de 1000 años.

Para explicar este fenómeno, Uceda en un principio propuso dos hipótesis. Una en el sentido que Mongoncillo sea descendiente directo del Paijanense, y esto se puede argüir por que en el Sitio 27 de Pampa de Los Fósiles (departamento de La Libertad) que debería corresponder al Paijanense final, Chauchat (1982: 521-537; Chauchat et al., 1992: 279-287) ha observado en la misma industria un fuerte aumento de talla bipolar (Chauchat, 1982: 525; Chauchat et al., 1992: 284) sobre pequeños guijarros. La fecha

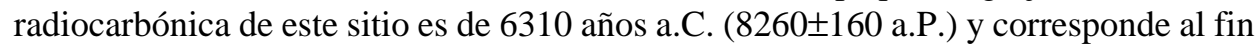
de esta ocupación en la región. La otra posibilidad sería que la fecha de 5040 años a.C. en Casma no corresponde a la ocupación Paijanense y, si se acepta las mismas fechas obtenidas en el departamento de La Libertad para el final del Paijanense de Casma, ello nos daría un lapso de dos milenios para el desarrollo de la industria de Mongoncillo (Uceda, 1986: 279).

Sin embargo posteriormente Uceda (1992a: 48-49) se inclinó más por la primera hipótesis, pues escribió refiriéndose a Mongoncillo:

"El fechado de estos sitios en Casma presenta algunas dificultades pues no poseemos ninguna evidencia o asociación arqueológica que date directamente esta ocupación. Sin embargo, esta industria ha sido fechada en Piura (complejos Siches, Estero y Honda) por Richardson entre 8000 y 4000 años antes del presente (Richardson, 1978). Si a esto se agrega que la ocupación paijanense en Cupisnique y La Cumbre se ubica entre 13500 a 8000 años antes del presente [en realidad el fechado de La Cumbre es 12360 y en Cupisnique hay fechas un poco menores, vide Chauchat et al., 1992: tabla 51, 340], podríamos calificar a la industria Mongoncillo como posterior y posiblemente heredera de la industria paijanense. De otro lado la fecha de 6000 para la industria más reciente [aquí el autor se refiere al Precerámico final que en Casma tiene una fecha de 6070 \pm 70 a.P.; vide Uceda, 1986: 261], nos obliga a pensar que la industria Mongoncillo en Casma es de corta duración."

El punto sobre el que discrepamos con Uceda, lo hemos dicho, es que no vemos relaciones entre la industria de Talara y la de Casma, pero consideramos que ello en el fondo no invalida el razonamiento del autor. 
Sin embargo con las calibraciones recientes el cuadro nos parece más claro y más coherente. Veamos en primer lugar cómo se plantea el problema en Piura. Richardson (1978: 282) obtuvo ocho fechados radiocarbónicos para el período Siches. Nosotros no tomaremos en cuenta los dos conseguidos a base de conchas, pues no son seguros. La calibración (Universidad de Oxford, 2000) (1) con la probabilidad del 91,3 \% al 95,4\% nos da un rango temporal cuyo promedio oscila entre el máximo de cal. 6082 y el mínimo de cal. 5490 años a.C. Para el período Honda, Richardson (1978: 283) ha estimado una edad entre 3550 y 2050 años a.C. que ahora debería ser revisada a la luz de las nuevas calibraciones.

La fecha que Uceda (1986: 279) le atribuye al Paijanense de Casma, de 6990 \pm 70 años, calibrada (Universidad de Oxford, 2000) (1) con la probabilidad del 91,3\%, oscila entre cal. 6000 y cal. 5720 años a.C. La datación de $8260 \pm 160$ años radiocarbónicos que tiene Chauchat (1982: 537) para el Sitio 27 de Pampa de los Fósiles y que debería corresponder al Paijanense final, con la calibración (Universidad de Oxford) (1) y con la probabilidad del 95,4\% nos da un lapso temporal entre cal. 7600 y cal. 6750 años a.C. Finalmente el fechado que tiene Uceda (1986: 261) para el Precerámico final de Casma de $6070 \pm 70$ años radiocarbónicos, con la calibración (Universidad de Oxford, 2000) (1) y con la probabilidad del 88,5\% nos da un rango que varía entre cal. 5150 y cal. 4780 años a.C.

A nuestro juicio, y a la luz de la evidencia de los fechados, el cuadro se debe plantear en los siguientes términos. La industria de Talara se inicia en los tiempos finales del Paijanense en la zona de La Libertad, pero aparentemente se prolonga hasta los tiempos que en la Costa Central y Nor-central se dan las épocas finales del Precerámico tardío. Por eso, insistimos, se trata de un fenómeno norteño que no se relaciona con lo que se desarrolla más al sur. Y ello confirma la conclusión a la que llegamos a nivel tipológico.

Si el Sitio 27 de Cupisnique representa las ocupaciones tardías del Paijanense, en el caso de Casma hay dos alternativas. O el Paijanense aquí es más tardío que en el norte o la fecha de Casma no corresponde a esta cultura. Ahora bien, si la primera alternativa fuera la correcta, tendríamos un lapso de tiempo de $c a$. 600 años para el desarrollo de la cultura Mongoncillo. Si la segunda fuera exacta, el tiempo se extendería a 1600 años. La primera hipótesis parece más lógica, si se ve en el contexto de lo que pasó en Huarmey y en la Costa Central. Uceda (1992a: 48-49) escribió:

"Como lo señala Chauchat para Cupisnique, la única indicación de una evolución, si ella existió en el Paijanense, sería un aumento de la talla bipolar (Chauchat, 1983 [recte 1982]). Si esto es cierto, no es del todo imposible que la industria Mongoncillo sea una derivación y adaptación de grupos paijanenses a las nuevas condiciones ecológicas que se produjeron hace ocho o siete mil años antes del presente."

Nosotros creemos que este razonamiento es correcto. Y el lapso de tiempo que nos da nuestra fecha para PV35-106 entre cal. 5750 y cal. 4950 años a.C. encaja perfectamente en este marco.

Ahora bien, de ser cierta la hipótesis que Mongoncillo es la continuación del Paijanense, PV35-106 estaría en la tradición de la gente que nos ha dejado las canteras 
del Complejo Chivateros de El Volcán (PV35-2) y Tres Piedras (PV35-3) en Huarmey (Bonavia, 1979; 1982a; 1982b: 417). Como escribimos en 1996:

"Hay que decir sin embargo, que este planteamiento no es definitivo. Él ha sido propuesto por Uceda (1986: 279; 1992b: 3) y nosotros lo hemos aceptado (Bonavia et al. s/f [en realidad se trata de este trabajo, vide nota 1; lege también Chauchat \& Bonavia, 1998: 432]). Es cierto sin embargo, que Chauchat no es categórico cuando se refiere al sitio 27 y deja ciertas dudas. Originalmente escribió: 'Es posible que el sitio de Pampa de los Fósiles 27 represente un momento posterior con respecto a las otras unidades. La forma de las puntas no parece diferente, sin embargo la tendencia a la reducción de las dimensiones, el desarrollo de la talla bipolar en relación con la abundancia de poliedros podrían ser el resultado de una evolución del utillaje. La fecha de $8260 \pm 160$ (GIF 4162) es efectivamente menor de todo el conjunto. Sin embargo, las diferencias del utillaje de Pampa de los Fósiles 27 son difíciles de describir con precisión y es prácticamente imposible descubrir en los otros campamentos las tendencias que han conducido a este último estadio.' (Chauchat, 1982: 659-660; Chauchat et al., 1992: 340-341)". (Bonavia, 1996: 174).

Posteriormente Chauchat nos ha manifestado que tiene algunas dudas sobre la situación cronológica del sitio 27, pues encuentra contradicciones entre el aspecto tipológico de la industria y el fechado radiocarbónico (Claude Chauchat, in litteris, 10 de octubre de 1995). En efecto, las puntas asociadas al sitio 27 son cortas y anchas tal como aparecen en el sitio en el que están asociadas con la punta "cola de pescado", lo que corresponde más bien a una fase inicial del Paijanense y no terminal. Allí estaría justamente la contradicción con el fechado radiocarbónico obtenido para el sitio 27. Además, siempre según Chauchat, hay problemas de interpretación de la talla bipolar. Concluye diciendo:

"En todo caso no estoy tan seguro de como se debe interpretar esto..."

(Claude Chauchat, in litteris, 24 de octubre de 1995). (Lege Bonavia, 1996: 174-175).

En 1996 (Bonavia, 1996: 175) manifestamos que comprendemos las dudas de Chauchat y estamos conscientes que la transición de la cultura Paijanense a la de Mongoncillo en el caso de Casma y a la de PV35-106 en el de Huarmey, es sólo tentativa. Pero en este momento y con las evidencias que se tienen, es la única respuesta probable que podemos dar. Hay, además, una lógica interna que — aparentemente — no plantea contradicciones ni graves interrogantes. La solución definitiva se tendrá, sin embargo, sólo cuando se encuentre en Pampa de los Fósiles o zonas aledañas, las pruebas de la transición entre el Paijanense y la cultura que le sucede y en el caso de Huarmey los sitios de ocupación del Complejo Chivateros (que es sinónimo del Complejo Paijanense) que permitan establecer las relaciones con la cultura de PV35-106.

Uceda supone que los ocupantes de Mongoncillo fueron sedentarios y que explotaron los recursos de las lomas y del mar (Uceda, 1986: 284). En el caso de Huarmey se pudo aprovechar las lomas vecinas pero pensamos que más se utilizó los recursos costeros y del cercano valle además, por supuesto, de los marinos. 
A parte de los sitios de Casma, no conocemos ningún otro yacimiento en el Perú que tenga una industria parecida a la de PV35-106. Tenemos sólo un dato que, aunque vago, merece la pena de ser citado. En la tesis inédita de Ravines (1971) se menciona el sitio de Puyenca (valle de Atico en el departamento de Arequipa), que fuera descubierto por Gary Vescelius. Según Ravines entre los artefactos líticos hay un conjunto de utensilios toscos sobre cantos rodados que él define "chopping tools" (aunque nos parece, por la descripción, que no se trata de hendidores bifaciales típicos), y puntas romboidales de obsidiana. Este sitio no ha sido nunca descrito y cuando Ravines lo visitó ya estaba destruido. El hizo la descripción a base de los materiales recogidos en la superficie por Vescelius. Sin embargo la descripción es muy pobre y no hay datos sobre la industria lítica (Ravines, 1971: 291-292), ni se incluyen dibujos de la misma.

Pero se muestra un cuadro de "distribución temporal aproximada de algunos tipos y clases de artefactos". Allí se incluyen algunos dibujos muy esquematizados de la industria lítica. El que se refiere a Puyenca, y que está identificado como pebble tool, es casi seguramente una pieza astillada típica (vide Ravines, 1971: cuadro sin número entre las pág. 331-332. El mismo cuadro ha sido publicado en Ravines, 1972: 175, pero en dicho tex to no hay referencia al sitio de Puyenca). En este cuadro se indica la relación y evolución de las diferentes formas de artefactos líticos, sin embargo en el caso de Puyenca la pieza mencionada aparece aislada, sin antecedentes y sin relaciones con alguna industria posterior. Cabe preguntarse si los "chopping tools" que menciona Ravines no son todos piezas astilladas, ya que en el cuadro no hay ninguna otra forma que podría ser identificada como un hendidor bifacial.

En su visita Ravines obtuvo de “... los estratos finales remanentes...” muestras de carbón vegetal que fueron analizados por el método del C14 y que dieron respectivamente fechas de 5905 \pm 150 años a.C. y 6120 \pm 145 años a.C. (Ravines, 1971: 292; Ravines \& Alvarez Sauri, 1967: 14, 15). Estas fechas calibradas (Universidad de Oxford, 2000) (1) y con la probabilidad del 95,4\% nos da rangos entre cal. 5250 y cal. 4400 años a.C. y entre cal. 5400 y cal. 4650 años a.C.

Finalmente cabe señalar unos hallazgos hechos por Ortiz-Troncoso en el área del estrecho de Magallanes, en la Patagonia chilena. Se trata de los sitios de Punta de Santa Ana y Bahía Buena (Ortiz-Troncoso, 1979). Allí existe una industria muy interesante, con puntas bifaciales y toda una serie de artefactos a base de guijarros, que va asociada con una importante industria de hueso (que incluye arpones).

Entre los artefactos de Punta Santa Ana se ilustra una pieza que el autor denomina "galet à encoche" (Ortiz-Troncoso, 1979: 156, fig. 10b) y que es una pieza astillada típica. Procede de los niveles medios del yacimiento. Mientras que entre los utensilios de Bahía Buena se ilustra otro "galet à encoche" (Ortiz-Troncoso, 1979: 173, fig. a y b), que parece haber sido producido por golpe bipolar. No es igual que los ejemplares de PV35-106, pues el desprendimiento de las lascas parece haber sido producido por golpes menos intensos. Este también procede de los niveles medios y superiores del sitio. Según se desprende de este estudio, hay artefactos de esta naturaleza en otros yacimientos de la Patagonia que no hemos creído necesario revisar para los efectos de este estudio. Siguiendo a Emperaire \& Laming (1961:30), el autor sugiere que estos guijarros fueron 
utilizados como pesas de pesca (Ortiz-Troncoso, 1979: 186), lo cual es muy factible, pero ello no descarta la posibilidad de que puedan haber sido usados también para mariscar. Sería interesante un análisis de estos utensilios en este sentido.

A base de una serie de fechas radiocarbónicas, el autor ha podido establecer que los habitantes de estos sitios llegaron allí entre los 4500 y 3000 años a.C. y sugiere inclusive que las puntas bifaciales puedan corresponder a una tradición que vino de los lejanos Andes. Estos habitantes patagones fueron probablemente grupos nómades, cuya economía se basó en la recolección de moluscos, huevos y quizá bayas, además de la pesca, la caza de mamíferos marinos y terrestres y de aves.

Jackson (1987) menciona la existencia de otros yacimientos ecuatorianos, además del Complejo Vegas y también en Panamá con percusión bipolar. Pero el tema es tratado superficialmente y sin conocimiento de causa y no permite ninguna inferencia.

Con todo lo expuesto no son muchas las conclusiones a las que se puede llegar. De acuerdo con los estudios de Uceda, hay relación sin duda entre las industrias de Casma y Huarmey. Hay cierta coincidencia en los tipos de artefactos e inclusive alguna semejanza en los porcentajes de los utensilios encontrados. Es así que las raederas en Mongoncillo representan el 7,41\%; nosotros tenemos la categoría compuesta de raedera-denticulada, que básicamente es una raedera, y su porcentaje de presencia es del $5,95 \%$. En el caso de las piezas escotadas sí hay una diferencia mayor, pues en Mongoncillo la cantidad asciende a 3,70 \%, mientras que en PV35-106 es tan sólo de $0,59 \%$. Lo mismo sucede con los útiles a posteriori que en Mongoncillo representan el $44,44 \%$ y en Huarmey el 26,20\%. Pero en términos generales las diferencias no son grandes, si se toma en cuenta que en el caso de Mongoncillo se ha hecho la evaluación a base de sólo 87 piezas. Los ejemplos de Puyenca en el sur peruano y el de la Patagonia chilena se han señalado sólo para indicar que las piezas astilladas tienen una difusión muy amplia y que posiblemente, si se busca, en el futuro se encontrará más. En el nivel de investigación en el que nos encontramos, no caben relaciones entre estas industrias, pero es muy posible que se trate de una tradición cuya historia desconocemos.

En efecto no parece casual que estas piezas tan típicas aparezcan en lugares tan distantes, prácticamente en el mismo lapso de tiempo, si se toma los fechados radiocarbónicos con la elasticidad necesaria. Aceptando la propuesta de Uceda (1986: 279), la fecha más antigua para Mongoncillo sería de 6000 años a.C. La datación de PV35-106 es de cal. 5750 años a.C., mientras que el promedio de las fechas más antiguas de Puyenca sería de cal. 5325 años a.C. Y con las advertencias del caso que hemos hecho para los yacimientos patagones, allí también la antigüedad oscila entre los 4500 y 3000 años a.C.

Consideramos, además, que es significativo que la secuencia de fechas obtenidas para el Precerámico medio y tardío de Huarmey, a base de los métodos del C14 y de la termoluminiscencia, tienen una coherencia y una continuidad indiscutible (Diagrama 7). Allí se ve que la situación cronológica de PV35-106 encaja perfectamente en el conjunto.

Hay que insistir que tanto en Huarmey como en Casma se ha trabajado con muestras muy reducidas, y que es la primera vez que se analiza una industria de estas características. Toda esta información debe tomarse con las precauciones del caso y con 


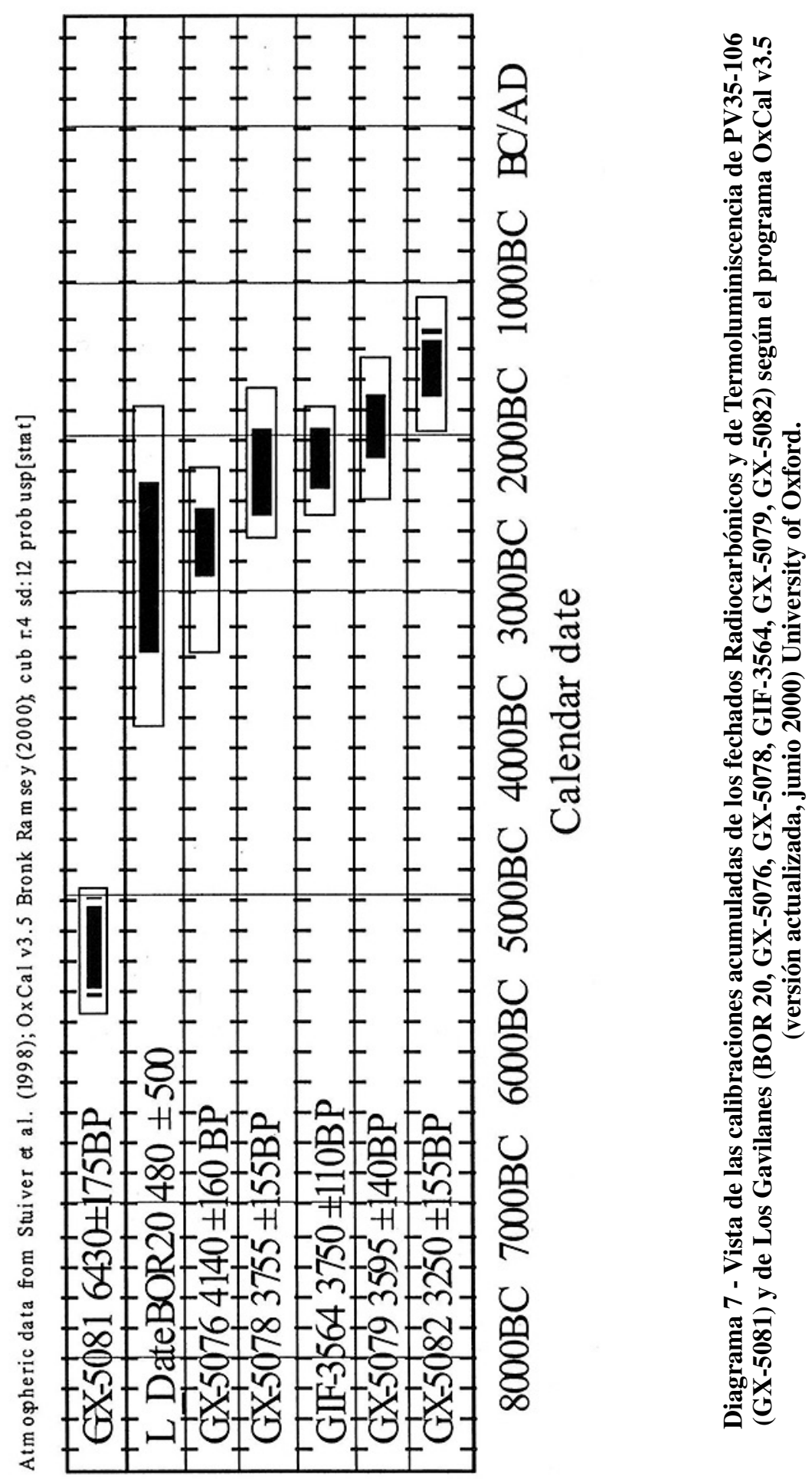


plena conciencia que ella podrá ser modificada el día que se haga un estudio más amplio y completo. Mientras tanto, se tiene un inicio y una base para la investigación de este tipo de yacimientos.

Hemos visto que la lista de plantas que se ha podido identificar en PV35-106 es muy reducida, pues hay sólo restos de dos cucurbitáceas, algunas gramíneas y tubérculos que no se han podido identificar.

En el caso de las cucurbitáceas, se ha encontrado sólo fragmentos de la corteza que pueden darnos muy poca información, pues su identificación es posible a base de la corteza y de las semillas. Pero la corteza puede ser usada cuando se tiene una gran cantidad de muestras en excelentes condiciones, en cuanto su estudio requiere que el ectodermo esté intacto y que exista el patrón de venación que cubre el interior del endodermo. De otra manera la erosión y el uso reducen el espesor de los fragmentos y eliminan los rasgos diagnósticos necesarios para poder determinar la domesticación (Richard I. Ford, in litteris, 10 de julio de 1989). Por eso Johson-Kelly, que ha analizado las muestras, sugiere que tanto los restos de Cucurbita sp. como los de Lagenaria siceraria hallados en este yacimiento, pueden corresponder a frutos que han sido utilizados como recipientes más que como residuos alimenticios de plantas domesticadas. Ella cree que a pesar de que las semillas de las cucurbitáceas son una fuente importante de aceite y proteína, las variedades domésticas tempranas a menudo tienen una cantidad relativamente pequeña de pulpa rica en vitaminas y carbohidratos. En un contexto como el de PV35-106, sobre todo los mates (Lagenaria siceraria) pueden haber sido usados como recipientes.

Sin embargo no podemos negar la posibilidad que estos frutos hayan sido utilizados también como alimento. En el caso de Cucurbita spp. los frutos de plantas silvestres tienen poca pulpa y ésta es muy amarga, por eso se presume que las semillas fueron utilizadas primeramente como alimento (Heiser, 1989: 474). Pero el caso de Lagenaria spp. parece ser diferente. Es así que si bien es cierto que los frutos fueron usados como recipientes, se ha sugerido que las semillas lo fueron como alimento. Es interesante que Heiser (1989: 476) ha encontrar referencias modernas del uso de las semillas para alimento, uno en China y otro en África. Se ha escrito que estas semillas son amargas y que contienen saponina, sin embargo la experiencia de Heiser en este sentido ha sido diferente. Él encontró semillas de varios cultivares, incluyendo algunos con pulpa amarga, que tienen un sabor agradable parecido a la almendra. Hubo alguna dificultad para sacar el tegumento, pero es posible que tostando la semilla ello se facilite. Además no parecen tener saponina (Heiser, 1989: 474).

A pesar de que hay información que señala que los frutos inmaduros de variedades amargas fueron utilizados como alimento, probablemente fueron poco usados hasta que se seleccionó los mutantes no amargos. Se ha señalado generalmente que la Lagenaria tiene poca pulpa que puede ser utilizada como alimento, sin embargo su uso con esta finalidad es bastante difuso y es aún empleada en algunas partes del mundo, particularmente en el Este asiático (Heiser, 1989: 476).

Además desde que el hombre comenzó a usar la Lagenaria, se puede suponer que la planta se convirtió en una maleza alrededor de los lugares de ocupación. En realidad ella pudo haber sido pre-adaptada a este tipo de hábitat como una planta diseminada 
cerca de las riberas de los ríos. De modo que no fue necesario cultivarla. Esto ha sido comprobado por Heiser y Pickersgill en el nordeste brasileño (Heiser, 1989: 477).

Esta información nos parece sumamente interesante, en cuanto nos permite suponer que quizá la Lagenaria pudo ser comida por los habitantes de PV35-106 y que, además, ella pudo haber encontrado un hábitat favorable en la parte baja del valle de Huarmey, no sólo en los bordes del río sino en toda el área que, como hemos visto, debió tener grandes zonas húmedas.

La presencia de estas plantas en Huarmey y dentro de este lapso de tiempo no llama la atención, más bien hubiera sido insólito no encontrarlas. Es así que Cucurbita sp. en la Costa Central peruana tiene una antigüedad mayor de 4000 años a.C. (Lanning, 1967b: 53) y en el Callejón de Huaylas más de 7000 años a.C. (Smith Jr., 1980: 104, tabla 5, 116; para el fechado lege Lynch et al., 1985). En Chile, Núñez (1974: 157) tiene una fecha radiocarbónica asociada a restos de esta planta de más de 7000 años a.C. (Para una revisión de los hallazgos arqueológicos de Cucurbita sp. con su respectiva bibliografía vide Bonavia, 1982a: 326-330). Además Cucurbita aparece muy temprano en el Este de los Estados Unidos de América, hacia los 5000 años a.C. (Smith, 1994-1995: 176) y en México tiene también ca. 7000 años a.C. (Smith, 1997). En el caso de Huarmey Cucurbita sp. ha sido encontrada en PV35-6 que corresponde al Precerámico final, antes que se introdujera el maíz. Se trata casi seguramente de plantas domésticas, pues es de notar que el tamaño de sus semillas concuerda con el de los especímenes de Padre Abán, Alto Salaverry, Los Gavilanes (Épocas 2 y 3) y La Galgada (Bonavia et al., 1993).

Lagenaria sp. en la Costa Central también tiene una antigüedad de 6000 años a.C., y Lagenaria siceraria correspondiente al mismo tiempo ha sido hallada en el valle de Lurín y en el área Ancón-Chillón y, aunque sin muchas pruebas, parece que en la Costa Norte también, en la localidad de Talara. (Para una revisión de los hallazgos arqueológicos de esta planta con su respectiva bibliografía, vide Bonavia, 1982a: 334338.). Weir \& Dering (1986) han informado la existencia de Lagenaria siceraria, aparentemente silvestre, en el sitio de Paloma con una antigüedad de 4000 años a.c. No hay que olvidar, finalmente, que en la Época 1 de Los Gavilanes se ha encontrado Lagenaria siceraria (Popper, 1982: 154 y 156) y si bien no tenemos fechas absolutas, es casi seguro que ella es contemporánea con PV35-106 (Bonavia, 1982a: 280; 1996: 172). Es importante señalar que Lagenaria siceraria ha sido hallada también en PV356 que, como se ha dicho, corresponde al Precerámico final antes de la introducción del maíz en la zona, es decir poco antes de la Época 2 de Los Gavilanes. Y por todos los indicios en estos tiempos ya estaba domesticada, a juzgar por las comparaciones de las medidas de las semillas de este yacimiento con las de otros sitios contemporáneos (Bonavia et al., 1993). Y es significativo que en los Estados Unidos de América, la Lagenaria hace su aparición antes que las demás plantas cultivadas y que en México esté presente antes de los 7000 años a.C. (Heiser, 1989: 475-478).

En todos estos casos, consideramos que sería sumamente importante si se pudiera encontrar muestras tales que permitan que se efectuén análisis como los señalados por Ford (vide supra, loco citato), para poder tener la seguridad si estamos frente a plantas silvestres o domesticadas. Por los datos que nosotros tenemos de Huarmey, pensamos 
que PV35-106 fue ocupado por un grupo humano que estaba en el umbral de iniciarse en el campo de la horticultura. Tan es así que en la Época 1 de Los Gavilanes, conjuntamente con Lagenaria siceraria ya había achira (Canna sp.), maní (Arachis hypogaea) y pacay (Inga Feuilley) que son definitivamente plantas alimenticias cultivadas (vide Popper, 1982: 149; Bonavia, 1996: 176). E inmediatamente después, en los tiempos transicionales entre las Épocas 1 y 2 de Los Gavilanes, en PV35-6 ya están presentes la palta (Persea americana), el fréjol (Phaseolus sp.) y quizá la coca (Erythroxylum sp.) (Bonavia et al., 1993). Es por esto que nosotros escribimos, que la Época 1 de Los Gavilanes

“... posiblemente... (es)... una fase terminal de (PV35-) 106, pues todo indica que las plantas cultivadas aparecen relativamente temprano en el valle de Huarmey y en cantidad importante. En ello puede haber jugado un rol fundamental el vecino Callejón de Huaylas, al que este valle tiene vía directa de acceso." (Bonavia, 1996: 176)

Y es significativo que un poco más al Norte, en el valle de Casma, por esos tiempos ya se cultivaba el maíz, pues Uceda tiene fechados radiocarbónicos de $6070 \pm 70$ a.d.P. (Cerro El Calvario) y $6050 \pm 70$ años a.d.P. (Cerro Julia) para los estratos con esta planta, que con la calibración (Universidad de Oxford, 2000) (1) y con la probabilidad de $88,5 \%$ en el primer caso significa un lapso de tiempo entre cal. 5150 y cal. 4780 años a.C. y con la probabilidad de $88,5 \%$ en el segundo entre cal. 5090 y cal. 4770 años a.C. (Uceda, 1986: 91, 255, 259, 261; 1987: 23; 1992a: 49; Bonavia \& Grobman, 1989: 459; 1999: 241-242).

La fauna es un aspecto que desafortunadamante no podemos discutir a nivel comparativo, pues como ya se dijo, Malpass en Casma no realizó excavaciones y los datos que nos ha dejado son muy escuetos. Él señala que solamente 11 de los 38 sitios con ocupación Mongoncillo tienen basura, y de éstos en 8 hay una probable asociación con una ocupación cerámica.

"La mayor parte de los restos de alimentos de los otros tres sitios fue de caracol terrestre Scutalus, sin embargo había también algunas conchas marinas." (Malpass, 1983: 142)

Esto lo lleva a pensar que la base del sustento de estos grupos humanos estuvo en las lomas vecinas. Es posible que Malpass tenga razón, pero nosotros preferimos ser más prudentes porque en este tipo de yacimientos, donde el trabajo eólico es muy fuerte, los indicios de superficie no son indicativos. En la superficie de PV35-106 no había nada que nos señalara la existencia de los restos que luego hallamos en las excavaciones. De todos modos es significativo que en Huarmey no se encontró ni un solo caracol terrestre. Uceda (1986) por su parte no toca este aspecto.

Para el caso concreto de PV35-106 si se observa la lista de moluscos, artrópodos y equinodermos, se podrá observar algunos hechos que son interesantes. En primer lugar que la gran mayoría son animales cuyo hábitat está en el medio del litoral rocoso, sólo tres de ellos viven en el sublitoral rocoso (Choromytilus chorus, Aulacomya ater y Crepipatella dilatata) y sólo dos en zona arenosa (Aequipecten purpuratus y Polinices sp.). Con ello queremos indicar que fueron animales cuya recolección no presentó grandes dificultades (vide Peña, 1982: 183-190). Hay que considerar, además, que de 
éstos hay por lo menos cuatro (Perumytilus purpuratus, Scurria parasitica, Tegula tridentata y Acmala viridula) que no tienen valor alimenticio. Pero lo más importante es observar que, a pesar de que la muestra es pequeña, se nota perfectamente que en la gran mayoría de casos los porcentajes están señalando que hubo una clara selección en la recolección. Es asíque mientras que en la gran mayoría de casos las cifras son tan bajas que prácticamente no significan nada, en unos pocos los porcentajes son importantes. Nos referimos en primer lugar a los barquillos (Enoplochiton niger) y luego a los erizos colorados (Arbacia spatuligera).

Los barquillos han sido utilizados de preferencia, pues representan el porcentaje más alto de todos los moluscos (prácticamente $34 \%$ ). Si se analiza la relación existente ( siempre en términos de porcentaje) entre el peso de la valva y el de la carne de algunos de los moluscos, se verá que en el caso del barquillo la carne representa un $62 \%$ contra el $37 \%$ de la valva (este cálculo se hizo sobre una docena de animales de todos los tamaños; vide Bonavia, 1982a: 388, cuadro 26), siendo este valor superado sólo por una lapa (Fissurella crassa). Resulta, además, que el uso del barquillo es una tradición en el valle de Huarmey, pues ha sido un alimento predilecto de los pobladores desde por lo menos los tiempos de PV35-106, a lo largo de todo el Período Precerámico (vide Bonavia, 1982a: cuadro 24, 385) y sigue siéndolo en la actualidad, como se desprende de las investigaciones etnológicas que hemos hecho en la zona. Es por esto más los datos técnicos que hemos presentado (vide supra) que estamos convencidos que los utensilios astillados han sido utilizados fundamentalmente para mariscar esta variedad de moluscos.

El erizo colorado (Arbacia spatuligera) es el único equinodermo que fue comido y representa el $21 \%$ de los animales consumidos. Si bien es cierto que el peso de la caparazón representa el $51 \%$ contra el $19 \%$ del contenido (calculado en este caso también sobre una docena de individuos de todos los tamaños; Bonavia, 1982a: 388, cuadro 26), hay que señalar que la recolección de estos animales es muy fácil, sobre todo cuando hay marea baja. En este sentido hay un hecho muy interesante. Este erizo fue parte importante de la dieta hasta fines de la Época 1 de Los Gavilanes, a juzgar por las evidencias de PV35-6 (Bonavia et al., 1993: 432). En tiempos posteriores se siguió comiendo erizos, pero de otro género, el decir el erizo gallinazo (Tetrapigus niger) y en forma exclusiva (Bonavia, 1982a: cuadro 24, 385). Y éste contiene un poco más (28\%) de partes gonadales del sistema reproductivo, que son las que se comen, que el erizo colorado. Pero pensamos que la causa de este cambio no tiene nada que ver directamente con el hombre y que se trata más bien de un fenómeno ecológico. Nuestra afirmación se basa en un hecho que hemos podido comprobar en el litoral de Huarmey durante nuestros estudios. En la actualidad hay en las costas huarmeyanas grandes colonias de erizos gallinazo y los colorados son prácticamente inexistentes y desconocidos. A estos erizos no se les da ninguna utilización y los lugareños ni siquiera saben que son comestibles. Sin embargo, algunos viejos marisqueros huarmeyanos nos informaron que hace muchos años, había en el mar de la zona grandes colonias de estos erizos colorados, aunque tampoco eran comidos, hasta que desaparecieron y fueron reemplazados por los erizos gallinazo. De modo que el hombre no ha intervenido para nada en su desaparición. No hay por que pensar que en la antigüedad el fenómeno fue diferente. 
Si seguimos la persistencia de los erizos a lo largo del tiempo, se podrá ver que Arbacia spatuligera aparece en forma predominante en la basura del Precerámico IV y V de Huarmey, pero no se encuentra en el Precerámico final (VI), época en la que se encuentra restos de Tetrapigus niger. Su consumo es pequeño a principios de este Período, pero va aumentando progresivamente hasta que en los tiempos finales en algunos sitios alcanza el 49,7 \%. En el Período Inicial su uso disminuye (Bonavia, 1982a: 388).

La cantidad de restos de peces es significativa, pero es difícil discutirla ya que muy pocos han podido ser identificados. De hecho fueron parte importante de la dieta de este grupo humano. Sin embargo no tenemos ninguna evidencia que nos permita saber cómo pescaban. No hemos encontrado anzuelos ni ningún tipo de cordeles o redes. Tampoco puntas de piedra que pudieron haber servido para alancear los peces, como en el caso de los paijanenses (vide Chauchat, 1982: 337). Quizá pudieron emplear algún tipo de nasa que al momento de ser inservible pudo haber sido abandonada en la playa. Este es uno de los problemas que queda por resolver.

Un dato que consideramos muy importante, son los 30 huesos de Pinnipedia que han sido identificados entre los 103 huesos de mamíferos. Si se les considera en términos absolutos de porcentaje, ellos representan solamente el $11 \%$, pero en este caso concreto consideramos que éste es irrelevante. Hemos señalado en más de una oportunidad (e.g. vide Bonavia, 1982a: 391-392) que con respecto a los lobos marinos, los huesos encontrados en los yacimientos precerámicos no pueden indicarnos con exactitud la cantidad de animales que han sido matados. Pues dado el enorme tamaño de éstos, ellos seguramente fueron descarnados en la playa, en el mismo lugar de la matanza y sólo la carne fue llevada a los campamentos y alguna otra parte del cuerpo que tuvo alguna utilidad para los cazadores. El esqueleto y los restos quedaron seguramente abandonados. Los huesos pequeños que se encuentran en los yacimientos arqueológicos, son los que estaban junto con la carne y no fueron desechados en el momento del descarne. Es muy probable que el lobo marino haya sido una parte muy importante de la dieta de estos hombres del Precerámico temprano, tal como lo fueron en el Precerámico medio de Huarmey (vide Wing \& Reitz, 1982).

A este respecto es conveniente recordar dos cosas. Primero que los lobos viven en manada y pasan parte de su tiempo en tierra firme, donde es relativamente fácil cazarlos a garrotazos en el hocico. Esta actividad se puede realizar a lo largo de todo el año. Hay una buena evidencia de ello no sólo en tiempos históricos, sino inclusive en los prehispánicos (e.g. lege Bonavia, 1982a: 391-392). Sería ocioso insistir sobre el asunto. Y, en segundo lugar, pero no por eso menos importante, se debe tener presente que el lobo marino fue un animal muy útil para el hombre no sólo como fuente alimenticia, pues su aceite tiene varios usos inclusive como combustible para alumbrarse, y el pellejo que también puede ser utilizado de diferentes maneras. Una de la que no tenemos evidencia y que será además muy difícil de obtener a nivel arqueológico, es la utilización del pellejo inflado a manera de balsa, como se hacía en Chile, y de las que nos han quedado buenas descripciones de los tiempos virreinales (Bonavia, 1982a: 392).

De las aves también es poco lo que se puede decir, pero no cabe duda que formaron parte de la dieta de esos tiempos. 
Consideramos, sin embargo, que si se hace una comparación global de los restos animales de PV35-106 con los otros yacimientos precerámicos de la zona (fundamentalmente con PV35-6 y Los Gavilanes), salvo en casos específicos como el de los erizos, en el fondo no hay grandes diferencias (vide Bonavia, 1982a: cuadro 24, 385; Bonavia et al.,1993). Ellas sin embargo son fundamentales en lo que a los restos botánicos se refiere. (Para la lista de plantas identificada en PV35-6, vide Bonavia et al., 1993 y para Los Gavilanes, vide Popper, 1982: cuadro 10, 149)

Donde sí parece haber una diferencia radical, es si comparamos los hallazgos de PV35-106 con los que menciona Malpass (1983) para Mongoncillo. Pero queremos insistir que nosotros no consideramos válida esta comparación, pues estamos convencidos que cuando se excave en los yacimientos de Casma, el cuadro variará enormemente.

Nada podemos decir sobre la cantidad de gente que pudo componer el grupo humano que ocupó este yacimiento. Para una inferencia de este tipo se debería poder excavar todo el sitio. A juzgar por el conjunto de datos que disponemos, tenemos la impresión - y no es más que eso— que a pesar que el área ocupada es considerable, se trató de una población pequeña que vivió dispersa. Es muy posible que el entierro del niño que encontramos a la base de nuestro corte estratigráfico en Los Gavilanes y que representa el inicio de ocupación de la Época 1, sea contemporáneo de estos pobladores y quizá era parte de este o de otro grupo asentado más al Norte (vide Bonavia et al., 1982; Bonavia, 1982a: 275).

Hay un aspecto de PV35-106 sobre el que no sabemos nada. Nos referimos al tipo de vivienda que utilizaron sus habitantes. En la superficie, como ya se ha dicho, no había ninguna huella de ello. Además, ésta ha sido sin duda afectada por los vientos que son constantes en la costa. Sólo con excavaciones de área se podría resolver esta interrogante.

Llama la atención la gran cantidad de carbón, restos quemados y cenizas hallados en los tres lugares donde se ha excavado. Ello hace suponer que se cocinaba sobre simples fuegos y, probablemente, en diferentes áreas. Quizá varios grupos estuvieron desarrollando esta actividad al mismo tiempo y a poca distancia.

No cabe duda que la época dentro de la cual se desarrolló PV35-106 es una de las menos conocidas de los tiempos precerámicos, de modo que se hace muy difícil intentar una comparación con otros sitios, que pueden ser contemporáneos pero que responden a una realidad distinta. Por eso señalamos nuestra diferencia con Uceda (1986: 279; 1992a: 48-49) cuando compara la industria de Casma con la de Piura. Y también discrepamos con Malpass (1983: 120) cuando intenta confrontar sus sitios de Casma (a los que nos hemos referido, vide supra) con los que estudió Richardson (1969; 1978) en el extremo Norte o, yendo más lejos, con los del Complejo Vegas en el Ecuador analizados por Lanning (1967a) y Stothert (1974). Todos estos yacimientos corresponden a áreas geográficas diferentes, que pueden servir sólo para darnos cuenta cómo el hombre ha reaccionado frente a diversos medios, pero de ninguna manera para entenderlos como un conjunto. Parece, como se verá, que en esta época en la Costa Norcentral y Sur-septentrional se estaba gestando una tradición nueva, pero no estamos aún en condiciones de entender este fenómeno en su totalidad, pues no tenemos datos suficientes para ello. Prácticamente los únicos artefactos que hemos encontrado son los líticos, no hay indicios de otros. Algunos arqueólogos frente a la falta de implementos 
elaborados a base de materiales perecederos, han supuesto que ello podría ser debido a problemas de conservación. En el caso de la costa del extremo Norte, ello podría ser posible (vide Richardson, 1969; 1978) dado que allí hay precipitaciones. Pero en la Costa Nor-central consideramos que no es así, por eso en este punto también no estamos de acuerdo con Malpass (1983: 143) cuando plantea este argumento para el valle de Casma. En el valle de Huarmey la prueba contraria está dada no sólo por la excelente conservación de los restos vegetales de este yacimiento, sino de todos los hallazgos correspondientes a la primera ocupación de Los Gavilanes (Época 1; Bonavia, 1982a). Con esto no queremos negar la posibilidad que en los tiempos de PV35-106 no se haya utilizado utensilios hechos de otros materiales que no son la piedra, como por ejemplo la madera, sino que estamos convencidos que simplemente dada la pequeñez de nuestra muestra no los hemos encontrado. Estamos casi seguros por nuestra larga experiencia en la costa peruana, que si se excavara extensivamente en este yacimiento, tendríamos más de una sorpresa.

Para terminar, y a manera de conclusión, podemos hacer algunos comentarios generales a base de lo expuesto.

Mientras la vinculación del contexto cultural de PV35-106 con el Precerámico posterior es bastante clara, ella no lo es con el Precerámico más temprano. Creemos - lo repetimos_ que Uceda (1986; 1992a) tiene la razón cuando plantea que en Casma Mongoncillo es posiblemente la continuación del Paijanense. PV35-106 a pesar de no tener una identidad con Mongoncillo, alguna relación tiene. En el caso de Huarmey, dado que no contamos aún con las evidencias de la ocupación Paijanense del que conocemos sólo las canteras de El Volcán y Tres Piedras (Bonavia, 1979; 1982a: 417; 1982b; León Canales, 2000: 82-153, 715-719), el cuadro es aún muy confuso. Chauchat \& Pelegrin (1994: 277) piensan que es posible que el proceso rápido de aridecimiento del litoral a principios del Holoceno, haya podido forzar a los últimos cazadoresrecolectores a una mayor dependencia del mar. Como escribimos en un trabajo anterior (Bonavia, 1996: 171), por la información que nosotros hemos podidoreunir en Huarmey hasta ahora, esta hipótesis nos parece correcta. Creemos, sin embargo, que tanto Mongoncillo como PV35-106 representan adaptaciones locales de grupos humanos que originalmente fueron paijanenses y que ya habían abandonado la caza y algunas formas de la recolección como base de su sustento. Es probablemente el resultado del sedentarismo o cuasi-sedentarismo en la costa con una modificación sustancial en los sistemas de vida. De la caza y recolección generalizada a la que estaban sujetos los grupos paijanenses, creemos que se pasa a una economía basada en la pesca y la recolección especializada con vida sedentaria cerca de la playa. La caza pasa a ser una actividad secundaria. Pero si bien es cierto que su base económica fundamental ha sido la explotación de los recursos marinos, las plantas ya comienzan a tener cierta importancia. Y vemos que muy poco tiempo después, a lo largo de lo que nosostros hemos llamado la Época 1 de Los Gavilanes, ellas comienzan muy rápidamente a jugar un rol muy importante y cada vez más trascendental. Como escribimos en más de una oportunidad (v.g. Bonavia, 1996: 171), esto demuestra que el uso de vegetales debió ser norma entre los grupos nómades de cazadores andinos (como además sucedió en otras partes del mundo, lege Harlan, 1992: 4-11), y cuyo uso desconocemos por problemas de conservación (vide Bonavia, 1991: 121-130; Chauchat, 1982: 677-678; Chauchat, 
1990: 45; Chauchat \& Pelegrin, 1994: 276; Chauchat et al., 1992: 355; Uceda, 1992b: 64). En el caso de Huarmey la importancia de PV35-106 es que - aunque parcialmentellena el vacío que teníamos entre los tiempos del Complejo Chivateros y el Precerámico final. Laguna que áun persiste en la gran mayoría de sectores de la costa peruana.

En estos tiempos la industria lítica está basada en los guijarros como materia prima y ellos, con su tecnología, parecen representar una tradición que, a juzgar por los pocos indicios que tenemos, se expande en un área geográfica muy amplia aunque no conocemos ni sus orígenes ni su desarrollo. La tipología que hemos propuesto es tentativa y quizá deberá ser modificada en el futuro. (Para entender el cambio cultural que se produjo en los tiempos inmediatos posteriores, lege Bonavia et al., 1993).

Nos falta información para poder comprender en términos globales a estos grupos humanos. Los restos con que contamos representan sin duda sólo una pequeña parte de las manifestaciones de su cultura. Sin mayores trabajos de excavación -insistimos - este problema no podrá ser resuelto. Nuestras excavaciones han sido muy limitadas, y sobre esto queremos ser enfáticos, por eso los datos deben ser tomados con la reserva del caso.

Desde el punto de vista cronológico, PV35-106 debe corresponder a los inicios de nuestra Época 1 determinada en Los Gavilanes (Bonavia, 1982a).

Este informe debe ser considerado como preliminar y nos señala, una vez más, que mientras los arqueólogos no entiendan que necesitamos más estudios concretos y sistemáticos de sitios, con amplias monografías sobre sus hallazgos, el cuadro general quedará con dudas y con afirmaciones de tipo general que siempre son equívocas.

\section{Agradecimientos}

En mi calidad de autor principal, debo agradecer en primer lugar a John Simon Guggenheim Memorial Foundation y Ford Foundation que me proporcionaron los fondos para efectuar esta investigación en el campo durante el desarrollo del "Proyecto Arqueológico Huarmey". Al Consejo Nacional de Ciencias y Tecnología (CONCYTEC) que me otorgó el apoyo para que se pudiera realizar los dibujos para este estudio y una parte de los trabajos de laboratorio.

Richard I. Ford me ofreció todas las facilidades del Laboratorio de Etnobotánica del Museo de Antropología de la Universidad de Michigan y me brindó sus valiosos consejos. Mario Peña me enseñó y supervisó la clasificación y el análisis del material malacológico. José Macharé y Carlos Angeles tuvieron la gentileza de revisar el material lítico en mi laboratorio y hacer la clasificación mineralógica. Félix Caycho Quispe me ayudó, una vez más y fue la última, en la elaboración de los dibujos con un conocimiento, destreza y paciencia que serán muy difíciles de igualar.

Con Claude Chauchat y Santiago Uceda discutí algunos aspectos de la tipología lítica. Joyce Marcus me ayudó en los contactos con el personal de la Universidad de Michigan. A todos ellos mis más sinceros agradecimientos, que debo hacer extensivos a mi esposa Ana y a mi hijo Aurelio que copiaron buena parte del manuscrito original. 
Una gratitud muy especial es la que le debo a Elmo León C., mi discípulo. Con él hemos discutido mucho este trabajo y él ha aportado críticas y sugerencias importantes. Además me ha ayudado en la elaboración de los diagramas y la calibración de los fechados readiocarbónicos (D. B.).

\section{Referencias citadas}

AMBROSE, S.H., 2001 - Paleolithic Technology and Human Evolution. Science, 291(5509): 1748-1753; Washington.

BEAUNE, S.A., 1989 - Exemple ethnographique de l'usage plurifonctionnel d'un galet de quartz. Bulletin de la Société Préhistorique Française, 86(2): 61-64; Paris.

BONAVIA, D., 1979 - Consideraciones sobre el Complejo Chivateros. In: Arqueología Peruana. Investigaciones Arqueológicas en el Perú, 1976 (R. Matos, comp.): 65-74; Lima. Seminario organizado por la Universidad Nacional Mayor de San Marcos y con el auspicio de la Comisión para Intercambio Educativo entre los Estados Unidos y el Perú.

BONAVIA, D., 1982a - Precerámico Peruano. Los Gavilanes. Mar, desierto y oasis en la historia del hombre, XXIII + 512p.; Lima: Corporación Financiera de Desarrollo, S.A. COFIDE, Instituto Arqueológico Alemán.

BONAVIA, D., 1982b - El Complejo Chivateros: una aproximación tecnológica. Revista del Museo Nacional, XLVI: 19-38; Lima.

BONAVIA, D., 1991 - Perú: Hombre e Historia, De los orígenes al siglo XVI, XIII + 586p., Lima: Fundación del Banco Continental para el Fomento de la Educación y la Cultura, Ediciones Edubanco.

BONAVIA, D., 1992 - Tipología lítica tentativa para el Precerámico final de la Costa Central y Septentrional del Perú. In: Estudios de Arqueología Peruana (D. Bonavia, ed.): 83-97; Lima: FOMCIENCIAS.

BONAVIA, D.,1996 - De la caza-recolección a la agricultura: una perspectiva local. Bulletin de l'Institut Français d'Études Andines, 25(2): 169-186; Lima.

BONAVIA, D., CASTRO DE LA MATA, R. \& CAYCHO QUISPE, F., 1982 - Entierro de niño. In: Precerámico Peruano. Los Gavilanes. Mar, desierto yoasis en la historia del hombre: 203-214; Lima: Corporación Financiera de Desarrollo S.A. COFIDE, Instituto Arqueológico Alemán.

BONAVIA, D. \& GROBMAN, A.,1989 - Andean maize: its origins and domestication. In: Foraging and Farming. The Evolution of Plant Exploitation (D. R. Harris \& G. C. Hilman, ed.): 456-470; London: Unwin Hyman.

BONAVIA, D. \& GROBMAN, A., 1999 - Revisión de las pruebas de la existencia de maíz precerámico de los Andes Centrales. Boletin de Arqueología PUCP 3. El Período Arcaico en el Perú: hacia una definición de los orígenes (P. Kaulicke, ed.): 239-261; Lima.

BONAVIA, D., JOHNSON, L. W., REITZ, E. J., WING, E. S. \& WEIR, G. H., 1993 - Un sitio precerámico de Huarmey (PV35-6) antes de la introducción del maíz. Bulletin de l'Institut Français d'Études Andines, 22(2): 409-442; Lima.

BORDES, F., 1961 - Typologie du Paléolithique Ancien et Moyen ; Planches, 85p.; Bordeaux: Imprimeries Delmas. Publications de l'Institut de Préhistoire de l'Université de Bordeaux. Mémoire $\mathrm{N}^{\circ} 1$.

BORDES, F., 1970 - Réflexions sur l'outil au Paléolithique. Bulletin de la Société Préhistorique Française, 67(7): 199-202; Paris.

BORDES, F., RIGAUD, J-Ph. \& SONNEVILLE-BORDES, D., 1972 - Des buts, problèmes et limites de l'archéologie paléolithique. Quaternaria, XVI: 15-34; Roma.

BREUIL, H. \& LANTIER, R., 1959 - Les hommes de la pierre ancienne, 360p.; Paris: Payot. 
BRÉZILLON, M., 1977 - La dénomination des objets de pierre taillée. Matériaux pour un vocabulaire des préhistoriens de langue française, 423p.; Paris: Éditions du Centre National de la Recherche Scientifique.

CASTRO DE LA MATA, R., 1982 - Hominidae. Homo sapiens sapiens. In: Precerámico Peruano. Los Gavilanes. Mar, desierto y oasis en la historia del hombre (D. Bonavia): 201-203; Lima: Corporación Peruana de Desarrollo S.A. COFIDE, Instituto Arqueológico Alemán.

CHAUCHAT, C., 1982 - Le Paijanien du désert de Cupisnique : Recherches sur l'occupation préhistorique de la côte nord du Pérou au début de l'Holocène. Thèse de doctorat d'État es Sciences. Université de Bordeaux, 719p.

CHAUCHAT, C., 1990 - Les Paijaniens. Premiers chasseurs cueilleurs du versant pacifique des Andes. Les Dossiers d'Archéologie, 145: 42-47 ; Dijon.

CHAUCHAT, C. \& BONAVIA, D., 1998 - Débuts de l'exploitation de la mer sur la côte du Pérou. In: L'Homme préhistorique et la mer (G. Camps, sous la direction de): 427-436; Paris: Éditions du CTHS.

CHAUCHAT, C., NORMAND, C., RAYNAL, J-P. \& SANTA-MARIA, R., 1985 - Le retour de la pièce esquillée ! Bulletin de la Société Préhistorique Française, 83(2): 35-41; Paris.

CHAUCHAT, C. \& PELEGRIN, J., 1994 - Le premier peuplement de la côte désertique du Pérou. Bulletin de la Société Préhistorique Française, 91(4-5): 275-280; Paris.

CHAUCHAT, C., WING, E., LA COMBE, J.-Ph., DEMARS, P.-Y., UCEDA, S. \& DEZA, C., 1992 - Préhistoire de la côte Nord du Pérou. In: Cahiers du Quaternaire, 18: 391p.; Paris: CNRS-Éditions.

CRESSON, J. H., 1977 - Reply to:The myth of bipolar flaking. J. Sollberger and L. Patterson (sic). Newsletter of Lithic Technology, V(3): 40-42, 1976. Lithic Technology, VI(3): 27; San Antonio.

ENGEL, F., 1973 - New Facts about Pre-Columbian Life in the Andean Lomas. Current Anthropology, 14(3): 271-280; Chicago.

EMPERAIRE, J. \& LAMING, A.,1961 - Les gisements des îles Englefield et Vivian dans la mer d'Otway, Patagonie australe. Journal de la Société des Américanistes, 50: 7-75; Paris.

FUNG PINEDA, R., 1968 - Los antiguos pobladores del Perú. Amaru, 8: 71-77; Lima.

HARLAN, J. R., 1992 - Crops \& Man, XIII + 284p.; Madison: American Society of Agronomy, Inc., Crop Science Society of America, Inc.

HAYDEN, B., 1980 - Confusion in the bipolar world: bashed pebbles and splintered pieces. Lithic Technology, IX(1): 2-6; San Antonio.

HAYNES, G., 1977 - Reply to: The myth of bipolar flaking. J. Sollberger and L. Patterson (sic). Newsletter of Lithic Technology, V(3): 40-42, 1976. Lithic Technology, VI(1-2): 5-6; San Antonio.

HEISER Jr, C. B., 1989 - Domestication of Cucurbitaceae: Cucurbita and Lagenaria. In: Foraging and Farming.The Evolution of Plant Exploitation (D. R. Harris \& G. C. Hillman, ed.): 471-480; London: Unwin Hyman.

JACKSON, D., 1987 - Percusión bipolar en instrumentos líticos tempranos de la costa del Ecuador. Gaceta Arqueológica, VI(14): 6-9; Lima.

KOZLOWSKI, J. K \& GINTER, B., 1975 - Técnica de la talla y tipología de los instrumentos líticos, 157p.; La Habana: Editorial Pueblo y Educación.

LANNING, E., 1963 - A pre-agricultural occupation on the Central Coast of Peru. American Antiquity, 28(3): 360-371; Salt Lake City.

LANNING, E. P., 1967a - Archaeological investigations on the Santa Elena Peninsula, Ecuador. Report to SNF on research carried out under grant GS-402; New York.

LANNING, E. P., 1967b - Peru before the Incas, 216p.; New Jersey: Englewood Cliffs, Prentice Hall, Inc.

LANNING, E. P., 1967c - Preceramic Archaeology of the Ancón-Chillón region, Central Coast of Peru, 41p.; New York: Report to National Science Foundation on research carried out under grant GS-869,1965-1966. 
LEÓN CANALES, E., 2000 - Zwei Beitrage zum Praekeramikum Perus:Das Paijanien der Fundstationen PV35-3 und PV22-Mit einer Bilanz der gesaments Steinwerkzeugtypologie ca. 12000-4000 v. Chr., 755p.; Bonn: Inaugural Dissertation zur Erlangung der Doktorwuerde. Rheinischen- Friederich-Wilhelms Universitæt zu Bonn.

LYNCH, T.F., 1967 - The Nature of the Central Andean Preceramic, 98p.; Pocatello: Occasional Papers of the Idaho University Museum, 21.

LYNCH, T. F., 1970 - Excavations at Quishqui Puncu in the Callejon De (sic) Huaylas, Peru, 105p.; Pocatello: Occasional Papers of the Idaho State University Museum, 26.

LYNCH, T. F. (edit.), 1980 - Guitarrero Cave. Early Man in the Andes, XVIII + 328p.; New York: Academic Press.

LYNCH, T. F., GILLESPIE, R., GOWLET, J. A. J. \& HEDGES, R. E. M., 1985 - Chronology of Guitarrero Cave, Peru. Science, 229(4716): 864-867; Washington.

MALPASS, M., 1983 - The Preceramic Occupation in the Casma Valley, Peru. A thesis sumbmited in partial fulfillment of the requirements for the degree of Doctor of Philosophy (Anthropology), University of Wisconsin. Madison, 264p.

MALPASS, M., 1991- Ocupación precerámica del valle de Casma, Perú. Boletin de Lima, XIII(76): 79-95; Lima.

MAZIÈRE, G., 1984 - La pièce esquillée, outil ou déchet ? Bulletin de la Société Préhistorique Française, 81(6): 182-187; Paris.

MERINO, J. M., 1994 - Tipología lítica, 480p.; San Sebastián: Munibe, Suplemento № 9.

NUÑEZ, L., 1974 - La Agricultura Prehistórica en los Andes Meridionales, 197p.; Antofagasta: Universidad del Norte.

OAKLEY, K., 1968 - Cronología del hombre fósil, 317p.; Barcelona: Editorial Labor, S. A.

ONERN, 1972 - Inventario, evaluación y uso racional de los recursos naturales de los ríos Casma, Culebras y Huarmey, Vol. II, III + 447-706p., Vol. III, 302p.; Lima: República del Perú. Presidencia de la República. Oficina Nacional de Evaluación de Recursos Naturales.

ORTIZ-TRONCOSO, O. R., 1979 - Punta Santa Ana et Bahía Buena: deux gisements sur une ancienne ligne de rivage dans le Détroit de Magellan. Journal de la Société des Américanistes, LXVI: 133-204; Paris.

PATTERSON, T. C. \& LANNING, E. P., 1964 - Changing settlement patterns on the Central Peruvian coast. Nawpa Pacha, 2: 113-123; Berkeley.

PATTERSON, L. W. \& SOLLBERGER, J. B., 1976 - The myth of bipolar flaking industries. Newsletter of Lithic Technology, V(3): 40-42; San Antonio.

PATTERSON, L. W \& SOLLBERGER, J. B., 1977 - Reply by Sollberger and Patterson to comments by Haynes and White on Bipolar Flaking. Lithic Technology, VI(3): 26-27; San Antonio.

PEÑA, M., 1982 - Mollusca, Arthropoda, Echinodermata. In: Precerámico Peruano. Los Gavilanes. Mar, desierto y oasis en la historia del hombre (D. Bonavia): 183-190; Lima: Corporación Financiera de Desarrollo S. A. COFIDE, Instituo Arqueológico Alemán.

POPPER, V., 1982 - Análisis general de las muestras. In: Precerámico Peruano. Los Gavilanes. Mar, desierto y oasis en la historia del hombre (D. Bonavia): 148-156; Lima: Corporación Financiera de Desarrollo S.A. COFIDE, Instituo Arqueológico Alemán.

RAVINES, R., 1971 - Toquepala: Estratigrafía y secuencia. Tesis para optar el grado académico de Doctor en la especialidad de Antropología. Universidad Nacional Mayor de San Marcos; Lima, 360p.

RAVINES, R., 1972 - Secuencia y cambios en los artefactos líticos del Sur del Perú. Revista del Museo Nacional, XXXVIII: 133-184; Lima.

RAVINES, R. \& ALVAREZ SAURI, J. J., 1967 - Fechas Radiocarbónicas para el Perú. Arqueológicas, 11: 3-58; Lima. 
RICHARDSON, J. B. III, 1969 - The preceramic sequence and the Pleitocene and postPleistocene climate of northwest Peru. Unpublished $\mathrm{PhD}$ dissertation.University of Illinois. Madison.

RICHARDSON, J. B. III, 1973 - The Preceramic Sequence of the Pleistocene and PostPleistocene Climate of Northwest Peru. In:Variation in Anthropology. Essays in Honor of John C. McGregor (D. Lathrap \& J. Douglas, ed.): 199-211; Urbana: Illinois Archaeological Survey.

RICHARDSON, J. B. III, 1978 - Early man on the peruvian north coast, early maritime exploitation and the Pleistocene and Holocene environment. In: Early Man in America. From a Circum-Pacific Perspective (A. L. Bryan, ed.): 274-289; Edmonton: University of Alberta. Occasional Papers $\mathrm{N}^{\circ} 1$ of the Department of Anthropology.

RICK, J. W., 1980 - Prehistoric Hunters of the High Andes. XIX + 360p.; New York: Academic Press.

SMITH, B. D., 1994-1995 - The Origins of Agriculture in the Americas. Evolutionary Anthropology, 3(5): 174-184; Philadelphia.

SMITH, B. D., 1997 - The Initial Domestication of Cucurbita pepo in the Americas 10,000 Years ago. Science, 276(5314): 932-934; Washington.

SMITH, Jr., C. E., 1980 - Plant Remains from Guitarrero Cave. In: Guitarrero Cave. Early Man in the Andes (T. F. Lynch, ed.): 87-119; New York: Studies in Archaeology, Academic Press.

STAFFORD, C. R., 1977 - Reply to: The myth of bipolar flaking. J. Sollberger and L. Patterson (sic). Newsletter of Lithic Technology, V(3): 40-42, 1976. Lithic Technology, VI(3): 2728; San Antonio.

STOTHERT, K., 1974 - Lithic technology of the Santa Elena Peninsula. Unpublished PhD dissertation; New York: Columbia University.

UCEDA CASTILLO, S. E., 1986 - Le Paijanien de la region de Casma (Pérou): industrie lithique et relations avec les autres industries précéramiques. Thèse présentée à l'Université de Bordeaux I pour obtenir le titre de Docteur. Bordeaux, 334p.

UCEDA CASTILLO, S. E., 1987 - Los primeros pobladores del Área Andina Central. Revisión crítica de los principales sitios. Parte I. Yunga, 1(1): 14-32; Trujillo.

UCEDA CASTILLO, S. E., 1992a - Industrias líticas precerámicas de Casma. In: Estudios de Arqueología Peruana (D. Bonavia, ed.): 45-67; Lima: FOMCIENCIAS.

UCEDA CASTILLO, S. E., 1992b - La ocupación Paijanense en la región de Casma, Perú. Ciencias Sociales, 2: 1-78; Trujillo.

WEIR, G. H. \& DERING, J. Philip, 1986 - The Lomas of Paloma: Human-Environment Relations in a Central Peruvian Fog Oasis: Archaeobotany and Palynology. In: Andean Archaeology (R. Matos M., S. A. Turpin \& H. H. Eling Jr., ed.): 18-44; Los Angeles: Institute of Archaeology, University of California. Monograph XXVII.

WHITE, J. P., 1977 - Reply to: The Myth of bipolar flaking industries. L. W. Patterson and J. B. Sollberger. Newsletter of Lithic Technology, V(3): 40, 1976. Lithic Technology, VI(12): 6; San Antonio.

WING, E. S. \& REITZ, E. J., 1982 - Pisces, Reptilia, Aves, Mammalia. In: Precerámico Peruano. Los Gavilanes. Mar, desierto y oasis en la historia del hombre (D. Bonavia): 191-200; Lima: Corporación Financiera de Desarrollo S.A. COFIDE, Instituto Arqueológico Alemán.

ZIÓLKOWSKI, M. S., PAZDUR, M. F., KRZANOWSKI, A. \& MICHCZYNSKI, A., 1994 Andes. Radiocarbon Database for Bolivia, Ecuador and Peru, 604p; Warzawa-Gliwice: Joint Publication. Andean Archaeological Mission of the Institute Archaeology, Warsaw University \& Gliwice Radiocarbon Laboratory of the Institute of Physics, Silesian Technical University. 